Andrews University

Digital Commons @ Andrews University

2009

\title{
An Exploration of Influences Affecting the Selection of Leveled Readers for Early Literacy Instruction
}

William K. Morelan

Andrews University, morelan@andrews.edu

Follow this and additional works at: https://digitalcommons.andrews.edu/dissertations

Part of the Education Commons

\section{Recommended Citation}

Morelan, William K., "An Exploration of Influences Affecting the Selection of Leveled Readers for Early Literacy Instruction" (2009). Dissertations. 1713.

https://digitalcommons.andrews.edu/dissertations/1713

https://dx.doi.org/10.32597/dissertations/1713

This Dissertation is brought to you for free and open access by the Graduate Research at Digital Commons @ Andrews University. It has been accepted for inclusion in Dissertations by an authorized administrator of Digital Commons@ Andrews University. For more information, please contact repository@andrews.edu. 


\section{ABSTRACT}

AN EXPLORATION OF INFLUENCES AFFECTING

THE SELECTION OF LEVELED READERS

FOR EARLY LITERACY INSTRUCTION

\section{by}

William K. Morelan

Chair: Shirley A. Freed 


\title{
ABSTRACT OF GRADUATE STUDENT RESEARCH
}

Dissertation

\author{
Andrews University \\ School of Education
}

Title: AN EXPLORATION OF INFLUENCES AFFECTING THE SELECTION OF LEVELED READERS FOR EARLY LITERACY INSTRUCTION

Name of researcher: William K. Morelan

Name and degree of faculty chair: Shirley A. Freed, Ph.D.

Date completed: December 2009

Problem

Educators have substantive concerns about the quality of children's literature in general and leveled readers in particular. Though thousands of titles are now available, educators appear to be searching for something better than the text and illustrations found in many of these books. But before educators, authors, and publishers can respond to this perceived need for better beginners' books, they need a clearer understanding of influences affecting the selection of leveled readers for early literacy instruction. 


\section{Research Design}

This qualitative study was based on a narrative inquiry approach. Nine participants were purposefully chosen to represent three distinct groups (university literacy professors, regional superintendents, and classroom teachers) that had the potential to impact the selection of leveled readers for early literacy instruction. Data were collected through qualitative inquiry and interpreted using a constant comparison method of data analysis.

A major focus of this study was the relationship of the data to what Clandinin and Connelly have called the three-dimensional inquiry space. This is a central core of narrative inquiry with roots that go back to John Dewey's work in the 1930 s. It is based on the assumption that reality is holistic, multidimensional, and always changing as opposed to being a single, fixed, objective phenomenon that is waiting to be discovered. This underlying construct informed every aspect of data collection and analysis throughout the study.

\section{Results}

Upon analysis of the data, four major themes emerged. An educator's professional life can influence the selection of leveled readers for early literacy instruction. Examples include literacy training, attending reading conferences, reading professional journals, and similar activities.

An educator's personal life can influence the selection of leveled readers for early literacy instruction. Examples include childhood experiences, religious beliefs, family concerns, and similar matters. 
An educator's personal preferences can influence the selection of leveled readers for early literacy instruction. Examples include illustrations, content, and style. Selections can reflect either positive or negative concerns.

An educator's post of employment can influence the selection of leveled readers for early literacy instruction. For example, superintendents in this study appeared to be more influenced by anticipated reactions of adult constituents, whereas classroom teachers and literacy professors appeared to be more influenced by the perceived needs of children.

\section{Conclusion}

An educator's professional life, personal life, personal preferences, and post of employment can influence the selection of leveled readers for early literacy instruction. Conscious awareness of these influences has the potential to not only improve the quality of the selection process, but also to impact the development of new early literacy materials. 
Andrews University

School of Education

\title{
AN EXPLORATION OF INFLUENCES AFFECTING THE SELECTION OF LEVELED READERS \\ FOR EARLY LITERACY INSTRUCTION
}

\author{
A Dissertation \\ Presented in Partial Fulfillment \\ of the Requirements for the Degree \\ Doctor of Philosophy
}

by

- William K. Morelan

December 2009 
(C) Copyright by William K. Morelan 2009

All Rights Reserved 


\title{
AN EXPLORATION OF INFLUENCES AFFECTING THE SELECTION OF LEVELED READERS \\ FOR EARLY LITERACY INSTRUCTION
}

\author{
A dissertation \\ presented in partial fulfillment \\ of the requirements for the degree \\ Doctor of Philosophy
}

by

William K. Morelan

APPROVAL BY THE COMMITTEE:
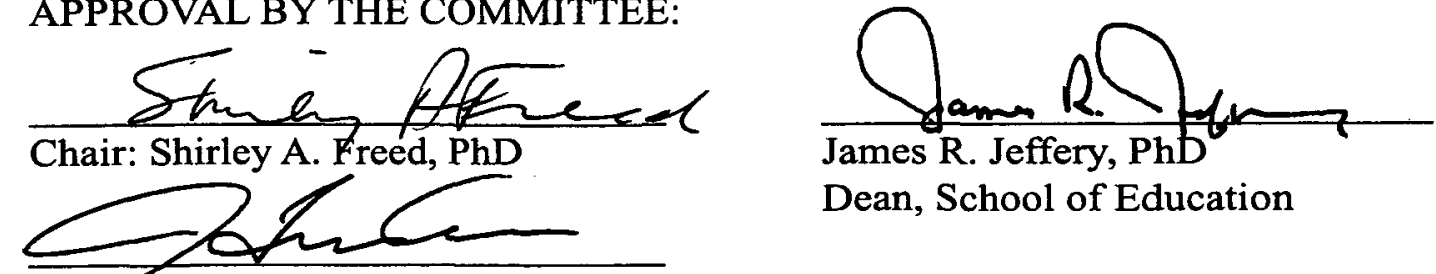

Meprber: James A. Tucker, PhD
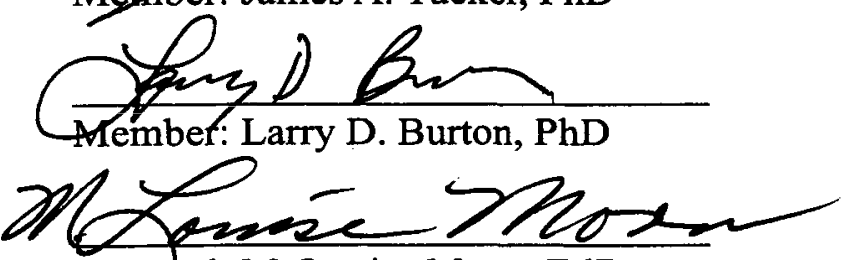

Exterhal: M. Louise Moon, EdD

$12 \cdot 15 \cdot 09$

Date approved 
This work is dedicated to Talena, Dustin, Sage, Jamie, Steve, Mason, Katie, Miah, Bianca, Tami, Hattie, and Mac — who patiently shared my limited time as I wrestled with the "paper monster." I love you, guys! 


\section{TABLE OF CONTENTS}

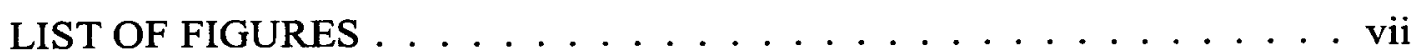

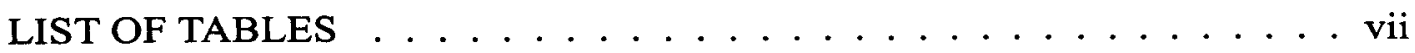

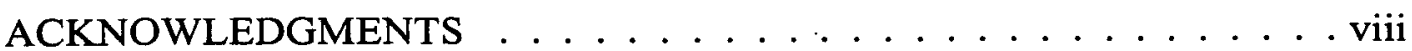

Chapter

I. THE PROBLEM .................. 1

Introduction ................. 1

Background to the Problem . . . . . . . . . . . 2

Statement of the Problem ............ 6

Purpose of the Study. . . . . . . . . . . . . 6

Central Research Question . . . . . . . . . . . 7

Research Design . . . . . . . . . . . . 7

Conceptual Framework . . . . . . . . . . 8

Definitions of Terms . . . . . . . . . . 8

Significance of the Study ........... 9

Basic Assumptions . . . . . . . . . . 10

Delimitations ................ 11

Limitations ................. . . 11

Organization of the Study . . . . . . . . . . . 11

II. LITERATURE REVIEW . . . . . . . . . . . . . . . . 14

Introduction . . . . . . . . . . . . 14

Historical Concerns ............. . . 14

Teacher Beliefs . . . . . . . . . . . . . 18

Teacher Beliefs About Early Literacy . . . . . . . . . 22

Selection Strategies and the Selection Process . . . . . 24

Summary of the Literature . . . . . . . . . . . 26

III. METHODOLOGY ................. 28

Introduction . . . . . . . . . . . . 28

Problem and Purpose . . . . . . . . . . . . 28 
Central Research Question . . . . . . . . . . . 29

Research Design . . . . . . . . . . . 29

The Pilot Study . . . . . . . . . . 31

The 3D Inquiry Model . . . . . . . . . . . . . . 32

Self as Research Instrument. . . . . . . . . . . . 34

Purposeful Sampling . . . . . . . . . . . . . 38

Data Collection ............. . . . 39

Data Analysis . . . . . . . . . . . . . . 44

Trustworthiness .............. . . 44

Generalizability ............. 50

IRB Issues and Answers . . . . . . . . . . . . . . 51

Informed Consent ........... 52

Confidentiality ............ 52

IV. PARTICIPANT NARRATIVES ........... 53

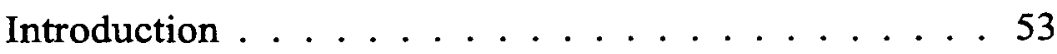

Participant Overview . . . . . . . . . . 54

Amy's Story . . . . . . . . . . . . . . . . . . 54

Betty's Story. . . . . . . . . . . . . . 59

Cheryl's Story . . . . . . . . . . . . 6 63

Debra's Story . . . . . . . . . . . . . 67

Elaine's Story . . . . . . . . . . . . . . . . 74

Francis's Story . . . . . . . . . . . . . 79

Gloria's Story . . . . . . . . . . . . . 88

Helen's Story . . . . . . . . . . . . . . . 93

Irene's Story . . . . . . . . . . . . . . 98

Summary of Participant Narratives . . . . . . . . 104

V. ANALYSIS OF NARRATIVE THEMES . . . . . . . 105

Introduction . . . . . . . . . . . . 105

Influence of Professional Life . . . . . . . . . . 106

Influence of Personal Life . . . . . . . . . . . . . 108

Influence of Personal Preferences . . . . . . . . . 110

Influence of Post of Employment . . . . . . . . . . . 113

Summary .................. 115

VI. CONCLUSIONS AND RECOMMENDATIONS . . . . . . 116

Introduction . . . . . . . . . . . . 116

Research Design. . . . . . . . . . . . . 117

Purposeful Sampling . . . . . . . . . . 118

Conceptual Framework . . . . . . . . . . . 119

Findings (Four Primary Themes) . . . . . . . . . . 119 
Additional Findings . . . . . . . . . . . . . 121

Discussion of the Underlying Construct . . . . . . . 123

Continuity . . . . . . . . . . 123

Interaction . . . . . . . . . . 125

Situation . . . . . . . . . . . 127

A Core Assumption. . . . . . . . . . . . . 128

General Recommendations . . . . . . . . . . . . . . 129

Recommendations for Further Study . . . . . . . . . . 131

Appendix

A. INFORMED CONSENT FORM . . . . . . . . . 133

B. SPECIFIC QUESTIONS . . . . . . . . . . . . . . 134

C. OVERVIEW OF PILOT STUDY $\ldots \ldots \ldots \ldots \ldots \ldots$

D. REPRESENTATIVE SAMPLE OF BOOKS . . . . . . . 142

REFERENCE LIST . . . . . . . . . . . . . . . . . 152

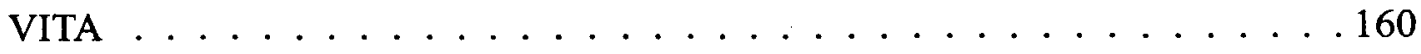




\section{LIST OF FIGURES}

1. Three-Dimensional Inquiry Model $\ldots \ldots \ldots \ldots \ldots \ldots$

2. Three-Dimensional Inquiry Model (Applied) . . . . . . . . . . 35

\section{LIST OF TABLES}

1. Participant Selections From Set $1 \ldots \ldots \ldots \ldots$

2. Participant Selections From Set $2 \ldots \ldots \ldots \ldots$ 


\section{ACKNOWLEDGMENTS}

Like most major endeavors, this work would not have been possible without the support and encouragement of friends and colleagues. My deepest gratitude goes to my committee, Dr. Shirley Freed (chair), Dr. Larry Burton, and Dr. Jim Tucker. Shirley's patience and guidance helped mold my passion for children's literature into a solid, scholarly work. Larry's willingness to share his professional expertise was a true asset. And without Jim's inspiration back at the beginning, this amazing journey never would have happened

I also want to thank Dr. Jean Clandinin and Dr. Michael Connelly whose work inspired the development of my graphic model of the 3D Inquiry Space.

Finally, I must acknowledge the vital role of my regional group members - Dr. Deborah Lange-Kuitse and (soon-to-be Dr.) Elaine Foster. The lasting friendship we've developed goes far beyond that of mere colleagues. Know that I will always be there for you as you have always been there for me. 


\section{CHAPTER ONE}

\section{THE PROBLEM}

\section{Introduction}

"I love this book!"

A moment earlier, the elderly teacher had looked as though she could barely take another step. The convention hall was filled with hundreds of exhibitors, and hours of walking the concrete aisles were obviously taking their toll.

But now, as she flipped through the pages of Michael Never Gives $U p$, she could hardly hold still. "This book is just wonderful!" Her eyes flashed with excitement as she finished the story. Then she reached for another title in the rack of leveled readers. "Oh, and look at this one!"

"It's so hard to find good leveled books," she continued, still turning the pages. "There are more than there used to be, but a lot of them are just awful." As we began to talk about early literacy instruction and the need for good children's literature, I asked her the same question I'd asked many others over the past 2 years. "So what makes a leveled reader good?"

“Oh, I don't know." She frowned a bit, thinking. "I guess for me it has to do with the book's message, and how my students will react to the book." She paused, then grinned. "And my kids will love these!" 
We talked a while about some of the issues in children's literature that concerned her, and about the frustrations that teachers felt when trying to select "good" leveled readers. It was a conversation I'd had many times before in many parts of the country.

As the loudspeaker announced the closing session, she suddenly turned and hugged me. "Please keep making more of these wonderful books!" she exclaimed. Then patting me on the arm, she slowly ambled away to get a good seat.

\section{Background to the Problem}

Early literacy education in the United States has experienced sweeping changes over the past two decades. New research on how children learn to read has led to an increased emphasis on more individualized forms of instruction, resulting in a gradual shift from basal texts to leveled readers (Bandre', 2005; Baumann, Hoffman, Moon, \& Duffy-Hester, 1998; Bear, Caserta-Henry, \& Venner, 2004; Dickinson \& Neuman, 2006; Fountas \& Pinnell, 1996; Kragler, 2000; Martinez \& McGee, 2000; McCardle \& Chabra, 2004; Rog \& Burton, 2002).

In the late 1980 s, reading programs increasingly began to move toward student-centered strategies that used leveled readers and other "tradebooks" for literacy instruction as opposed to traditional one-size-fits-all basal textbooks. A national survey of elementary teachers taken in the late 1990s (Baumann et al., 1998) found that only $2 \%$ of respondents still used basal texts exclusively for reading instruction, whereas $56 \%$ reported using basals supplemented by tradebooks, $26 \%$ used tradebooks supplemented by basals, and $16 \%$ were 
using tradebooks exclusively as the foundation for all literacy instruction. This is a very different picture from the early 1980 s when up to $95 \%$ of all early literacy instruction was based on the use of basal readers exclusively (Goodman, Shannon, Freeman, \& Murphy, 1988; Shannon, 1982).

And this trend appears to be gaining momentum. According to Bandre' (2005), "children's literature plays an increasingly important role in the classroom, and its value is only projected to increase over time" (p. 6). Martinez and McGee (2000) predict that "theory, instructional practices, and children's literature will continue to evolve into the next century, allowing literature to maintain a central role in reading and writing instruction" (p. 166).

Research suggests that young children make the most progress in reading when books are not too easy or too difficult (Allington, 2006; Clay, 1993; Fountas \& Pinnell, 1999; O'Connor, Bell, Harty, Sackor, \& Zigmond, 2002; Rasinski, 2003; Szymusiak, Sibberson, \& Koch, 2008). The texts used must be easy enough to help the student develop confidence and to facilitate comprehension, but difficult enough to provide a challenge (Clay, 1993; Fountas \& Pinnell, 1999). Matching texts to a student's reading level can increase the reader's fluency and comprehension, help a struggling reader take on the traits and skills of better readers, and can lead to increased reading achievement (Allington, 2006; O'Connor et al., 2002; Rasinski, 2003; ). Discussing the importance of this shift to leveled readers, Szymusiak et al. (2008) concluded that:

There is clearly a need to provide students with extensive opportunities to read a variety of materials, with a significant number of instructional books meeting the interests and capabilities of every 
reader in the classroom. The challenges [of using leveled readers] are many, but the benefits are clear. (p. 11)

With the advent of this new literature-based approach to reading instruction, educators began actively searching for more leveled readers to expand their supply of reading resources. Teachers suddenly needed access to a broad selection of books that offered "just enough challenge to support problem solving but easy enough to support fluency and meaning" (Fountas \& Pinnell, 1996, p. xvi). This often meant adding hundreds of new titles to school book collections.

Publishers responded with a proliferation of leveled books. Whereas the supply of leveled readers was somewhat limited in the late 1980 s, today educational publishers introduce huge numbers of new titles each year. According to Harvey and Goudvis (2007), “the sheer number boggles the mind: Nearly 5,500 new books for young people in 2005 alone; at that rate, approximately 55,000 to come in the next decade" (p. 60).

Yet even though the rapid growth of the leveled reader genre has significantly broadened the number of titles available in children's literature, many educators continue to lament the lack of "good" children's books (Buxton \& Austin, 2003; Darigan, Tunnell, \& Jacobs, 2002; Donovan \& Smolkin, 2002; Duke, 2000; Kruse, 2001; Lempke, 1999; Lowery, 2000; Short \& Fox, 2003; Wolfson, 2007; Worthy, Moorman, \& Turner, 1999; Yenika-Agbaw, 2003). The commercial imperative to place new readers into circulation has not always resulted in children's literature with thoughtful content or suitable illustrations, nor has the different format and size of leveled readers made them immune to historic prob- 
lems related to selecting children's literature in general (see chapter 2).

In addition to historical concerns, the continued shift from basal texts to leveled readers introduces some new elements. According to Fountas and Pinnell (1996), book selection for an early literacy program must be "balanced." The selection process should consider

enjoyment, meaning, and interest to children; accuracy and diversity in multicultural representation; breadth of type of genre; depth in the number of titles at each level of difficulty; links across the collection (common characters, authors, settings); quality of illustrations and their relationship to text; content; length; and format. (p. 107)

While lists such as this do reflect some historical concerns, many of the criteria have unique applications to the selection of leveled readers.

Other concerns include the fact that although leveled texts are easier to read, they may still "lack relevance and significance in the lives of children forced to read such a limited diet" (Szymusiak et al., 2008, p. 10). Also, focusing solely on text difficulty can limit students' choices, which can lead to “boredom and resistance" (Worthy \& Sailors, 2001, p. 238). In addition, leveled book collections often do not cover a wide variety of genres. Until recently, most texts have primarily been fiction, with very few non-fiction titles available (Szymusiak et al., 2008, p. 11). Finally, if reading level is rigidly applied to book selection, students tend to lose interest because they have no choice of what they read, and may develop "a skewed vision of the purpose of reading" (Worthy \& Sailors, 2001, p. 239).

In summary, sweeping changes in early literacy education over the past 
two decades have markedly changed the landscape in which early literacy instruction takes place. The material and methods used for reading instruction today are very different from the materials and methods that were quite common just 20 years ago. As illustrated in the introduction, my personal experience at workshops and educational conventions nationwide supports the notion that educators have real concerns when selecting children's books. And with children's literature now playing a central role in reading and writing instruction (Martinez \& McGee, 2000), understanding influences affecting the selection of leveled readers is increasingly important.

\section{Statement of the Problem}

Educators appear to have substantive concerns about the quality of children's literature in general and leveled readers in particular. Though thousands of titles are now available, educators are searching for something better than the text and illustrations found in many of these books (Buxton \& Austin, 2003; Darigan et al., 2002; Donovan \& Smolkin, 2002; Duke, 2000; Kruse, 2001; Lempke, 1999; Lowery, 2000; Manjari, 1998; Short \& Fox, 2003; Wolfson, 2007; Worthy et al., 1999; Yenika-Agbaw, 2003). But before educators, authors, and publishers can respond to this perceived need for better beginners' books, they must have a clearer understanding of influences affecting the selection of leveled readers for early literacy instruction.

\section{Purpose of the Study}

The purpose of this qualitative study was to explore influences affecting 
the selection of leveled readers for early literacy instruction. More specifically, it took a closer look at how three groups of educators made decisions when selecting specific titles from sets of leveled readers. Because the use of leveled readers can affect reading achievement, the overall goal of this study was not only to raise awareness of how educators select leveled readers, but also to identify areas needing further study.

\section{Central Research Question}

This research query focused on one central question: What influences affect the selection of leveled readers by professional educators for use in early literacy instruction? Specific interview questions helped explore influences related to temporal dimensions, social/personal contexts, and the notion of place.

\section{Research Design}

This qualitative study was based on a narrative inquiry approach. It grew out of a pilot study on this topic (Morelan, 2003). The current study used the same participants and built on their responses from the earlier study. A major focus was the relationship of the data to what Clandinin and Connelly (2000) have called the "three-dimensional inquiry space" (p. 50). This includes the concepts of interaction (personal and social dimensions), continuity (past, present, future), and situation (the notion of place), and how they may have influenced the selection process. This underlying construct informed every aspect of both data collection and analysis throughout the study. 


\section{Conceptual Framework}

The conceptual framework of this study narrows as it flows from constructivism (Bruner, 1966; Dewey, 1938; Piaget, 1950; Vygotsky, 1962), to teacher beliefs (Clark \& Peterson, 1986; Fang, 1996; Hargreaves, 1994; Parker \& Neuharth-Pritchett, 2006; Pajares, 1992; Richardson, 2003; Thompson, 1992; Vartuli, 2005), to beliefs about early literacy instruction (Hart \& Rowley, 1996; Fountas \& Pinnell, 1996; Meral, 2002; Scharer, 1992; Wollman-Bonilla, 1998; Zarillo, 1989). Within the field of early literacy instruction, it moves from strategies for selecting children's literature to the selection process itself-and ultimately focuses on influences affecting the selection of leveled readers for early literacy instruction.

\section{Definition of Terms}

Clearly defined terms are an important part of any research study. For the purposes of this study, the terms italicized below use the definitions that follow.

Guided Reading is an instructional approach that allows the teacher to support a small group of students in learning, applying, and practicing effective reading strategies while reading from appropriately leveled readers.

Leveled Readers are books used in early literacy instruction to provide small incremental increases in difficulty from one level to the next. These "levels" offer opportunities for active engagement without reading frustration.

An influence is "a power affecting a person, thing, or course of events, especially one that operates without any direct or apparent effort" (The American 
Heritage Dictionary of the English Language, 2008).

The Three-Dimensional Inquiry Space is a metaphorical construct developed by Clandinin and Connelly (2000) that expands on Dewey's (1938) theory of experience. It recognizes the fact that "studies have temporal dimensions and address temporal matters; they focus on the personal and social in a balance appropriate to the inquiry; and they occur in specific places or sequences of events" (Clandinin \& Connelly, 2000, p. 50). A discussion of the 3D Inquiry Space, including a graphical representation, is presented in chapter 3 .

Continuity is one dimension of the 3D Inquiry Space. It refers primarily to temporal matters-the relationship of any experience to the past, the present, and the future. It "addresses temporal issues by looking not only to the event but to its past and to its future" (Clandinin \& Connelly, 2000, p. 50).

Interaction is another dimension of the 3D Inquiry Space. It is based on the relationship between the personal (inward) and social (outward) aspects of any experience. It involves the balance between "feelings, hopes, aesthetic reactions, and moral dispositions" and "existential conditions" such as social influences (Clandinin \& Connelly, 2000, p. 50).

Situation is the third dimension of the 3D Inquiry Space. It refers to the notion of place--"the specific concrete physical and topological boundaries of inquiry landscapes" (Clandinin \& Connelly, 2000, p. 51).

\section{Significance of the Study}

There appears to be a disconnect between the types of leveled readers that 
educators are looking for and the books that authors and publishers are actually producing (Buxton \& Austin, 2003; Darigan et al., 2002; Donovan \& Smolkin, 2002; Duke, 2000; Kruse, 2001; Lowery, 2000; Short \& Fox, 2003; Worthy et al., 1999). Research is needed to help address this problem.

This study adds to the scholarly research in the field of early literacy by describing conclusions derived from interaction with participants selected from three groups of educators who evaluate and select thousands of leveled readers each year. It has the potential to improve the practices of classroom teachers, university literacy professors, and regional superintendents by providing insights into how leveled readers are selected, and how the selection process is impacted by the three-dimensional inquiry space.

In addition, this study also has the potential to provide specific insights for authors and publishers. Raising their awareness of what influences affect the selection of leveled readers should assist them in producing books that are better suited to the needs of literacy professionals and the children they serve.

\section{Basic Assumptions}

Educators are constantly making individual decisions in the selection of leveled readers for early literacy instruction. The basic assumption underlying this study is the belief that, given opportunity, educators can reflect on such decisions and accurately describe the reasons for their choices.

A further assumption is that an analysis of converging data can yield a better understanding of why educators select specific books. This could lead to 
improved professional practice and better classroom instruction.

\section{Delimitations}

This study was intentionally limited to educators who participated in a pilot study of this topic (Morelan, 2003). Pre-existing data from that study provided a unique opportunity to explore how the responses and reflections of these educators changed over time.

\section{Limitations}

Although participants in this study have had experience in both public and private school settings, many of the participants have spent a large portion of their careers affiliated with private Christian educational institutions. In addition, although participants were intentionally chosen to represent five distinct geographic regions (Northeast, Southeast, Midwest, Southwest, and West) and three distinct professional settings (classroom teacher, district superintendent, and university literacy professor), commonalities such as gender (all female), race (all

Caucasian), education (all master's degree or above), and educational interest (all former members of an advisory team for a publisher that produces leveled readers) may have had an impact on participants' responses and reflections.

\section{Organization of the Study}

This dissertation has 6 chapters. Chapter 1 begins with an introduction to the study, the background to the problem, the statement of the problem, the purpose of the study, the central research question, and an introduction to the 
research design and conceptual framework. It also includes definitions of terms, the significance of the study, the basic assumptions, the delimitations, and the limitations. It concludes with this section on the organization of the study.

Chapter 2 provides an overview of literature related to the topic. It begins with a review of historical concerns about children's literature, then explores the impact of teacher beliefs on classroom instruction. It continues to narrow in focus as it reviews studies related to teacher beliefs about early literacy instruction, studies on formal strategies for selecting early literacy materials, and studies on the selection process itself.

Chapter 3 explains the methodology and research design. It begins with a review of the problem, the purpose, and the central research question. It includes descriptions of the research design, the population that was studied, the procedures used for data collection and data analysis, and a discussion of "self as research instrument." The chapter concludes with a discussion of various issues related to trustworthiness, generalizability, and IRB guidelines.

Chapter 4 is a presentation of the data in the form of participant narratives. Embedded in these narratives is a descriptive overview of each participant. The chapter concludes with a summary of the narratives.

Chapter 5 is an analysis of the narrative themes. It begins with a description of the specific themes that emerged in this study, then makes specific literature connections to the themes of professional life, personal life, personal preferences, and post of employment. The chapter also includes a summary based on the analysis of these themes. 
Chapter 6 contains conclusions and recommendations. It begins with a review of the problem, the purpose, the central research question, the research design, the purposeful sampling, and the conceptual framework. It continues with a discussion of the findings of the study, and a discussion of the underlying construct. The chapter concludes with general recommendations for educators, authors, and publishers, as well as recommendations for further study. 


\section{CHAPTER TWO}

\section{LITERATURE REVIEW}

\section{Introduction}

This chapter provides a basic overview of the research in five related categories-historical concerns about children's literature, the impact of teacher beliefs on classroom instruction, teacher beliefs about early literacy education, strategies for selecting early literacy materials, and studies on the selection process itself.

The first section provides a background against which the other sections can be viewed. Subsequent sections lead from the broader field of how teacher beliefs impact classroom instruction to the very specific topic of selecting individual leveled readers for the classroom.

\section{Historical Concerns}

As stated in chapter 1 , the commercial imperative to place new readers into circulation has not always resulted in children's literature with thoughtful content or suitable illustrations. Nor has the different format and size of leveled readers made them immune to historic problems related to selecting children's literature in general.

One historical area of concern in selecting children's literature is 
cultural diversity (Darigan et al.., 2002; Igoa, 1995; Lempke, 1999; Lowery, 2000; Perry \& Fraser, 1993; Short \& Fox, 2003; Yenika-Agbaw, 2003). Perry and Fraser (1993) point out that the authors and illustrators of children's literature are often from the mainstream culture and that their work tends to reflect the world they live in. Darigan et al. (2002) support this view, noting that "writers of color and authors with special needs often recall that one of the main reasons they became writers was because as youth they were rarely able to find themselves in the books they read" (p. 302). In spite of the fact that the United States admits large numbers of new immigrants each year, Lempke (1999) states that few immigrant children see reflections of their world in popular children's literature-even in books promoted by respected literary journals. Lowery's (2000) review of immigrant literature suggests that many children's books have significant cultural inaccuracies, and that even today, children's literature continues to perpetuate many ethnic and cultural stereotypes.

Although publishers of children's literature seem to have made an effort in recent years to include people of different ethnicities and cultural backgrounds, especially in the illustrations, a study of cultural authenticity in children's literature by Short and Fox (2003) found that children's literature continues to foster misperceptions. Indeed, Darigan et al. (2002) assert that in many children's books the characters that are said to portray diversity are essentially just middle-class children with darker skin shades who demonstrate the attitudes and beliefs that one would expect in a typical White middle-class setting.

Gender bias is another area of concern in the selection of children's 
literature. Studies on gender bias have focused on everything from the overall content of books, to the language used, to the way books are illustrated (Bender \& Alyce, 1990; Campbell, 1993; Manjari, 1998; Witt, 1997; Yeoman, 1999).

In a study of gender stereotypes in children's literature, Bender and Alyce (1990) found that "males outnumber females by a significant proportion" and that "males are most likely to be portrayed as positive, active, and competent, while females are more likely to be portrayed as negative, passive, and incompetent" (p. 192). Manjari (1998) detected gender bias not only "in the content, the language, and the illustrations of a large number of children's books" but also "in the extent to which gender was represented as the main character, and how that gender was depicted" (p. 1). Witt (1997) analyzed the basal reader programs of six major publishers. She found that "male characters in the books outnumbered female characters, biographies of males outnumbered biographies of females, and illustrations of males outnumbered illustrations of females" (p. 11).

Campbell's (1993) research discovered that books with male-based content were more often praised and less often rejected than books with femalebased content. She concluded that "there is certain discrimination towards works whose content is female based" (p. 580). In a discussion of gendered storyline, Yeoman (1999) went even further. She asserted that traditional sources of children's literature — such as Perrault, Grimm, and Disney-were so biased in content that the only strong females were witches, and that "these witches are typically wicked, and females other than witches are often victims who survive only because they are rescued by men" (p. 12). 
Of course, gender bias is not limited to characters and content. Witt (1997) suggests a relationship between gender bias and the authors themselves. Her study of children's literature from major publishers found that "female authors were more likely to fairly represent both male and female characters and to write characters who possessed a balance of masculine and feminine traits" whereas "male authors write almost exclusively about males and masculine experiences and rarely portrayed males as androgynous" (p. 10).

There are also a variety of social issues that can pose potential problems in the selection of children's literature (Kramer \& Radey, 1997; Kruse, 2001; Rodman, 1994). Kramer and Radey (1997) evaluated an approach to improving sibling relationships in which social skills training was used to coach small groups of children. They found that children who read books with negative sibling interactions were much more likely to behave in undesirable ways with their own siblings than children who don't read such books. Kruse (2001) conducted a study of children's picture books in which a farm setting was integral to the plot, character development, or theme. She limited her study to books that had been published within the last 10 years. Kruse concluded that farmers were consistently shown as solitary, foolish, or old-fashioned. Although Kruse admits that "a single book is unlikely to entrench limiting stereotypes," she points out that "the cumulative effect of negative or inaccurate images cannot be salutary" (p. 28). Rodman (1994) analyzed how the concept of "home" was depicted in children's literature. His study was based on 100 children's books randomly selected from 23 public libraries. He concluded that images depicting the concept of home have 
changed little over the last 50 years - the most common scene by far being a traditional White nuclear family living in a suburban, single-family, detached house. This stands in stark contrast to changes that have taken place over the years, not only in the composition of the average family, but also in the kinds of places they call home. These are just a few examples of the diverse social issues that can raise concerns in the selection of children's literature.

\section{Teacher Beliefs}

The concept that teacher beliefs can impact classroom instruction has its roots in constructivism and the works of such notables as John Dewey, Jean Piaget, Lev Vygotsky, and Jerome Bruner. It is based on the concept that humans construct meaning from current knowledge structures, and that this provides a path through which educators can best facilitate learning.

Historically, the study of belief systems has waxed and waned. From the early 1900 s to the mid-1920s, social psycologists displayed considerable interest in studying the nature of beliefs and their influence on people's actions. In the years that followed the Great Depression, however, interest faded and the topic nearly disappeared from psychological literature. Thompson (1992) has theorized that this was "due in part to the difficulty in accessing these beliefs for study, and also in part to the emergence in the 1930 s of associationism and the subsequent rise of behaviorism" (p. 131).

Through the following decades, American education remained primarily under the influence of behaviorism. Most studies from that era focused on teacher 
behavior, student behavior, and student achievement. But as America entered an era of change in the mid-1960s, interest in the study of beliefs again began to flicker in fields as diverse as political science, psychology, anthropology, and eduction. In education, this interest was also fueled by a slow paradigm shift away from the behaviorists' process-product approach to teaching.

Clark and Peterson (1986) were among the first to raise the idea of studying the relationship between teacher belief and classroom practice. Since their initial work over 20 years ago, research on teacher beliefs has continued to slowly increase - primarily in the fields of reading, early childhood education, and mathematics.

Over the past two decades, researchers have begun to focus on the nature of teacher beliefs and their impact on various aspects of education (Brickhouse, 1990; Campbell, Kyriakides, Muijs, \& Robinson, 2004; Fang, 1996; Hargreaves, 1994; Hedrick, Harmon, \& Linerode, 2004; Parker \& Neuharth-Pritchett, 2006; Pajares, 1992; Ravitz \& Snow, 1998; Richardson, Andres, Tidwell, \& Lloyd, 1991; Richardson, 1996, 2003; Vartuli, 2005; Wilcox-Herzog, 2002; Zeichner \& Gore, 1990). It is an expanding field where "beliefs and teaching practices can be disaggregated by subject, grade level, achievement levels of students, school professional culture, and teacher academic background" (Ravitz \& Snow, 1998, p. 1), and there is a growing body of research for each of these areas.

However, it should be noted that some scholars (Fang, 1996, Parjares, 1992; Thompson, 1992; Vartuli, 2005) have detected traces of the behaviorist mind-set in two related assumptions underlying many studies of teacher beliefs. 
The first is the assumptions that belief systems are static entities waiting to be uncovered. The second is that the relationship between belief and practice is a simple linear-causal one. Thompson (1992) points out it is important to remember that "most research strongly suggests that the relationship between beliefs and practice is a dialectic"-a constantly changing reality rather than "a simple cause-and-effect relationship" (p. 140).

Experience is the basis of teacher beliefs, and as life experience grows and changes, it can directly affect classroom practice. Pajares (1992) found a "strong relationship between teachers' educational beliefs and their planning, instructional decisions, and classroom practices" (p. 332). Vartuli (2005) stated that "belief systems guide teachers' expectations about child behavior and the decisions they make in classrooms" (p. 86). And Hargreaves (1994) commented that "it is what teachers think, what teachers believe, and what teachers do at the level of the classroom that ultimately shapes the kind of learning that young people get" ( $p$. ix). Collaboration for this last assertion comes from the fact that Hargreaves's comment has been widely quoted in numerous books and scholarly articles on teaching and education (Dean, 2001; Dillion \& Maguire, 2007; Hodkinson \& Issitt, 1994; Nolan \& Meister, 2000; Sugrue, 1997).

These concepts also appear to hold true when applied to more specific subjects. Studies of teacher beliefs about early literacy instruction (Meral, 2002; Mills \& Clyde, 1991; Scharer, 1992; Sierra \& Combs, 1990; Wollman-Bonilla, 1998) support the idea that teacher beliefs directly impact the way teachers implement literacy instruction in their classrooms. In the words of Meral (2002), 
"What teachers believe about children's literature and reading determines how they use children's literature in their classrooms" (p. 62).

These beliefs may also impact decisions such as what strategies educators use when selecting classroom reading materials to be used. Studies on various strategies for selecting reading materials (Kragler, 2000; Lukens, 1999; Richardson \& Miller, 2000; Rog \& Burton, 2002; Williams, 2000) have been helpful in establishing formal criteria for the book selection process. Lists of formal criteria are now fairly common.

But studies that focused on the selection process itself (Hart \& Rowley, 1996; Sword, 1982; Wollman-Bonilla, 1998) have shown that the selection process may not be directly related to formal criteria. These studies suggest that there may be other influences affecting the selection of general reading books for the classroom. In addition, there are substantive differences between general reading books and instructional-leveled texts (Brabham \& Villaume, 2002). Thus different influences may come into play when making selections from the specific genre of leveled readers as opposed to general reading books.

Since the use of leveled readers as an instructional tool is growing rapidly, a real need exists to explore such influences as they relate to leveled readers. The conceptual framework of this study - from constructivism, to teacher beliefs, to beliefs about early literacy instruction, to the specific topic of this studyprovides an appropriate environment in which to explore influences affecting the selection of leveled readers for early literacy instruction. 


\section{Teacher Beliefs About Early Literacy}

Over the past two decades, early literacy education has seen a gradual shift from basal texts to leveled readers. There is a growing body of research that suggests such literature-based programs are highly effective. Indeed, the names of such researchers as Marie Clay, Pat Cunningham, Irene Fountas, and Gay Su Pinnell are now an integral part of the language of early literacy.

But the success of any program is often dependent upon teacher attitudes and beliefs, especially since the teacher plays a key role in implementation. This is a direct reflection of the constructivist nature of teacher beliefs. Meral's (2002) comment bears repeating: “What teachers believe about children's literature and reading determines how they use children's literature in their classrooms" (p. 62). Or to put it another way, belief impacts implementation.

A foundational study by Zarillo (1989) supports this concept. Zarillo studied three distinct groups. The first group believed that children learn to read by reading. This group implemented their belief with a whole-language approach to reading instruction. The second group believed that reading should focus on developing specific skills. This group implemented their belief by teaching reading as a separate subject. The third group believed in a combination of these two philosophies. This group implemented their belief by combining a wholelanguage approach with specific skills lessons. It is important to note that in spite of major differences in implementation, all three groups believed they were using a "literature-based program" since instruction was based on the use of children's literature instead of basal readers. 
Belief systems are not static, however. As previously noted, the constructivist nature of teacher beliefs makes them "dynamic and permeable mental structures susceptible to change in the light of experience" (Campbell, Kyriakides, Muijs, \& Robinson, 2004, p. 50). Thus, as teacher beliefs change, new instructional practices may be implemented. Then as those practices succeed or fail, new beliefs may emerge.

Sierra and Combs (1990) studied teachers who were making the transition from basal readers to literature-based instruction. They found that as the teachers became more familiar with the literature-based approach, their instructional practices gradually changed, as well as their beliefs. They concluded that "as we begin to tune into ourselves and our children, new directions slowly become clearer" (p. 125). Research by Scharer (1992) supports this conclusion. She found that as teachers in her study were provided assistance through in-service training, conferences, and similar informative help, they began to change both their practices and beliefs about reading instruction.

However, a number of studies (Allen, Freeman, \& Lehman, 1990; Allen, Freeman, Lehman, \& Scharer, 1995; Altieri, 1998; Bawden, Buike, \& Duffy, 1979; Richardson et al., 1991) caution that significant inconsistencies exist between teachers' stated beliefs and their actual practices. Since successful reading programs are fundamental to the success of students, the seriousness of such discrepancies cannot be ignored.

A study by Mills and Clyde (1991) shows how teacher beliefs and practices can impact an individual child. Their research involved a student moving from 
a school with a structured reading program to a school that offered a literaturebased, whole-language approach. In the first school, the boy performed poorly. In the second school, the boy made rapid progress. The teacher from the first school described the boy as immature with a short attention span and poor motor skills. The teacher from the second school described the same student as smart, happy, and helpful. The researchers concluded that beliefs teachers hold have a direct impact on the development of students.

All of these studies suggest that teacher beliefs directly impact the way that teachers implement literacy instruction. But these studies do not specifically address the question of whether such beliefs transfer to the process of selecting early literacy materials.

\section{Selection Strategies and the Selection Process}

There is a growing body of literature outlining strategies for choosing books for beginning readers (Atkinson, Matusevich, \& Huber, 2009; Brooks, 1996; Fountas \& Pinnell, 1996; Kragler, 2000; Lukens, 1999; Richardson \& Miller, 2000; Rog \& Burton, 2002; Smith \& Sensenbaugh, 1992; Williams, 2000). Such studies suggest several types of selection criteria.

Among these works are foundational studies suggesting that the selection of books for children should be based on broad factors. These factors include such things as "composition and readability, concepts, balance, and literary value"' (Crawley, 1977, p. 2).

One highly respected team (Fountas \& Pinnell, 1996) has stated that 
choosing books for an early literacy program must be "balanced." The selection process should consider the following nine criteria:

enjoyment, meaning, and interest to children; accuracy and diversity in multicultural representation; breadth of type of genre; depth in the number of titles at each level of difficulty; links across the collection (common characters, authors, settings); quality of illustrations and their relationship to text; content; length; and format. (p. 107)

In addition, there are a number of studies listing specific criteria for a variety of special situations. This includes studies on the selection of materials for children with special needs (Pascual, 1972; Smith \& Sensenbaugh, 1992).

Such research is representative of the body of literature outlining various formal strategies for choosing books for beginning readers. But these studies do not specifically address the selection process itself, nor do they explore what influences may affect the actual selection of reading books for the classroom.

Some research (Hart \& Rowley, 1996) has suggested that selection decisions are more influenced by the individual's personal preferences than by formal criteria. Hart and Rowley found that personal concerns such as "the extent to which the teacher personally connects to the literature" (p. 4) played a major role in making book selections. This concept is supported by Donovan and Smolkin (2002). They found that teacher book selections tended to be based on subjective factors such as "visual features" and "potential uses for the books" rather than formal criteria. They also discovered "underlying assumptions that science is boring ... and information books are too difficult to read aloud" (p. 412).

Other researchers have posited that personal concerns of a negative 
nature may play a role in choosing books for young readers. One study (Wollman-Bonilla, 1998) found that teachers rejected children's literature when they believed the books might frighten or corrupt children; fail to represent dominant social values or myths; or fail to identify racism or sexism as a social problem.

Earlier studies (Miller, 1979; Sword, 1982) have even suggested that formal criteria are rarely referenced at all. Miller (1979) found that although teachers placed a high value on various criteria, they "displayed no differential strategy for judging based on the importance of any one factor" and that ultimately "there was no difference between the judgmental ability of experienced reading teachers and undergraduates with no training or experience" (p. 158). In Sword's (1982) research, specific criteria for evaluating the "quality of plot, characterization, and style of picture books" were suggested. But according to Flood, Lapp, Squire, and Jensen (2003), Sword (1982) discovered that the majority of teachers continued to rely "on their own knowledge" when making book selections for young readers (p. 259).

The consensus of these studies seems to be that the influences that affect reading material choices are not directly related to formal selection strategies. There may be other substantive influences at play.

\section{Summary of the Literature}

Studies of teacher beliefs suggest that teacher beliefs directly impact the way that teachers implement literacy instruction in their classrooms. However, these studies do not directly address how such beliefs influence the selection of 
materials used to support classroom implementation.

Studies on strategies for selecting reading materials have been helpful in establishing formal criteria for book selection. But these studies do not address whether those criteria are actually tied to classroom practice.

Studies focusing on the selection process itself suggest that formal strategies are rarely used to select reading materials for the classroom. They suggest that there may be other influences that are not directly related to established criteria. This last group of studies has been helpful in determining what does not take place when teachers are selecting books for young readers, but not in identifying what influences do affect the selection process.

In addition, while these studies explore the selection process as it relates to general reading materials, there are substantive differences between leveled readers and general reading books. Since the use of leveled readers as an instructional tool is growing rapidly, a real need exists to explore such influences as they relate to this new genre. 


\section{CHAPTER THREE}

\section{METHODOLOGY}

\section{Introduction}

This qualitative study used narrative inquiry to explore influences affecting the selection of leveled readers for early literacy instruction. More specifically, it took a closer look at how three groups of educators (classroom teachers, university literacy professors, and regional superintendents) made decisions when selecting specific titles from sets of leveled readers.

This chapter begins with a review of the problem, the purpose, and the central research question. It includes descriptions of the research design, the population that was studied, the procedures used for data collection and data analysis, and a discussion of "self as research instrument." The chapter concludes with a discussion of various issues related to trustworthiness, generalizability, and IRB guidelines.

\section{Problem and Purpose}

Both empirical research and anecdotal experience indicate that educators have concerns about the quality of children's literature in general and leveled readers in particular. Even though thousands of leveled reader titles are now available, educators appear to be searching for something better than the text and 
illustrations found in many of these books (Buxton \& Austin, 2003; Darigan et al., 2002; Donovan \& Smolkin, 2002; Duke, 2000; Kruse, 2001; Lempke, 1999; Lowery, 2000; Manjari, 1998; Short \& Fox, 2003; Wolfson, 2007; Worthy et al., 1999; Yenika-Agbaw, 2003). But an effective response to this perceived need for better beginner's books requires a clearer understanding of influences affecting the selection of leveled readers for early literacy instruction. Because the use of leveled readers can lead to increased reading achievement, the purpose of this study was not only to raise awareness of how educators select leveled readers, but also to identify areas needing further study.

\section{Central Research Question}

The central research question is, "What influences affect the selection of leveled readers by professional educators for early literacy instruction?" Specific interview questions helped explore influences related to temporal dimensions, social/personal contexts, and the notion of place.

\section{Research Design}

This qualitative study was based on a narrative inquiry approach. A major focus was the relationship of the data to what Clandinin and Connelly (2000) have called the "three-dimensional inquiry space" (p. 50). This is a central core of narrative inquiry with roots that go back to John Dewey's (1938) work in the 1930s. It is based on the assumption that "reality is holistic, multidimensional, and ever-changing; it is not a single, fixed, objective phenomenon waiting to be discovered" (Merriam, 2001, p. 202). 
Dewey (1938) believed that all experience arises from the interaction of two key principles-continuity and interaction. His "continuity" referred to the belief that each experience a person has will influence his/her future for better or worse. Dewey's “interaction" referred to the situational influence on one's experience. In other words, one's present experience is a function of the interaction between one's past experiences and the present situation.

Clandinin and Connelly (2000) expanded Dewey's concepts of continuity and interaction into three dimensions that they call continuity, interaction, and situation. Here "continuity" describes the temporality of experience-looking not only at an event as it occurs, but backward to its past and forward to its future. "Interaction" is based on the relationship between personal (inward) and social (outward) experiences. And "situation" is the notion of place-what they call "the specific concrete physical and topological boundaries of inquiry landscapes" (Clandinin \& Connelly, 2000, pp. 50-51).

By using this set of terms, any particular inquiry is defined by a threedimensional space. "Studies have temporal dimensions and address temporal matters; they focus on the personal and social in a balance appropriate to the inquiry; and they occur in specific places or sequences of events" (Clandinin \& Connelly, 2000, p. 50).

This underlying construct was an integral part of a pilot study that I conducted 6 years ago (Morelan, 2003). Since that initial exploration formed a starting point for the current study, an overview of that study is provided in the next section. 
The Pilot Study

At the time the current study began, participants from the pilot study were all still available and all willing to participate in further research on this topic. Thus the population for this study was identical to the population that was used in the pilot study.

As part of the pilot study, I not only preserved all artifacts related to the study, but I also took great care to document any related data that might serve as a reference point for any future study. For example, the dates that specific questions were sent to participants and the dates of each individual response were logged in case there was a need to later explore this aspect of the study. This detailed documentation allowed me to easily access and reference pre-existing data as needed in the current study.

In addition, the research questions used in the current study (see Appendix B) were virtually identical to the questions that were used in the pilot study. The exceptions were the addition of a sixth reflection question and, as would be expected, differences in questions related to the different sets of books reviewed (see Data Collection).

The richness and depth of the participants' responses from the pilot study served as an excellent starting point for the current study, providing a fascinating source of pre-existing qualitative data. Many of the responses strongly reflected the personal/social dimensions of the model, and the passage of time only increased the significance of temporal aspects. (For a detailed description of the pilot study, see Appendix C.) 


\section{The 3D Inquiry Model}

As part of the pilot study, I developed a model of the 3D Inquiry Space that graphically illustrates the construct (see Figure 1). This model is designed to show how responses are affected by multiple dimensions, and to provide a graphic representation of the concept that every response is influenced by various interactions and is only "exact" at a particular moment. This model was helpful not only in applying the concept of the three-dimensional inquiry space to the research I was conducting at that time, but also proved to be a valuable tool in framing the present study.

This underlying construct informed every aspect of data collection and analysis in this study. For example, in the pilot study, Gloria (see Participant Narratives, chapter 4) was asked, "What past experience(s) have you had that might have influenced your selections?" She responded in part by saying, "Most of my teaching experience has been in the lower grades, so I am looking at these books through the eyes of a teacher in the grades these books serve."

But 6 years have passed in Gloria's life. Shortly after the pilot study, she became a school principal, and today she serves as a regional superintendent. She has also moved from the East Coast to the Midwest. The three-dimensional inquiry space reminds us that every decision a person makes is impacted by issues of continuity (temporal dimensions), interaction (social/personal issues), and situation (the notion of place).

In Gloria's case, she is 6 years older, her post of employment is significantly different, and she has moved to a different part of the country. As a 

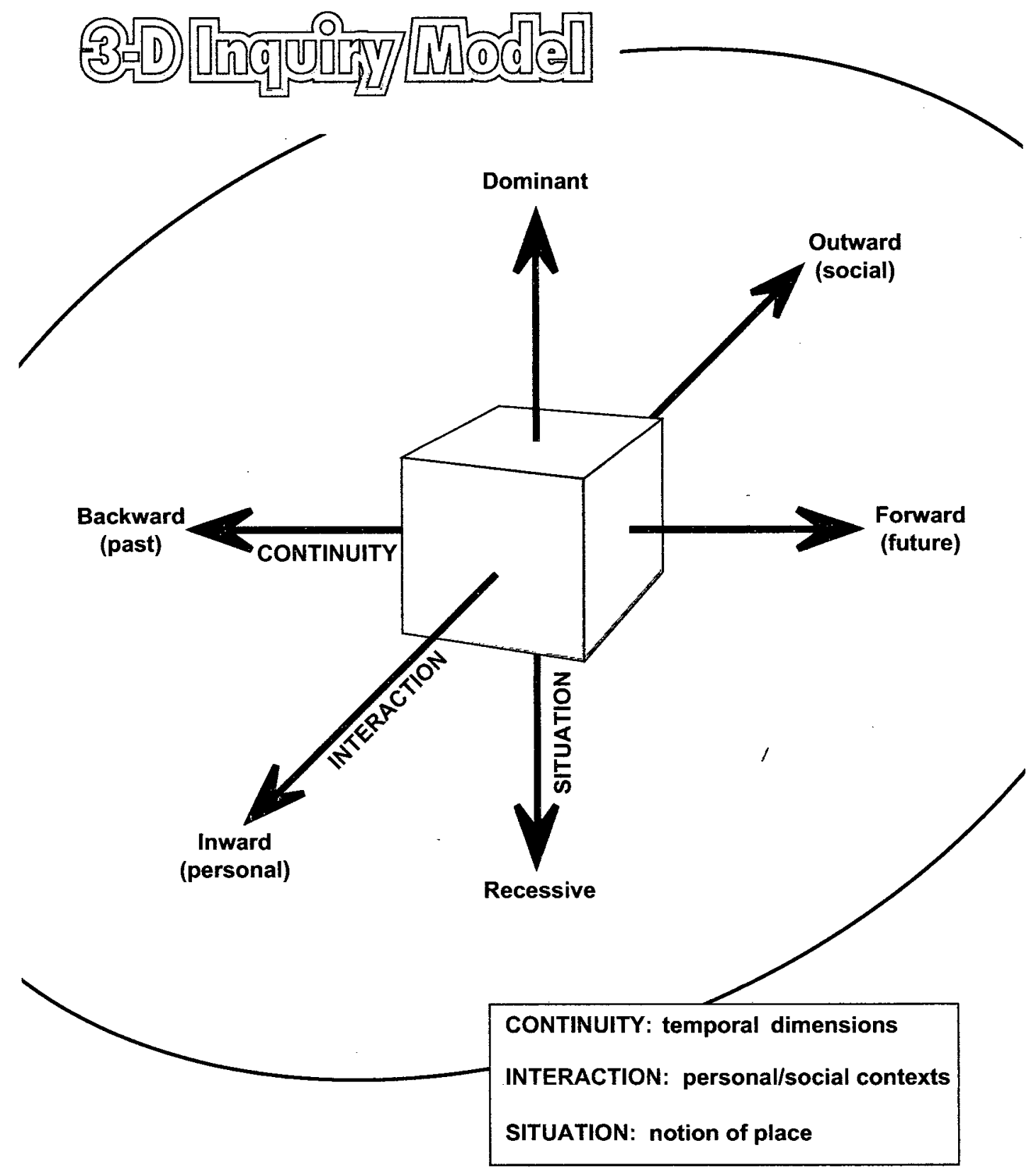

Figure 1. Three-Dimensional Inquiry Model.

Note. This model serves as a graphic representation of the "three-dimensional inquiry space" as it relates to qualitative research. It is based on the assumption that "reality is holistic, multidimensional, and ever-changing; it is not a single, fixed, objective phenomenon waiting to be discovered" (Merriam, 2001, p. 202). It has its roots in the works of John Dewey (1938), and it reflects conceptual expansions by Clandinin and Connelly (2000). 
qualitative researcher, I must consider how such changes have impacted her responses, and how they ultimately might influence her selection of leveled readers for early literacy instruction. (Figure 2 is a graphic representation showing how additional examples might be applied.)

In essence, this underlying construct implies a belief that continually referencing the three-dimensional inquiry space in this fashion can greatly enhance the richness and depth of both the data collection and its analysis.

\section{Self as Research Instrument}

Clandinin and Connelly (2000) point out that "the way an interviewer acts, questions, and responds in an interview shapes ... the ways participants respond and give accounts of their experience" (p. 110). This is just one example of the way that the researcher can affect a qualitative study.

Because of this critical relationship, LeCompte and Preissle (1992) suggest that a description of "the investigator's position" should be a part of any qualitative study. In addition to an explanation of the assumptions that led to the study, the researcher's relationship to the participants, the researcher's basis for selecting participants, a detailed profile of each participant, and the social context in which the data were collected, this should include relevant data about the researcher himself, allowing the reader to better understand the inquiry space in which the study took place.

Since most of these issues are covered elsewhere in this dissertation, the focus of this section is on helping the reader better understand "where I' $m$ 


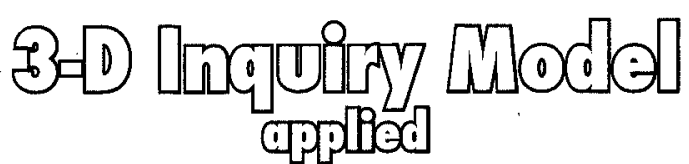

"I have taught elementary school reading as well as university reading method courses
"Personality wise I am a melancholy type. I'm not sure how that affects book selection, but I know it likely has a part to play. I'm also introverted, and I think for that reason I find it easier to spend more time with books than some people do."
"As a classroom teacher, I think that I looked at [books] with a narrower viewpoint ... just what appealed to me. But I think that now ... I fit books into the curriculum and integrate curriculum a lot better than I would have before."

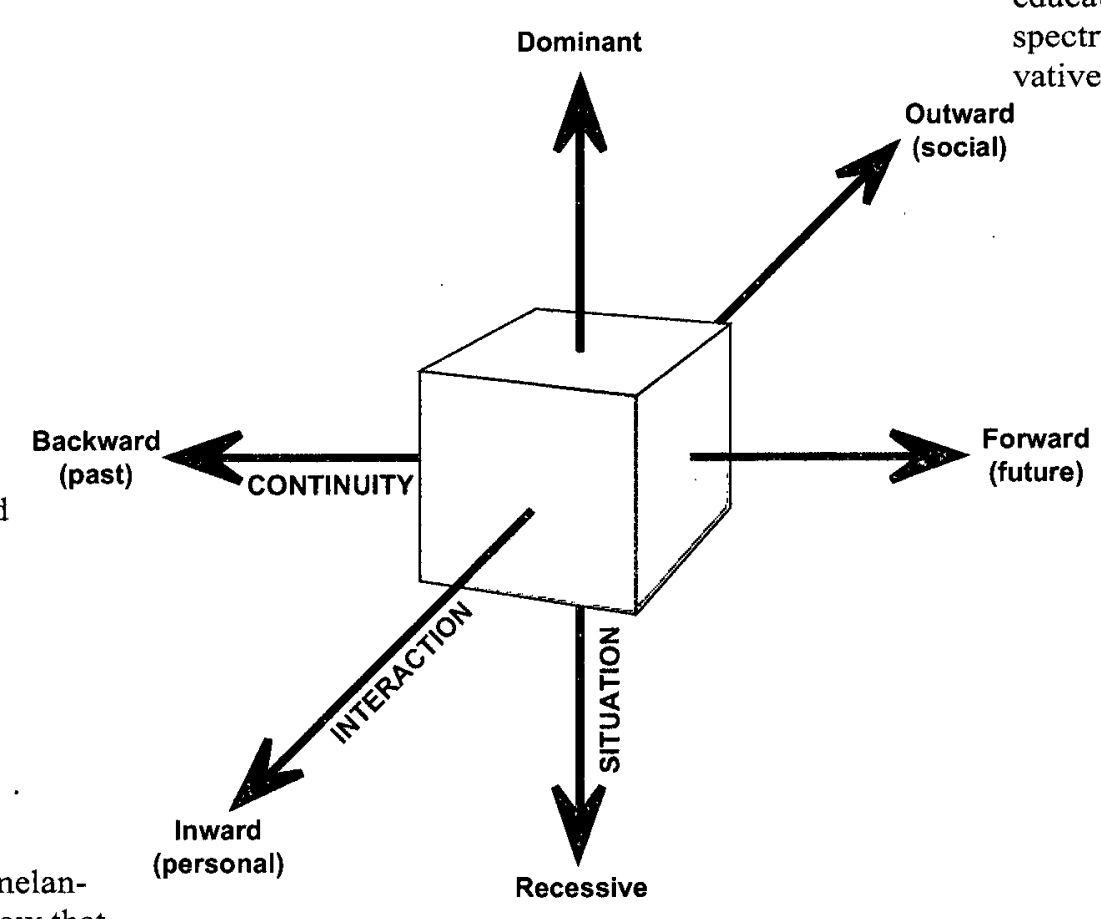

Debra has "a strong desire to apply all my skills in choosing only the best" leveled readers for sharing her love of reading with her grandchildren.

Figure 2. Three-Dimensional Inquiry Model (Applied). 
coming from" as a researcher. Among other data, this includes a description of my educational background and my personal educational philosophy.

An examination of my Vita shows that I've been involved with education in both the public and private school sectors for over 30 years. I've served as both a teacher and a principal, and was the senior editor for several elementary school curricula. I've also authored a number of books, and have been a presenter at many national educational conferences.

In terms of philosophy, I view American education today as the direct descendant of three main schools of thought. "Intellectual traditionalists" such as Horace Mann, Frederick Taylor, and Edward Thorndike believed the purpose of education was the acquisition of facts. Today we can see evidence of this in such programs as No Child Left Behind. "Social behaviorists," such as Herbert Spencer, believed that the purpose of education was to create good citizens. Their influence can primarily be seen in such curricular additions as driver's ed, home economics, and sex education. "Experientialists," such as John Dewey, Jean Piaget, and Jerome Bruner, believed that the purpose of education was to create critical thinkers. Their influence is evident in many educational reform models.

Regardless of rhetoric, which is often misleading, or the fact that many classrooms contain a composite of belief systems, I believe that it is fairly easy to detect an educator's basic philosophy by looking at his or her primary focus. Intellectual traditionalists tend to focus on content. Social behaviorists tend to focus on programs. Experientialists tend to focus on learners.

While content and programs are very important, my personal belief is 
that the challenges facing America today require more than just fact-memorizers or socially adjusted citizens. Our future requires critical thinkers and effective communicators who can become the Dean Kamens, Maya Angelous, or Richard Feynmans of tomorrow.

I also believe that learning, by its very nature, is a constructivist activity. It requires reasoning, analyzing, problem-solving, and other critical thinking skills. This puts it squarely in the experientialist camp. But unfortunately, people often mistake concentration for learning. A child may appear to be "learning" while diligently memorizing names and dates-but if he/she is unable to explain any significance in terms of history, then no real learning has taken place. In other words, you cannot always tell by simply observing outside behavior. It is only when you have the opportunity to dialog with a child, to collect feedback, that you discover what is really going on in his/her mind. (This has obvious connections to the way I conducted this qualitative study.)

In addition, less than a year ago I started a small educational publishing company. Thus in addition to being a researcher, I am now one of those authors who needs further insights on how to produce better leveled readers. My latest project, writing and developing leveled readers and teacher guides based on the National Science Education Standards, has already been incorporating emerging data from this qualitative study. Based on what I have learned, specific criteria were applied to all illustrations and content. (See "Additional Recommendations," chapter 6.) Of course, whether the application of these data to a specific product line will translate into better literacy resources remains to be seen. 
In summary, quality education is my passion. It is a process that I believe should not only be meaningful, but fun! Perhaps this is because I have spent my entire life surrounded by kids-from helping my parents raise foster children as a teen, to working at summer camps, to mentoring in college, to years spent in my own classroom, to (more recently) reading books to my daughter's kindergarten class. And like my daughter, I am first and foremost a teacher. I love kids and I love the business of education. As an outgrowth of this, I truly believe that the best administrators and curriculum writers are those who have had significant classroom experience. Simply put, in order to best serve children and teachers, you have to fully understand the world they live in.

\section{Purposeful Sampling}

Participants in this study were purposefully chosen to represent three distinct groups who have the potential to significantly impact the selection of leveled readers for early literacy instruction. These three groups were university literacy professors, regional superintendents, and classroom teachers.

University literacy professors often help mold perspective teachers' views of leveled readers even before those teachers have classrooms of their own. Regional superintendents can formulate policies that impact the selection of such books, often determining which books are placed in classrooms. Individual classroom teachers usually make the final decision regarding which leveled readers they will use on a regular basis.

The population for the pilot study (Morelan, 2003) included three 
classroom teachers, three regional superintendents, and three university literacy professors. For reasons outlined earlier, these same participants also composed the population for the current study.

As would be expected, some changes in the composition of these groups have taken place over time. For instance, one of the superintendents is now teaching literacy classes at a university, and one of the classroom teachers now serves as a regional superintendent. However, such changes simply added to the richness of the narrative, providing those participants with even broader perspectives into the selection process.

Primary commonalities of participants in this study included gender (all female), race (all Caucasian), education (all master's degree or above), and educational interest (all previously advisors in the development of leveled readers). Primary diversities of participants included geographic spread (coast to coast, north to south), age difference (47 to 71 ), and variations in major constituencies served (student teachers, regional districts, school boards, parents, and students).

\section{Data Collection}

Data in qualitative studies are generated by experience. These experiences, whether individual or group, are usually expressed as words-either spoken or written. Patton (1990) identifies three types of "word data" that are especially valuable to qualitative researchers: direct observation consisting of "detailed descriptions of people's activities, behaviors, and actions," written documents of various kinds including "excerpts, quotations, or entire passages," and 
open-ended interviews with "direct quotations from people about their experiences, opinions, feelings, and knowledge" (p. 7).

Detailed descriptions involve physical observation. Observing an educator as she chose a specific book from a set of leveled readers might have been interesting, but due to the wide geographic spread of the participants, these types of data would have been next to impossible to facilitate logistically. And data gathered this way would have had little relevance to the topic being studied.

Exploring written documents assumes that excerpts and quotations are available from a personal written body of work related to the topic. Although a few participants in this study have written papers related to early literacy, and one has even co-authored a textbook on reading, none of these documents offers detailed individual reflections about influences affecting the selection process.

The third method, open-ended interviews to collect direct quotations, relies on data gleaned from interviews, correspondence, phone conversations, and other forms of direct, personal communication. Since this study was based on stories and reflections that participants shared about their decisions, this was the most suitable source of data.

Specific background data on each participant were collected in Phase I. Questions in this phase were designed to gather demographic information such as age, gender, education, career history, geographic heritage, and so on. (Specific questions used in all three phases can be found in Appendix C.)

Phase II questions specifically focused on the evaluation of two sets of leveled readers that participants were asked to review. For part one of Phase II, 
participants were asked to make selections from a group of 15 leveled readers. These readers were randomly selected from recent additions to the same series that participants reviewed in the pilot study-the $A$ Reason For ${ }^{\circledR}$ Reading series published by the Concerned Group. (See Appendix D for samples of the text and illustrations.) Since these books were very similar to the set used in the pilot study, both in format and content, certain incidents of interest (see Data Analysis) were readily apparent. This portion of the study was especially helpful in isolating potential influences related to the continuity (temporal dimensions) portion of the model.

In part two of Phase II, participants were asked to make selections from a second group of 15 leveled readers-the Little Leveled Readers series Set C, published by Scholastic. (See Appendix D for samples of the text and illustrations.) These books were chosen not only because they were part of a popular series, but because texts and illustrations were very different from the books reviewed in part one. This variety in both format and content led to different incidents of interest that offered additional insights. This portion of the study was especially helpful in isolating potential influences related to the interaction (personal/social) portion of the model.

Phase III questions were reflective in nature. They were designed to help participants identify and reflect on specific influences that may have impacted the selection process. Questions in Phase III were also directly related to the three-dimensional inquiry space, encouraging participants to reflect about how temporal dimensions, personal and social issues, and the notion of place might have played 
a role in their responses.

In addition, to seek deeper insights into the selection process and the influences that impacted their decisions, a follow-up interview was conducted with each participant after Phase III was complete. As a starting point, the interview began with the question, "What personal or professional changes have you experiened over the past 6 years, and how do you think this may have impacted the way you select leveled readers?'- - but additional questions and responses were open-ended and were based on where the conversation led. This opportunity for reflective dialog, specifically as it related to the three-dimensional inquiry space, was designed to elicit more of the kind of introspective, insightful comments that qualitative researchers seek.

\section{Data Analysis}

The essence of narrative analysis is a concentrated focus on "the ways humans experience the world" (Clandinin \& Connelly, 1990, p. 2). As a research technique, narrative analysis reflects "the study of experience through stories . . . and on how these stories are communicated. . . First person accounts of experience form the narrative text" (Merriam, 2001, p. 157).

Once these first-person accounts have been collected, however, the researcher may analyze the data from any number of ideological perspectives. "There are no fomulae or recipes for the best way to analyze the stories we elicit and collect. Indeed, one of the strengths of thinking about data as narrative is that this opens up the possibilities for a variety of analytic strategies" (Coffey/Atkin- 
son, 1996, p. 80).

At its heart, analysis in qualitative research is about discovering the meaning contained in experience. Merriam (2001) refers to it as "consolidating, reducing, and interpreting what people have said and what the researcher has seen and read" (p. 178) until the researcher has a better understanding of the thing that is being studied. Bloomberg and Volpe (2008) point out that this "is essentially about searching for patterns and themes; that is, the trends that you see emerging from your findings" (p. 129).

Responses to specific questions, as well as reflections about the decisionmaking process and the three dimensions, resulted in field texts rich with data. These data were interpreted using a constant comparison method of data analysis (Merriam, 2001, p. 159). This is an inductive, concept-building approach to data analysis that reflects the concepts discussed above. It is also in harmony with the orientation of this study and the underlying nature of qualitative research in general.

Field texts and audio files were sorted into related groups, then read and reread (and played and replayed) to find incidents of interest. These incidents of interest were compared to other incidents of interest in the related groups, leading to the construction of general categories. These general categories were constantly compared, analyzed, and rearranged until they formed specific categories. These specific categories then evolved into specific themes about influences affecting the selection of leveled readers for early literacy instruction. 


\section{Trustworthiness}

Trustworthiness, sometimes referred to as internal validity, is about how closely the research findings match reality. "Internal validity in all research thus hinges on the meaning of reality" (Merriam, 2001, p. 201).

But what is reality? Sculptor Louise Nevelson (1978) once called reality "an agreement that people have arrived at to make life more livable." Psychology professor David Myers (2006) points out that "there may be an objective reality out there, but we view it though the spectacles of our beliefs, attitudes, and values." Both of these views highlight the need for qualitative research.

Trustworthiness in a qualitative research study is based on the previously discussed assumption that "reality is holistic, multidimensional, and ever-changing; it is not a single, fixed, objective phenomenon waiting to be discovered" (Merriam, 2001, p. 202). Thus, trustworthiness in qualitative research can best be derived from how well the researcher is observing and documenting "people's construction of reality—how they understand the world" (Huberman \& Miles, 2002, p. 50).

In this study, trustworthiness was enhanced through the use of several specific strategies. These strategies included member checks, peer examination, clarifying researcher bias, triangulation, and direct comparison.

A member check is the process of "taking data and tentative interpretations back to the people from whom they were derived and asking them if the results are plausible" (Merriam, 2001, p. 204). In my work as a writer and senior editor for various publishing projects, I engage in a similar process almost every day. 
Finished texts rarely resemble the original raw manuscripts sent in by authors, so regular feedback is vital in maintaining the integrity of the finished product. Throughout this study, continuous interaction with participants served as "member checks" to ensured my data and interpretations were valid.

Peer examination involves "asking colleagues to comment on the findings as they emerge" (Merriam, 2001, p. 204). I am fortunate that my peers include not only PhDs and doctoral students, but also a number of experienced educators. I actively solicited input from these sources as the study progressed. In addition, participants in this study were also peers in that we are all educators. Thus the member checks also served as a kind of ongoing peer examination.

Researcher bias helps clarify “the researcher's assumptions, worldview, and theoretical orientation at the onset of the study" (Merriam, 2001, p. 205). Establishing these biases was an integral part of the introduction to this study. In addition, the trustworthiness of findings was verified through various types of triangulation. Rudestam and Newton (2001) refer to triangulation as "soliciting data from multiple and different sources as a means of collaborating evidence and illuminating a theme or a theory" (p. 100). Merriam (2001) defines it as "using multiple investigators, multiple sources of data, or multiple methods to confirm the emerging findings" (p. 204).

A type of methodological triangulation occurred when there was a match between findings in the pilot study, the current study, and the literature. For example, all three sources indicated that educators were more influenced by personal preferences than by formal criteria when selecting books for young children. 
Triangulation also occurred when there was a match in responses from all three groups studied (classroom teachers, university literacy professors, and regional superintendents). For example, at least one member of each group specifically reflected on the influence of temporal dimensions on the selection decisions that she made.

Finally, triangulation occurred when there was a match in the responses of at least three individual participants. For example, responses from every participant in this study indicated that an educator's post of employment can influence the selection of leveled readers for early literacy instruction. Similar triangulation occurred with each of the four primary themes.

Trustworthiness in this study was further enhanced through the creation of participant response matrices (Tables 1 and 2) that allowed a direct comparison between the selections of all participants. Participant selections from Phase I, both part one and part two, were entered into a simple matrix format. This provided a graphical representation showing which books were selected as favorites and which as least favorites by each participant.

As the matrices show, many books were the "favorite" for one participant, but the "least favorite" for another participant. These included The Empty Tomb, The King on Trial, What Do You Know?, The Wedding Feast, George Washington Loved His Country, Same and Different, Shapes All Around, Squanto the Pilgrim's Friend, and Super-Duper Sandwich. When participants' rationales for making these selections were compared, the influence of the personal/social dimension of the underlying construct became readily apparent. 
Table 1

Participant Selections From Set 1

\begin{tabular}{|c|c|c|}
\hline Leveled Reader & Favorite & Least Favorite \\
\hline Baby Moses & $\mathbf{H}$ & \\
\hline David and Goliath & $\mathbf{H}$ & \\
\hline Deborah & $\mathrm{C}, \mathrm{E}, \mathrm{I}$ & \\
\hline The Empty Tomb & $\mathrm{A}, \mathrm{F}, \mathrm{I}$ & C, D \\
\hline My Friend and I & $\mathrm{B}, \mathrm{C}$ & \\
\hline The Good Samaritan & $\mathrm{D}, \mathrm{E}$ & \\
\hline Jonah and the Whale & I & \\
\hline Josiah, Boy King & $\mathrm{F}$ & \\
\hline The King on Trial & $\mathrm{E}$ & $A, B, F, G$ \\
\hline Let's Clean Up & & I \\
\hline What Do You Know? & $\mathrm{D}, \mathrm{G}, \mathrm{H}$ & $\mathbf{E}$ \\
\hline The Wedding Feast & $\mathrm{B}, \mathrm{C}$ & $\mathbf{H}$ \\
\hline The Prodigal Son & $\mathrm{B}, \mathrm{F}, \mathrm{G}$ & \\
\hline Ruth & $A, D$ & \\
\hline The Surprise Breakfast & $A, G$ & \\
\hline
\end{tabular}

Note. $\mathrm{A}=\mathrm{Amy}, \mathrm{B}=$ Betty, $\mathrm{C}=$ Cheryl, $\mathrm{D}=$ Debra, $\mathrm{E}=$ Elaine, $\mathrm{F}=$ Francis, $\mathrm{G}=$ Gloria, $\mathrm{H}=$ Helen, $\mathrm{I}=$ Irene. 
Table 2

Participant Selections From Set 2

\begin{tabular}{|c|c|c|}
\hline Leveled Reader & Favorite & Least Favorite \\
\hline \multicolumn{3}{|l|}{ Animals on the Go } \\
\hline Autumn Leaves Are Falling & $\mathrm{D}, \mathrm{E}, \mathrm{F}, \mathrm{I}$ & \\
\hline George Washington & $A, B, G$ & $\mathrm{E}$ \\
\hline Gifts Are Great! & B & G \\
\hline I'm a Little Tadpole & $\mathrm{D}$ & $\mathbf{H}$ \\
\hline In the Dark of the Night & $\mathrm{G}, \mathrm{I}$ & \\
\hline Peek-a-Boo & $\mathrm{H}$ & \\
\hline Same and Different & $\mathrm{A}, \mathrm{C}$ & $\mathrm{F}, \mathrm{I}$ \\
\hline Shapes All Around & $\mathrm{C}, \mathrm{F}$ & $\mathrm{D}$ \\
\hline Some Things Feel Soft & & B \\
\hline Squanto the Pilgrim's Friend & $\mathrm{F}, \mathrm{G}$ & A \\
\hline Super-Duper Sandwich & $\mathrm{B}, \mathrm{D}, \mathrm{H}, \mathrm{I}$ & $\mathrm{E}$ \\
\hline When I Grow Up & $\mathrm{C}, \mathrm{E}$ & \\
\hline Who Is Sleeping? & $\mathbf{H}$ & $\mathrm{C}$ \\
\hline Who Lives in the Pond? & $\mathrm{A}, \mathrm{E}$ & \\
\hline
\end{tabular}

Note. $\mathrm{A}=\mathrm{Amy}, \mathrm{B}=$ Betty, $\mathrm{C}=$ Cheryl, $\mathrm{D}=$ Debra, $\mathrm{E}=$ Elaine, $\mathrm{F}=$ Francis, $\mathrm{G}=$ Gloria, $\mathrm{H}=$ Helen, $\mathrm{I}=$ Irene. 
For instance, Betty chose Super Duper Sandwich as a favorite because "it has a central character that is the age of the intended audience. Concrete and vivid language portrays the actions of the main character. ... [The book] expands children's awareness of the important concept of 'sequencing.' . . Layout of the text is also well-conceived. . . . These characteristics converge to create a satisfying whole." Yet Elaine listed Super-Duper Sandwich as tied for her least favorite book (she chose two) because of the "reference to ham," and "the stupidity of putting all those food groups together."

Similarly, Francis chose Squanto the Pilgrim's Friend as a favorite because "it has values that are worth emphasizing. It also lends itself to many related activites for language and social studies." Yet Amy listed the same book as her least favorite because "it seems way off in its leveling. Pattern changes and difficult words ... make it quite hard for a level D book."

Also, the fact that every book in both Set 1 and Set 2 (except Animals on the Go) showed up as either a favorite or a least favorite on some participant's list helps emphasize the diversity of personal and social influences that can impact the selection process.

Eisner (1998) refers to comparative processes like those described above as "structural corroboration." As a part of verifying a study's trustworthiness, the researcher identifies "recurrent behaviors or actions, those theme-like features of a situation that inspire confidence that the events interpreted and appraised are not abberant or exceptional, but rather characteristic of the situation" (p. 110).

In summary, the use of member checks, peer examination, researcher bias, 
triangulation, direct comparisons, and structural collaboration helped verify the trustworthiness of this study. Each of these tools played a role in determining that the research findings did indeed match reality.

\section{Generalizability}

Generalizability is concerned with "the extent to which the findings of one study can be applied to other situations" (Merriam, 2001, p. 207). The issue here is that the things that qualitative researchers study are by nature difficult to generalize-at least in the traditional sense of the term.

However, Eisner (1998) makes a strong case that generalization of qualitative research is not only possible, but is an inherent part of such studies. He credits David Berliner as the first to suggest to him that "the process of generalization is inherent in all learning" (p. 211).

Eisner points out that all learners, including researchers, constantly generalize in terms of skills, images, and ideas. For instance, when we apply a skill in a different situation than the one in which we learned it, we are generalizing that skill. Eisner suggests that this is true for images and ideas, too. "For qualitative research, this means that the creation of an image-a vivid portrait of excellent teaching, for example-can become a prototype that can be used in the education of teachers, or for the appraisal of teaching" (p. 199). In other words, once a researcher has a clear image of a concept, he or she can apply this image to a variety of situations.

For the qualitative researcher, an important part of such generalization is 
the use of "rich, thick description." Merriam (2001) describes this as providing "enough description so that readers will be able to determine how closely their situations match the research situation, and hence, whether the findings can be transferred" (p. 211).

Rich descriptions create rich images. Eisner (1998) points out that "such images can function, just as propositions can, as categories that enable us to seek and sort the world we encounter. They are the devices through which our experience is construed" (p. 201). Creating and interpreting such images is a vital part of any qualitative research study. Throughout this study, care has been taken to provide this kind of narrative.

\section{IRB Issues and Answers}

According to guidelines set forth by Andrews University's Institutional Review Board, if a proposed research project "does not place the subjects at more than minimal risk and is included in one of six categories of research which are exempt from full review under the provisions of the Code of Federal Regulations for the protection of human subjects from research risk," then the research project in question is exempt from full IRB review.

Since all the participants in this study are adult educational professionals, and since the behavior being studied involves "normal educational practice" (see section 1, IRB Application for Approval), this research project met the qualification of being exempt from full IRB review. The remaining obligations of the researcher relate to requirements of "obtaining informed consent and maintaining 
confidentiality." Compliance was met as follows:

\section{Informed Consent}

This research presented "no more than minimal risk or harm to subjects and involves no procedures for which written consent is normally required outside of the research context." To avoid potential questions of authorization, however, written consent was obtained from all participants before any portion of the study began. Development of the consent form reflected the most recent edition of the IRB guidelines. A copy of the informed consent form that was signed by all participants can be found in Appendix A.

\section{Confidentiality}

Full confidentiality was maintained by assigning each participant in this study a pseudonym after data collection was complete. These names were selected from census data on the 100 most common female names in the U.S. population (retrieved April 29, 2009 from http://names.mongabay.com/female_names .htm). Participant profiles, responses, and reflections were never referenced in any fashion except by the assigned pseudonym. 


\section{CHAPTER FOUR}

\section{PARTICIPANT NARRATIVES}

\section{Introduction}

This qualitative study was designed to explore influences affecting the selection of leveled readers. Through the use of narrative inquiry, it examined how three groups of educators made decisions when selecting specific titles from a set of leveled readers.

This chapter contains the participant narratives. Embedded in each narrative is a descriptive overview of the participant, "a typical approach in qualitative studies" (Rudestam \& Newton, 2001, p. 158). Providing details about the individual participants in a study is a critical part of qualitative research because the findings of the study are a direct reflection of the participants and their personal life experiences.

Participant narratives also include presentation of the data. As mentioned in chapter 3, data in qualitative studies are generated by experience. Experiences, whether individual or group, are usually expressed in words. Patton (1990) pointed out that "direct quotations from people about their experiences, opinions, feelings, and knowledge" (p. 7) are especially valuable to qualitative researchers. The data embedded in these participant narratives are primarily of that nature. 


\section{Participant Overview}

Participants in this study were purposefully chosen to represent three distinct groups who have the potential to significantly impact the selection of leveled readers for early literacy instruction. These three groups were classroom teachers, regional superintendents, and university literacy professors.

As discussed in chapter 3 , primary commonalities of participants in this study included gender (all female), race (all Caucasian), education (all master's degree or above), and educational interest (all previously advisors in the development of leveled readers). Primary diversities included geographic spread (coast to coast, north to south), age difference (47 to 71 ), and variations in the major constituencies served (student teachers, regional districts, school boards, parents, and students).

In order to help protect their identities, participants were assigned pseudonyms after data collection was complete. These names were selected from census data on the 100 most common female names in the U.S. population (retrieved April 29, 2009 from http://names.mongabay.com/female_names.htm). The participant pseudonyms chosen were Amy, Betty, Cheryl, Debra, Elaine, Francis, Gloria, Helen, and Irene.

\section{Amy's Story}

Amy is a 47-year-old female with a Masters' in Curriculum and Instruction and National Board Certification in early/middle childhood literacy. For most of her adult life, Amy has lived in small towns in the Northwest-although her 
dream has always been "to live in a loft in a large city."

At the time of the pilot study, Amy had been working as a classroom teacher (Kindergarten, 1st, 2nd) for over 20 years. She has since become an Intervention Specialist.

Amy's post of employment "involves working as a mentor/coach with teachers as well as working with one small group of fourth-graders, one group of third-graders, and team teaching an extended-day kindergarten program between morning and afternoon kindergarten sessions." Amy is also Title 1 facilitator for her building, "which means I work with the Title 1 para-pros and plan the family involvement activities for our building once a month. I also lead out in book studies and arrange professional development for both para-pros and teachers."

Amy's professional life appears to have influenced the way she selects leveled readers. For instance, she achieved National Board Certification in 2005. That process taught her to "connect everything to the goals I have set out. Instructional materials have to be in line with your goals or you might as well just toss whatever book comes to hand in front of the kids." She also learned to connect specific skills with specific books. "Beginning readers need to see that the skills they are working on have a connection to what they are really reading. This is critical when choosing books." As a result of her professional training, Amy believes that "when skills and reading in context don't connect, it's not as powerful. There will still be kids who make those connections and become readers, but those who struggle will simply be left out."

Amy made an interesting connection between her personal life and the 
selection of leveled readers. Since her participation in the pilot study in 2003, her husband was diagnosed with cancer and her mother passed away. How have these personal crises influenced the selection process? In Amy's words, "I have learned that life is short. If we need to make every minute count, then that goes double for the books we choose for our beginning readers."

Because Amy spent years teaching early primary school, she "developed very definite opinions about children's literature." These personal preferences, both positive and negative, appear to be a major influence in her selection of leveled readers.

Amy reflected that, "I tend to avoid 'rhymy' books. They have to be really good before I will even consider them for use with my kids." This preference is apparent in the fact that although there were several books with a rhyming pattern in the pilot study, as well as in Set 1 and Set 2, Amy did not choose any of these as a favorite.

Amy also stated, "I'm not an overtly patriotic person. That's not to say that I don't love my country, but I don't like sappy patriotic books. I'd rather have just the facts." Although Amy did select George Washington Loved His Country as a favorite, she explained that this was because the book used the facts-based approach she preferred, and "wasn't full of overly sappy patriotism."

Amy expressed a strong aversion to "preachy" books. This was clearly illustrated in her comments about Let's Clean $U p !$ "It goes along great until the last page. The repetition is great. The high frequency words are great. The vocabulary matches the pictures." Amy continued pointing out the book's strong points, 
but suddenly changed her tone when commenting on the last page of the book (God likes everything to be clean!). "So those of us who don't manage to have everything clean aren't in God's favor? God is unhappy when my desk is a mess or my daughter's carpet is buried under three layers of clothes?" She concludes by saying, "I really think God has much more important things to worry about! I seriously don't like this book. In fact, I am on my way to the shredder!"

Some of Amy's personal preferences go back to childhood. "Growing up with Bible stories made me aware of how accurate stories are written. If there are too many differences from how I grew up hearing the story, I'm not likely to choose the book for my kids." This preference was apparent in her comments on Ruth. "Ruth has always been one of my favorite stories. I like the accuracy of the storyline, the focus on the happy ending ... [and] that it brings out the fact that Jesus was a descendant."

Amy has strong preferences related to illustrations as well. "Both sets of books we reviewed this time had a more cartoony style, but that's ok with me. ... I prefer bright, colorful illustrations that connect well to the text." Amy made many comments about illustrations, both in the pilot study and in the current study. "The illustrations with the similar faces are delightful" (Angels Care for $\mathrm{Me}$ ); "The illustrations of Naaman dipping in the river are cute and clever" (Naaman); "The illustrations are what make this book terrific" (I Can Draw); "The cover illustration shows complete joy!" (The Empty Tomb); "The kids in this book have great facial expressions" (Same and Different); "My favorite illustration is Peter cannon-balling off the side of the boat" (The Surprise Breakfast); 
"The overcast sky fits in the somber mood of the women" (Ruth).

Through the years, Amy's posts of employment have always involved working directly with children-first as a classroom teacher, then as an Intervention Specialist. When discussing potential influences related to her daily work (constraints, expectations, regulations, etc.), Amy immediately thought of benchmark testing, and the fact that she was currently working with two groups of Kindergarten students who were all below benchmark. "Our children have to be at certain levels each year to meet state benchmarks. If a book isn't going to help a child reach those benchmarks, it's a waste of my time, and more importantly, a waste of their time." Amy indicated that government-mandated tests "definitely have an influence on how I now select books," but insisted that her primary focus is still on the needs of the individual child.

Amy pointed out that as an Intervention Specialist, she sees readers every day who “just don't get it - and by third and fourth grade they don't like reading." According to Amy, many of these young readers have completely given up. "We must learn to choose quality materials that engage kids and help them connect to their learning at all ages and in all grades. Successful readers are motivated to continue reading as they experience more success." Amy also made a connection to her personal life. "Readers who struggle are not motivated to keep at it-much like I'm not very motivated to do anything that frustrates me or that I view myself as bad at."

Near the end of the study, Amy expressed some concern that at a different time she might have chosen different books. "I'm not sure if this messes up 
your study or not," she commented, "but my choices might be different 6 months from now." Although Amy's responses in this study do reflect her increased level of training and her awareness of broader themes compared to her responses in the 2003 study, overall the types of books that she selected or rejected (and the reasons she gave for these choices) were very similar to the responses she gave 6 years ago.

Regarding selection strategies, Amy did not refer to a list of formal criteria when evaluating and selecting leveled readers in this study. However, her responses do reflect two of Fountas and Pinnell's (1996) nine criteria: "enjoyment, meaning, and interest to children" and "quality of illustrations and their relationship to text."

\section{Betty's Story}

Betty is a 53-year-old female with a PhD in Reading. She describes herself as "a small-town resident" living in the Southwest. Betty spent 19 years as a classroom teacher in small, private schools throughout her state. At the time of the pilot study, she was in her 5th year as an Associate Director of Education -but before that study was complete, she became a Professor of Education at a private Christian university (enrollment about 850 ).

Betty's professional life appears to have influenced the way she selects leveled readers. She has taught elementary school reading as well as university reading method courses. She has also edited a number of publications for reading instruction and served on several reading curriculum committees. She "continues 
to do much professional reading as well as attending reading conferences." In addition, Betty visits student teachers and is frequently in and out of classrooms "where I observe the materials being utilized for reading instruction." According to Betty, "all of these things impact my views of the reading process and how I select leveled readers."

Betty has never been married and has no children. Her professional life appears to be the primary focus of her attention. Other than the death of her father (an event which caused her to withdraw from the 2003 study before it was complete), Betty indicated that she hasn't "experienced any dramatic changes over the past 5 years." With the exception of a few comments like, "My time is flexible, so I can accomplish projects like this at my leisure," and "I completed these tasks at home where there are few distractions and I could focus totally on the selection process without any interruptions," Betty's responses provided fewer glimpses into her personal life than most other participants in this study. When we discussed this, she commented that, "other than my personal preferences, my personal life probably has very little influence on how I select books."

Betty did, however, express a number of personal preferences that appear to influence her selection of leveled readers. For instance, she prefers "texts that have a positive, uplifting theme." This was apparent in her selection of $M y$ Friend and I, The Prodigal Son, and Gifts Are Great-all of which have positive, uplifting storylines.

Betty also has a preference for "good illustrations" that "provide cues for reading development" and are "age appropriate." She made comments, both 
negative and positive, about the illustrations in every book she selected. Referring to The King on Trial, Betty commented that "the illustrations, as well as the ending, set a dark tone or mood for this story. It is not a satisfying read for there is no feeling of hope weaved into the story."

Betty prefers leveled readers with a certain style of text. "Books with natural language are advantageous since they approximate the literary quality of authentic literature." Her selection of Super-Duper Sandwich, a book with single page spreads and simple language, is a good example of this preferencealthough all the books Betty chose as favorites were written in language with an easy, natural flow. Commenting on her selection of The Wedding Feast, Betty said that "concrete and vivid language that portrays the actions of the main characters, particularly dialogue, is used throughout the text."

She also expressed this preference through negative concerns. In reference to Some Things Feel Soft, chosen as a least favorite book, she said, "There is little 'zest' to this story. There is an absence of vivid language, and the ending is not well-conceived. For these reasons, it is not a satisfying read."

Betty has strong preferences regarding religious content as well. She pointed out that "the text needs to complement my religious beliefs if I am to use it for instructional purposes." More than most participants, Betty seemed to recognize the role that personal preference plays in her selection of leveled readers. She summarized this by saying, "Once a book meets my academic requirements, I tend to evaluate both the text as well as illustrations based on my personal preferences." 
One of the findings of this study is that based on their comments, those in supervisory posts (superintendents, directors of education, etc.) appear to be more influenced by the anticipated reactions of adult constituents (parents, school boards), whereas classroom teachers appear to be more influenced by perceived needs of children. Betty was the one exception. However, although Betty was an Associate Director of Education when the pilot study began, she served in this post for only 5 years. The majority of Betty's career has been spent as either a classroom teacher (19 years) or a university literacy professor ( 7 years). This may explain why her comments tended to be more similar to those of classroom teachers and university literacy professors than to participants in supervisory posts.

Regarding selection strategies, Betty's comments followed a very precise pattern for each book chosen, as though she were answering very specific questions. Does the book have a central character that is the age of the intended audience? Does it address an issue that is of concern to children? Is concrete and vivid language used to portray the actions of the main character throughout the text? Does the book expand children's awareness of an important concept? Does it develop a central theme without overt teaching or moralizing? Do illustrations provide cues for reading development, and are they age-appropriate? Is the layout of the text well conceived? Do these characteristics converge to create a satisfying whole? These questions refiect at least three of Fountas and Pinnell's (1996) nine criteria: "enjoyment, meaning, and interest to children," "quality of illustrations and their relationship to text," and "format."

When asked about this pattern, Betty responded, "It's not actually a formal 
list, but rather a synthesis from several sources that I use for my children's literature classes." So even though Betty does not rely on a formal list when evaluating leveled readers, formal criteria have clearly influenced her in aspects of the selection process.

\section{Cheryl's Story}

Cheryl is a "60-something" female with a Master's in Administration and Supervision plus "many graduate hours in related fields." She spent much of her childhood with her missionary parents in Latin America, then her teen years as a "PK" (preacher's kid) back in the United States.

Cheryl's career began with over 20 years as a classroom teacher and school administrator in Christian schools before moving into school supervision. Since then, she served as a school superintendent for over 9 years at the state level, and is now in her 11 th year as an Associate Education Director at the seminational (multi-state) level. Cheryl lives in the Northeast.

Cheryl's professional life appears to have influenced the way she selects leveled readers. Since the 2003 study, she has spent "considerable time" serving on a national-level committee to develop a denominational reading program. As part of that experience, Cheryl says that she read hundreds of children's booksrejecting over 300 per grade level "that did not meet our standards." Cheryl feels that this process "has given me a tremendous insight of what is available, as well as the broad spectrum of the quality of the writing and artwork. It has definitely sharpened my skills for analyzing children's literature." In all of her responses, 
both written and verbal, Cheryl referred back to this project often, implying that this experience has had a significant impact on the way that she selects leveled readers for early literacy instruction.

Much of Cheryl's committee work focused on leveling. The influence of that experience was apparent in the books she chose as her least favorites. The first book she rejected was The Empty Tomb. "While I like the story, I feel that the leveling is inappropriate-too many words, print too small as compared to other Level I books. See The Surprise Breakfast sent with this group or Blind, Blind, Bart from the earlier study." The second book she rejected was Who Is Sleeping? "This was my least favorite mostly because I felt the text was not up to Level D children in content or vocabulary."

The influence of Cheryl's committee work can also be seen in her comments on the books she chose as favorites. Deborah and The Wedding Feast were chosen "because they are stories that are not usually included in most children's literature." My Friend and I was chosen "because of its message of acceptance and diversity." Same and Different, When I Grow Up, and Shapes Are All Around were chosen because "I felt they would be a starting point for a good dialogue with children."

Cheryl's responses gave little insight into her personal life. In follow-up conversations, she seemed to draw strong lines between her personal and professional interests, displaying a reluctance to discuss the former beyond basic demographics. This made it difficult to draw any conclusions regarding what aspects of her personal life (if any) may have influenced the selection process. 
Regarding personal preferences, Cheryl specifically stated that her personal preferences played little role in the selection process. Instead, she asserted that she was guided by the "literature selection policy" of her denominational school system "that guides in selecting materials placed in our schools."

However, Cheryl did express some very strong preferences, especially related to illustrations. In the pilot study, she had strong criticisms for Esther Becomes Queen, Rahab, and Naaman-favorites of several other participants. "My main objection is the artwork in these books. Steven Butler tends to over 'caricaturize' people. The women look like Barbie, triangular shaped, oversized eyes; human expressions on the animals; Naaman looks like Brutus or Superman." Referring to illustrations of Esther and Rahab, she commented, "These characters are overly made-up and heavy with jewelry. I think the point could have been made that Esther stood out from the others for her inner beauty rather than all those adornments. Schools would get flack if this book were sent home to read to parents!"

Regarding the illustrations in Set 1 of the current study, she felt they were filled with "cartoonish artwork, especially of Bible characters, which is not well accepted by teachers or parents." Referring to the illustrations in the Set 2 books, she commented that they contained "poorly executed artwork that is amateurish instead of childlike. Even children produce better artwork than is seen in some of these selections!"

As mentioned earlier, when selecting leveled readers, those in supervisory posts appear to be influenced by the anticipated reactions of adult constituents. 
Cheryl's responses clearly supported this theme. "Unlike teachers who only have to worry about how the parents in one school will accept the materials, I have to work with parents, school boards, pastors, and educators from eight states. The spectrum runs from ultra conservative to anything goes." She also noted that "often more criticism revolves around standards (dress, food, pictures, particularly Bible characters) than about the actual course content," and pointed out that such criticism obviously has a strong effect on the selection process.

Cheryl's post of employment appeared to influence her selection of leveled readers in other ways, because she is currently involved in implementing a new literacy program. Leveled readers are "the actual instruction piece for Pathways, the new NAD [North American Division of Seventh-day Adventists] literacy program," and "each classroom in the division is building a collection of leveled readers as part of the implementation process." She went on to say that "being we are a system, we have a literature selection policy for both print and non-print materials as well as the art contained therein that guides in selecting materials placed in our schools." As a Director of Education, this policy has a marked effect on the leveled readers Cheryl chooses for early literacy instruction.

Regarding selection strategies, Cheryl did not refer to a list of formal criteria when evaluating and selecting leveled readers in this study, relying instead on her "35 years of working with parents, school boards, and pastors." However, her responses do reflect at least three of Fountas and Pinnell's (1996) nine criteria: "breadth of type or genre," "depth in the number of titles at each level of difficulty," and "quality of illustrations and their relationship to text." . 


\section{Debra's Story}

Debra is a 63-year-old female. She has an EdD in Curriculum and Instruction with an emphasis in Early Literacy, and is a certified Reading Specialist and Learning Disability Specialist. Debra has lived in a variety of places, but mostly in "small Midwestern towns or near large Midwestern universities."

Debra began her educational career with 6 years in the public schools3 years in a self-contained classroom, 2 years as a special education resource specialist, and 1 year in a self-contained learning disabilities classroom. She eventually went on to become a university professor, a path she followed for the next 22 years. At the time of the pilot study, Debra was a Professor of Education at a private Christian university (enrollment around 1,700) in the Southeast. She has since retired, and now travels extensively with her husband doing Habitat for Humanity projects around the country.

Although most participants in this study lived far away, Debra lived just down the street. Quiet and unassuming in face-to-face interaction with adults, Debra is passionate about reading and working with children. Begin a discussion about children, books, and reading, and you can suddenly see the excitement in her eyes and hear it in her voice. This passion was also apparent in the fact that Debra's responses were among the longest and most detailed of any in the study.

Debra's professional life appears to have influenced the way she selects leveled readers. Like most participants in this study who were classroom teachers or university literacy professors, Debra primarily focused on the needs and reactions of children. For example, in her comments on What Do You Know? 
Debra said, "This book contains basic sight vocabulary that is repeated throughout the text. This provides opportunities for beginning readers to see and read sight words again and again in story format. The text is also patterned. If a child can master the first few sentences, he/she can successfully read the whole story. The patterned text is similar to Bill Martin Jr's Brown Bear, Brown Bear, What Do You See? and it can be read in a rhymical [sic] fashion. This provides momentum for the reader, promoting quick, fluent reading of the text. Most importantly, the catchiness of the patterned text adds to the fun and enjoyment of reading this book. Children may thus associate reading with play."

One recent change in Debra's professional life has influenced the selection process by deepening her convictions. "Since I retired from active teaching at the university level, I've had the opportunity to tutor in the public schools. I'm now even more acutely aware of the need for quality children's literature.... More than ever I'm convinced that beginning and struggling readers need literature that motivates them to read and that provides characteristics known to support the reading process."

Like Amy, Debra was very open about her personal life and the influence it may have on the selection of leveled readers. "I suspect my personality type and religious beliefs affected the evaluation of these books." As an example, she noted her strong attraction to the Set 1 books. "These books provide opportunities for discussion regarding quality personality traits and the incomparable love of our Father-all good foundational beliefs. Such understandings build an understanding God and can contribute to the building of character. These books are 
wonderful because I can use them not only to share the love of our Father, but also good character traits."

Debra happily pointed out another recent change in her personal life. "I now have six grandsons! Our last little miracle was born in January, and I am looking forward to using these books to introduce my new grandson to the wonderful world of reading." Debra's passion for sharing the love of reading with her grandchildren has resulted in "a strong desire to apply all my skills in choosing only the best" leveled readers for their use. This is an obvious social/personal context (see 3D Inquiry Model, Figure 1) that continually recurred in our discussions.

Not surprisingly, Debra also has a number of personal preferences that influence her selection of leveled readers. She appeared well aware of this, pointing out two major preferences that influence her selections. "I tend to evaluate children's literature from two perspectives: aesthetic appeal and utility." Her preferences regarding "esthetic appeal" mostly revolved around illustrations. "Illustrations in any genre must be rich in context so that the reader can tap into that to help him work through the text and gain an understanding beyond the print on the page. ... Whenever I review any book, I look for quality illustrations that support the text and attract the reader."

Debra made numerous comments about illustrations, both in the pilot study and in the current study. "The illustrations present the concept that 'God sends his angels to watch over us' in a way that children can easily understand" (Angels Care for Me); "I especially like the caricatures of Joseph as a 
fine-looking boy and young man" (Joseph's Dreams); "Sometimes we forget to help children see that Jesus was not only the Son of God, but he was also very human. The pictures in this book show Jesus as a young boy helping his father, thus illustrating this key concept, as well as showing a positive character trait" (Jesus Helps His Dad); "The illustrations coordinate well with the text, providing the reader with additional context cues to aid in decoding such words as mother, father, and grandmother" (What Do You Know?); "The illustrations in this book provide strong support for the text. For example, on page 9 the word 'ravine' could be decoded by studying the illustration. Also, the thought bubbles on page 8 reinforce the fact that Jesus is telling a story. Both these illustrative devices provide teaching moments for teachers to show how illustrations provide important context cues" (The Good Samaritan); "Illustrations are well coordinated with the text on the page" (Autumn Leaves Are Falling Down); "The illustrations in this book coordinate fairly well with the text, but they lack color. In addition, the items need to be more clearly illustrated, especially such things as pickles, jellybeans, and ham" (Super-Duper Sandwich).

One of the best examples of Debra's focus on illustrations came from her comments on Ruth. "The illustrations in this story ... allow teachers to call attention to conventions that may be used by a skillful illustrator. For instance, the illustrations appear darker while Ruth is in Moab. They become lighter/brighter after Ruth and Naomi arrive in Bethlehem. This is similar to the way Wood and Wood created their illustrations in The Napping House. Teaching children to look for such conventions enhances their enjoyment of reading, and promotes their 
ability to comprehend texts in greater depth."

Debra's negative concerns about illustrations were just as strong. Commenting on The Empty Tomb, she said, "My major concern has to do with the illustrations. On page 3, the illustration is confusing. Mary is on her way to Jesus' tomb. However, the illustration shows Mary with her hands on the wall of a house and her eyes closed. To many young readers, this might appear as if Mary is blind and is feeling her way along the street. On pages 14 and 16, we are told that Mary is happy and that 'her heart was filled with joy and love.' However, the illustrations on these pages contain dark colors which portray a somber mood. More specifically, on page 14 the text notes that Mary 'felt the warm sunshine on her face.' Yet the illustration is not only dark and somber, but there is no hint of sunlight whatsoever!"

And Debra's negative concerns about illustrations were not limited to specific books. Responding to what she perceived to be a major weakness in all of the Set 2 books, she said, "Children deserve not only quality storylines and text that enables them to work through new text conventions and new words, but also illustrations that are more than just a few squiggly lines on a page!" In her comments on Shapes All Around, she added, "As in the other books in this series, the illustrations are too simplistic and lack color. There is nothing to attract children here. Well-conceived color illustrations can provide an essential source of context for young readers, and these are sadly lacking in all the books in this series."

Debra's personal preferences regarding "utility" appeared to be directly related to her experience as a reading specialist and her post of employment as a 
university literacy professor. Her comments consistently contained suggestions on how the books might be used in an instructional setting - an employment perspective that clearly influenced the selection process.

Here are some examples: "This story provides several opportunities for teaching the use of context clues. For example, on page 15, the first sentence reads, ' . . . where reapers were cutting grain.' This allows the teacher to point out that 'reapers' must be 'people who cut grain.' On page 16, Boaz tells Ruth to "glean with my young women.' The teacher could lead the students in rereading part of the previous page where 'Ruth followed the reapers, picking up as much as she could'-thus decoding the word 'glean.' Pointing out the connection between text and context cues equips children with important skills which allow them to be successful and independent readers" (Ruth); "This story employs the use of repeated sentence patterns. For example, on pages 17 and 21 , these sentences appear: 'The could have helped him.' 'The should have helped him.' This kind of repetition can provide confidence in young readers. And introducing new terms within repeated sentence patterns (i.e., 'Levite' and 'priest') allows young readers with the kind of support they need when being introduced to a new word in context" (The Good Samaritan); "A number of basic sight vocabulary words are used in this book-are, down, love, now, them. Not only are they used, but they are repeated, some numerous times. This allows for practice reading within the format of running text" (Autumn Leaves Are Falling Down); "This book is written such that the text can be sung to the tune of London Bridge-a familiar nursery song. Thus the text can be either chanted or 
sung. This provides momentum when reading and promotes fluent reading. This would also seem to be enjoyable for young children" (Autumn Leaves Are Falling Down); "Words in this book that might be new to young readers follow predictable phonemic rules. This allows more opportunity for young readers to decode new words. These types of words also lend themselves to good word sorts--thin, win, bin, fin; shrink, rink, blink, link; grow, row, low, mow" (I'm a Little Tadpole); "One thing that drew me to this book was the potential to use it as a writing prompt, which could then become another opportunity for reading. Children could review the book, then be led to write their own classroom book on how to make the 'super-duper sandwich' of their choice. This could be student illustrated, assembled, and then read repeatedly. All this supports reading, writing, spelling, and the development of basic literary concepts" (Super-Duper Sandwich).

Debra also expressed negative concerns regarding use of certain books in an instructional setting-again reflecting the influence of her post of employment on the selection process. "This book contains many words that are probably new to young readers - tomb, burial, thoughtfully, immediately, whispered, recognized, etc. These last three words all appear on one page! Introducing so many new words at once is far too challenging for most readers. In addition, the word 'lagged' appears on page 4, but this is the only time the term is used, making it difficult to decode from the context" (The Empty Tomb); "The author claims that the text for this book can be sung to the tune of 'The Wheels on the Bus'. However, the text on pages 3 and 8 does not synchronize with the tune or the music of this song! Also, the text on pages 4 and 6 have too many repetitions of the same 
word. Because we do not speak using such language patterns, many young readers would be confused, making it difficult for them to keep their place while reading these pages. . . Finally, this book offers too many opportunities for semantic confusion, which may lead to frustration on the part of young readers" (Shapes All Around).

Regarding selection strategies, Debra did not refer to a list of formal criteria when evaluating and selecting leveled readers in this study. However, her responses do reflect three of Fountas and Pinnell's (1996) nine criteria: "enjoyment, meaning, and interest to children," "quality of illustrations and their relationship to text," and "content."

During our final interview, just hours before Debra left on another Habitat build, she made a point of bringing to my attention the subjective nature of her responses. "You do realize, don't you, that I might have chosen some different favorites if I was working with a particular student and was looking for a book for a specific instructional purpose?" As we discussed this further, however, Debra felt that even if she had chosen different books, they still would have been the same types of books based on the same basic preferences. This assumption is supported by the books Debra chose, and the rationale she gave for those choices, in the pilot study. It also provides a good example of the concept of continuity.

\section{Elaine's Story}

Elaine is a 53-year-old female with a Master's in Curriculum and an EdS in Educational Administration. She describes herself as a "Midwestern city girl" 
and she lives in a major metropolitan area.

Elaine began her educational career with 13 years as a classroom teacher in Christian schools. She then spent 2 years as an Associate Superintendent at the state level, followed by 5 years as Superintendent. She is now in her 10 th year as an Associate Education Director at the semi-national (multi-state) level.

Like Cheryl, Elaine has spent a significant amount of time over the past few years serving on a national-level committee to develop a denominational reading program. She believes that this has had an influence on how she selects leveled readers. 'I'm sure I was influenced by my work on this committee, as well as my earlier participation as a member of the steering committee for the $A$ Reason For Reading project."

One example of this influence was Elaine's sensitivity to the need for "new" storylines. This was apparent in her comments on several of her favorites. "I like Deborah because it is a story that is rarely told. I also appreciate the focus on a female role-model in the Bible" (Deborah); "The writing was a fresh retelling of an old story. It was also accurate with the biblical account" (The Good Samaritan); "While this story is often told, it is usually just part of the crucifixion story. I like the way this book pulls this part out and gives it a fresh focus" (The King on Trial).

Elaine's professional life has also included some unique challenges. "I have been incredibly busy this year since we were without an Education Director for 8 months. My biggest challenge was operating without this support during that time, then adjusting to the new Director of Education when he arrived." Yet 
Elaine did not feel that this situation influenced the selection process in any way. "The fact is that I approached this experience in the same way as I would have if I had had more time. I almost always go with my first reaction because I feel it is the real reaction to the literature. It was a process of narrowing selections down to the number requested in the survey. Most of the time I was able to review an entire set in less than an hour."

Like Amy, Elaine faced a significant personal challenge after the pilot study. "The biggest personal challenge over the past 5 years was moving my father out of my house and into a nursing home, and then dealing with his death last summer." But Elaine had an interesting spin on how these challenges, both professional and personal, related to participating in this study. "It was fun to participate in this project! It gave me much-needed relief from the pressures of my personal life and my job."

Like other participants in this study, Elaine appears to have personal preferences that influence the way she selects leveled readers. These preferences were primarily related to the illustrations. "I know I was affected by my desire for more realistic illustrations. So when I was reviewing the literature, I was continually looking for illustrations that were less cartoonish and more real."

This personal preference was reflected in many of Elaine's comments. "The illustrations in this book were not too over-the-top and added to the story" (The Good Samaritan); "The illustrations are clean, clear, interesting, and engaging" (When I Grow Up); "The illustrations in this book caught my eye. Most in this series did not. I like the way it shows the animals in isolation, then how they 
live together" (Who Lives in the Pond?); "I like the lyrical text and the simple illustrations" (Autumn Leaves Are Falling Down).

Elaine also expressed negative concerns related to illustrations. "The final illustration in this book bothers me, and that is what turned me away from this book. This representation of God looks like Santa Claus in pajamas-although thankfully they're not red! I think there are much better representations of God's love to be drawn" (What Do You Know?); "There's also a problem with the final illustration in this book. The prophetess looks like a ghost or an old hag witch!" (Josiah, Boy King). Commenting further, she added, "The writing in these two books is very good, but these specific illustrations greatly disturbed me. These books are probably tied for my least favorite in this series because of those illustrations."

Elaine also expressed a preference for books with "authentic content." This was demonstrated by her total distain for books that did not meet this standard. "The text in this book is NOT accurate! George Washington did NOT sail the sea-he crossed a river. I don't care if the story is simplified, the basics should be accurate!" (George Washington Loved His Country); "I really disliked the content of this book. Not only is the ham reference inappropriate for my SDA schools, but also the stupidity of putting all those food groups together" (SuperDuper Sandwich).

During the final interview, Elaine reflected that there was another way her personal preferences may have influenced the selection process. She felt that even though participants in this study evaluated the two series separately, she 
may have been a bit biased toward the $A$ Reason For ${ }^{\circledR}$ series of books. In her words, "This was because they were richer and more in-depth, and I was much more positively aligned toward them for that reason. I just felt like they were giving the kids a much bigger picture, and I liked that."

Elaine's post of employment appears to influence the way she selects leveled readers. Like other participants in this study who were in a supervisory position (Cheryl and Gloria), Elaine often focused on the anticipated reactions of adult constituents. "My choices were greatly affected by thinking about a typicalto-conservative Adventist school. I looked at each piece of literature through the eyes of whether or not it would be appropriate for use in any Adventist school, and what the reactions of the parents and teachers might be. I believe this is probably because of my heavy involvement in the North American Division language arts series development and because of our sensitivity to utilizing literature that is acceptable in all types of Adventist schools." She went on to say, "This has become a part of who I am when I review children's literature."

Many of Elaine's comments reflected her supervisory status and concerned "what I perceive as appropriate literature for Christian schools, since that is my work focus." For example, she summarized her comments about the Set 1 books by saying, "The writing in the books in this series is very good. Some are more in line with the biblical story than others, but no great license was taken. This is very important to my parents and school board members." She also shared her belief that "leveled readers will be an integral part of the future as we help early readers grow through guided reading experiences," but felt she was influenced by 
this belief only "in the sense that I was looking for leveled readers that provided an authentic reading experience."

Regarding selection strategies, Elaine did not refer to a list of formal criteria when evaluating and selecting leveled readers for this study. However, her responses do reflect three of Fountas and Pinnell's (1996) nine criteria: “accuracy and diversity" "quality of illustrations and their relationship to text," and "content."

\section{Francis's Story}

Francis is a 71-year-old female with a Master's in Reading Education and an EdD in Leadership (cognate Reading). She was born in Oklahoma, lived in rural northern California until after college, and has spent the past 40 -plus years in the rural Midwest.

Francis spent almost a decade as a reading diagnostician and tutor, then director of a reading center. Her university experience has spanned 22 years, including 3 years as a Reading Recovery teacher leader. At the time of the pilot study, Francis was an Associate Professor at a private Christian university (enrollment around 3,400) teaching in the Teacher Education and Reading MA programs. She has since retired, and now devotes the majority of her time to her quilting business.

Francis's professional life appears to have influenced the way she selects leveled readers. She reflected at length on the many influences throughout her working career, and felt that even though she is now retired, those influences 
continue to play a role in her selections. "During the years I taught Reading Recovery, I was constantly observing things that seemed to make children select specific books, or pass them by. It might be something novel that caught the child's interest, or his/her feeling of success in being able to read a particular book well. One child I remember was very aware of the smallest details and differences in illustrations, so something novel in an illustration was a big hit for him!" Francis felt that during this portion of her career, her study of Marie Clay's work also had a significant impact on how she looked at leveled readers.

In addition, Francis mentioned her training in the Action Phonics and Orton Gillingham programs, which taught her to value certain kinds of texts for reading instruction. "I worked in a time period when the 'reading wars' raged from skills to whole language-and then supposedly on to 'balanced reading.' I believe that it's naïve to think that just because a child reads Brown Bear, Brown Bear umpteen times, he/she will no longer confuse $\mathrm{b}$ and $\mathrm{d}$. Though that approach may work fine for some children, for others it doesn't work at all. My years of tutoring and testing struggling readers convince me of this. Some children need a carefully structured type of training which has them overlearn and learn through a multi-sensory approach what others pick up incidentally or naturally. Because of my experience with these things, I see value in some books for certain purposes that may not be needed by another child."

In addition to job-related experience and literacy training, Francis pointed out the influence of professional conferences. "At the yearly Reading Recovery conferences, I was able to hear such experts as Lee Skandalaris and the Ohio 
State Professors who brought Reading Recovery to the United States. These annual conferences also provided a great opportunity to talk with other reading professionals, and to review lots of new children's books at the various exhibits."

Like Amy and Debra, Francis was very open about her personal life and the influence it may have had on the selection of leveled readers. "Personality wise I am a melancholy type. I'm not sure how that affects book selection, but I know it likely has a part to play. I'm also introverted, and I think for that reason I find it easier to spend more time with books than some people do. Perhaps that makes it easier for me to like some books that others wouldn't have time for."

Francis's childhood experiences also influenced her selection of leveled readers. "As a child I went to SDA [Seventh-day Adventist] schools and took the typical Bible and reading classes offered in those long-ago days. Often the study materials did not seem very appealing. But I loved to read and went to libraries often, and my parents always bought me books. . . I often felt the religion materials available at school and church were rather boring. And just memorizing facts, even though I did it fairly easily, was also boring. Looking back now, I don't think I was helped to think in much depth about any of the stories or issues."

There is an obvious connection between this negative personal experience and Francis's desire to provide a richer experience for students. Several of her selections were chosen because they provided conversation starters, crosscurricular connections, or other ways of encouraging deeper thinking. "The text and illustrations provide an opportunity for children to experience the emotions 
and questions and discoveries associated with the events" (The Empty Tomb); "This book provides a good lead into discussion about how important it is to follow where God leads" (Josiah, Boy King); "The story offers a model of a solution to many problems - admit a mistake and go back. It works for reading, and it works for life! Also, the story of a person who has hit hard times is one that many children can identify with. It provides an opportunity for great discussions and lessons regarding money, relationships, how to solve a problem, and so forth for the lives of kids now! And the conversation starters help students explore and express feelings - something many children raised in Christian homes do not get enough opportunity to deal with openly" (The Prodigal Son); "This book could be used as a springboard for writing and art" (Autumn Leaves Are Falling Down); "This book has content with values that are worth emphasizing. It also lends itself to a good many related activities for language and social studies" (Squanto The Pilgrim's Friend); "It could be used to coordinate with shapes lessons in math and art" (Shapes All Around).

Francis also pointed out that "when I was a child learning to read, I learned a lot of phonics. I learned a lot more as an adult when I learned to teach dyslexic students. So this no doubt affects my way of looking at instructional materials for reading. Just as 'you can take the boy out of the country but you can't take the country out of the boy,' you can try to remove a teacher from the phonics camp, but to a great extent, the phonics remains a part of this teacher."

Like many other participants, Francis has also been influenced by family concerns. "I'm keenly aware that my 10 -year-old grandson, who is progressing 
very slowly in reading, is really hooked by books with some personal interest and humor. Over the years, I've also been impacted by the reactions of my grandchildren, my grand niece, and the grandchildren of my friends, as they read the A Reason For ${ }^{\circledR}$ Reading books and other books for children."

The biggest change in Francis's personal life since the pilot study has been her retirement from active teaching. She now spends much of her time operating a custom quilting business. "I have relegated to my past life most things that have to do with teaching reading and reading methods classes. . . . I no longer attend professional conferences or read the professional literature in that area as I once did." Francis also indicated that since retiring, she has given away most of her extensive collection of materials related to reading instruction since "I do only a little work with teachers and children in that area."

However, it is evident that Francis still has a warm spot in her heart for reading instruction. "Near the time I retired and just after, I continued to do part-time supervision of student teachers. I was delighted to see more teachers in small schools begin to use leveled readers and to find satisfaction from teaching that way. And their stories of children loving the little books I had helped create were very gratifying."

Personal preferences also appeared to have an influence on Francis's selection of leveled readers. "I see a need for Christians to have a sense of humor, especially in dealing with children. I like upbeat music, stories, etc. I find it much easier to share others' laughter and humor than their sorrow and woe."

In the current study, this preference was expressed through negative 
concerns about her least favorite books. Commenting on The King on Trial, she said, "While this story was included in the canon for a reason, I feel it would be difficult for young children to comprehend the dynamics of what takes place here. And unless this book is used along with the rest of the series in such a way that there is balance between the positive and negative aspects of the whole crucifixion and resurrection story, it could be either very jarring for a child or could be a lot of words with little meaning that sink in. Without "the rest of the story," it's simply a sad, depressing book."

Francis's comments on Same and Different were even more pointed. "The thing I dislike about this book is that it alludes to a very important belief about human beings-but doesn't seem to put the idea across with anything to grab the reader! Simply put, it's very ho-hum. And as with all of the books in this series, the lack of color provides fewer meaning cues from the pictures."

This preference for upbeat stories and humor was also apparent in Francis's comments on illustrations. "In general, I'd probably prefer a more traditional and realistic style of art. But where the humor is prominent in the artwork, it tends for that reason to draw me in to like those books a bit more."

This preference was very apparent in Francis's selection of Naaman and Angels Care for Me in the pilot study. While Gloria rejected Naaman because the artwork "made Naaman appear to be a superman [who] looks like he spent his entire life in the gym," Francis chose Naaman as a favorite, commenting that "from what I've seen in using the book, the humorous artwork seems to grab the attention of both kids and adults. I think humor is important in learning, and if 
you really think about it, God demonstrated a sense of humor in this healing miracle." Also, while Elaine rejected Angels Care for Me because "the illustrations gave the impression that angels are visible" and "the illustration of the guardian angel wearing a bike helmet is silly," Francis selected the book as a favorite because "the power of the humorous illustrations pulls kids in . . the real magic is in these illustrations."

Francis also expressed a preference for a specific kind of religious book. "I have a strong need to see God as a personal God. I feel much closer to the 'merciful, friend to all' side of God than I do to the 'power/justice' side. Intellectual doctrinal discussions are of far less interest to me than the relational concepts that are at the core of religion and spirituality."

Commenting on Josiah, Boy King, she said, "This book and David and Goliath both have a young person as the central character. Both stories illustrate what happens when a young person has a faith relationship with God and follows where God leads. I also like the way this story presents the relationship of Josiah and his mother, and how she helped develop his love for God, as well as helping shape the goals and aspirations of her son."

Francis also noted that at least one of her personal preferences had its roots in her childhood. "As a child I was restricted from reading the fiction genre. So I never came to have much love for poetry, or the broader range of literary works that some enjoy." However in this case, Francis's preference seems to be overruled by her sensitivity to the needs of children. Regarding her choice of Autumn Leaves Are Falling Down, a book with text based on the sing-song refrain of the 
children's ditty "London Bridge Is Falling Down," she explained, "I think many of the children I taught would have wanted to choose this book to reread. The storyline's connection with a familiar song gives that emotional lift associated with a catchy rhythm, and a fun activity has the potential to make reading this book successful for many children."

Like other participants in this study who were classroom teachers or university literacy professors, Francis's personal preferences often reflected her focus on the needs of children. "I really prefer books that kids love. I know that l've often been influenced by the process of leveling books with numerous kids. As they read and enjoyed certain books, it added greatly to my appreciation of those books."

Francis's post of employment as a university literacy professor also influenced the selection process. Like Debra, her comments consistently contained suggestions on how the books might be used in an instructional setting-an employment perspective that clearly influenced how she selected leveled readers.

"I believe the story is well suited to a multi-grade, multi-age lesson. . . . There are enough vocabulary and language challenges in this story to advance reading skills for young readers" (Josiah, Boy King); "There is enough text here for good reading practice and plenty of skills lessons" (The Prodigal Son); "There is an opportunity to work with an in/on confusion if it comes up on pages 6 and 7. The words autumn and around look enough alike to provide something to work on for those kids in the group who are a little further along than in/on" (Autumn Leaves Are Falling Down); “This book uses repetition that should aid 
children who still need practice in one-to-one matching. And it could help some in building fluent phrasing" (Shapes Are All Around); "The difference in sentence lengths and patterns could be great for some kids needing to be weaned from too much of regular text patterns, but hopefully there are less ho-hum books to use for this purpose" (Same and Different).

Francis also brought up a concern about the nature of this study that was directly related to her post of employment. "I must protest a little here. From my perspective, choosing books without reference to the child (or group of children) for whom they will be used, and the timing of when they will be used, is a bit artificial. In general, while making my choices, I often felt like I was engaging in an exercise where I was missing a key element-what child, with what interests, and what stage of reading strategy development is this book to be chosen for?"

She went on to say, "Of course, if you are building a library or classroom collection, this sort of thing is exactly what you must do. I just think it's important to note that depending on the time and situation, most of these books could have been either a favorite or least favorite for me... The three factors that are biggest in my thinking about selecting books are the spiritual/values influence of the books; the interest/excitement that I expect children will experience with the books; and the skill/strategy needs of beginning readers-especially the slow progress or struggling readers. But again, the priority given to each of these three areas might be different with different books."

One of the findings of this study was that educators may choose different leveled readers at different times. Within the context of continuity, selections may 
vary, reflecting the impact of other influences. Not only do Francis's comments in the previous paragraph support this view, but she also emphasized this concern again in her follow-up interview. "When I'm asked about a favorite of anything, it seems to vary from one time to another. So whatever I choose is simply representative of the type of thing I like, not the one favorite. I like variety, so perhaps on another day, I may have made a different choice. In fact, right now I can't remember exactly which books I said were my favorites!"

Regarding selection strategies, Francis did not refer to a list of formal criteria when evaluating and selecting leveled readers in this study. However, her responses do reflect four of Fountas and Pinnell's (1996) nine criteria: "enjoyment, meaning, and interest to children," "quality of illustrations and their relationship to text," "content," and "format."

\section{Gloria's Story}

Gloria is a 49-year-old female with a Master's in Curriculum and Instruction. She is currently pursuing a $\mathrm{PhD}$. Gloria was born in the Appalachian Mountains of Virginia, but has spent much of her adult life in major metropolitan areas. Because of this, she jokingly describes herself as "a highly-educated redneck." Gloria is currently a regional Superintendent of Schools, and she lives in a large city in the Midwest.

Of all the participants in this study, Gloria has perhaps seen the most significant change in her professional life since the pilot study. Six years ago, she was a classroom teacher with over 25 years of experience. Then in just a few 
short years, she made the transition to a full-time school administrator, and then to a regional Superintendent of Schools.

Gloria's professional life appears to have influenced her selection of leveled readers. "During the years when I was teaching in the classroom, most of my experience was in the lower grades. Working with small children for so many years allowed me the privilege of seeing things through their eyes. I have tried to bring that background with me as I moved into supervision, and hope it still is a major influence on me in the selection process."

Although many aspects of Gloria's personal life appear to have influenced the way she selects leveled readers, two of these are especially strong. "First and foremost, my particular worldview is from a biblical perspective. Therefore, $I$ do not apologize for evaluating any type of reading material on how it fits into that view. Does the book introduce the child to Jesus? Does it lead to spiritual development? Does it contain values consistent with my Christian beliefs? These are the kinds of questions I ask first."

Gloria also recognized the influence of her childhood on the selection process. "I love books and I love reading. As a child I always had a backpack filled with books from the library. That stash was replenished regularly. Even today, I get a thrill from holding a handful of new readers. This is the kind of love for reading that I want to pass on to my teachers and students."

One very specific example of how Gloria's personal life directly influenced the selection of a leveled reader relates to her choice of The Surprise Breakfast as a favorite. Gloria grew up in a family that loved to camp and cook 
out. In her comments on this book, Gloria laughingly admitted that "I love surprises and I love breakfast! This book reminds me of my family camping and cooking over an open fire. Good memories!"

Like the other participants, Gloria has personal preferences that appear to have had a strong influence on the way she select books. From her comments, it is clear that if a book does not appeal to her, then she simply will not recommend its use.

Many of Gloria's comments were based on her personal reaction to a book's content. "This is one of my favorite Bible stories. It's about forgiveness, and I can personally identify with it" (The Prodigal Son); "I love the theme of this book. It's about how much Jesus loves me, my family, and the whole world. My whole family is in this book! And as I get older, I appreciate stories about family more and more" (What Do You Know?); "The message about something bad turning into something good is very important for all ages" (The Surprise Breakfast); "This book has a wonderful rhyming pattern" (In the Dark of the Night); "We rarely think of George Washington as a boy. Young children can identify with young George. They also can see that they can grow up to be anything" (George Washington Loves His Country); "I appreciate the fact that a Native American is portrayed in a positive manner-as a friend! Many contributions of Native Americans are pointed out in this book, and this helps children realize the debt we owe these early people" (Squanto the Pilgrim's Friend).

Gloria also expressed negative concerns that reflect her content preferences. "The theme of this book bothered me greatly! It's all about receiving. 
I wanted it to end with the greatest gift being the one you gave, not the one you got. This book teaches the wrong lesson and emphasizes the wrong thing!" (Gifts Are Great!); "I'm concerned because the 'story' doesn't end where this book ends. There is no resolution and the ending is not positive" (The King on Trial).

A sense of fun and humor is important to Gloria, too. This was evident not only in her stated preference for fun, upbeat books, but also in the little side comments she occasionally added. For instance, her footnote to The King on Trial said, "As usual, the ending would have been different if the man would have just listened to his wife!"

Gloria has a personal preference for "colorful, creative illustrations." Because of this, she had a difficult time evaluating the Set 2 books. "This task was very hard because in general, I did not like these books. The covers were not attractive and the illustrations inside were not well done-plus they were only black and white drawings, not colorful pictures." She went on to say, "For me, illustrations, especially those on the cover, play a huge role in the selection process because I know that small children are first attracted to that. The illustrations are just as important to the overall book rating as the actual words on the page."

This preference was clearly apparent in all of Gloria's comments on illustrations. "The illustrations make me look at them over and over. Each time I see something new in the picture. The pigs even look happy while standing in the mud puddle and munching on corn cobs! On the cover, the dad looks happy with the son. I especially like the illustrations where the son changes his dirty, torn clothes for new pretty ones, and where the boy gets to eat at the table in contrast 
to sitting with the pigs" (The Prodigal Son); "I'm a Dale Earnhardt fan, and the toy car on the cover has Dale's number 3 on it. I thought this was a fun little touch" (What Do You Know?); "This is a very inviting cover. The four men are all smiling and happy" (The Surprise Breakfast).

Gloria also expressed negative concerns that reflect her illustration preferences. Commenting on The King on Trial, she pointed out that "the cover looks terribly sad. The colors throughout are dark and dreary. There is not one happy, smiling face in this entire book." And in reference to Gifts Are Great, her other least favorite book, she said, "The illustrations are unrealistic and poorly conceived. This is just made worse by the fact that they are all black and white." Gloria's post of employment continues to influence her selection of leveled readers. She expressed concerns about some of the same constraints as Cheryl related to working with multiple constituents. "I must admit that I did view all of the selections by asking myself if I could recommend that book to the specific schools that I administer." She also noted that "even though I have schools where almost anything goes, it seems as though it is the conservative schools that often guide curriculum decisions."

She continued, "In my current job, I must see curriculum materials through the eyes of my parents and school boards. I have to consider what their possible reactions to a book might be." Contrasting this to the early part of her career where her focus was primarily on the needs of the children in her classroom, Gloria expressed some concerns. "It wasn't that long ago I was a classroom teacher, but in some ways it seems like forever. I pray that I will always 
have the heart of a teacher. If I lose that, then I feel I will no longer be an effective administrator."

In our final follow-up interview, she referred to these concerns again. We discussed the constraints she faces related to widely divergent classrooms. Then she said, "In spite of all the outside pressures, I hope I will always remember to look at leveled readers through the eyes of a child!"

Gloria's administrative perspective was also apparent in her final comments on the books reviewed for this study. Although she indicated that she saw little use for the Set 2 books, she excitedly projected a number of future uses for the Set 1 books, including classroom libraries, resources for guided reading teachers, additions to book collections for the Pathways reading program, and "give-a-ways for events like Vacation Bible School."

Regarding selection strategies, Gloria did not refer to a list of formal criteria when evaluating and selecting leveled readers in this study. However, her responses do reflect five of Fountas and Pinnell's (1996) nine criteria: enjoyment, meaning, and interest to children; accuracy and diversity in multicultural representation; quality of illustrations and their relationship to text; content; and format.

\section{Helen's Story}

Helen is a 54-year-old female with an MEd in Early Childhood Education. Growing up, Helen lived in a variety of places - from California, to Canada, to Mexico. For the past 20 years, however, she has been "putting down roots" in a 
large city in the Southeast.

At the time of the pilot study, Helen was a classroom teacher with 15 years experience. She has since become an independent educational consultant in the area of literacy, working with such diverse groups as educational publishers, private schools, and her state's literacy council.

Helen's professional life appears to have influenced the way she selects leveled readers. She shared her strong feelings about some bad experiences in her early teaching years-what she called the "basal battle." "I taught first grade when basals were assumed to be the proper method of instruction. I used a selfdesigned, literature-based approach and was chastised!" But Helen is known for her strong-willed nature, and she persevered. Today, that same school system expects teachers to use a guided reading style program, although "there is still resistance to change," which Helen believes is due to "a lack of training, a lack of materials, and a lack of leadership that understands the process." According to Helen, watching these changes over time helped her see that "the bottom line is that children need good books they want to read . . . books that offer teachable moments ... and teachers that know how to use them."

Like Amy and Gloria, Helen left the classroom shortly after the 2003 study. "Professionally, I am completely out of the classroom. I am doing educational consulting, conducting the occasional teacher workshop, and tutoring a special-needs student I have known since he was in first grade." But she pointed out that "one thought rings just as true today as when I was in the classroom. The books teachers have to choose from are limited in many ways." Helen sees this as 
having a major influence on the selection process. "The supply is limited by cost and by what is available. The number of books each child reads is also limited by time. So every book must be evaluated to see if it will capture the student's interest, offer teachable moments, and have a message worth reading. We can't afford so-so books!"

In addition, Helen has also "continued my study of reading instruction" by reading professional journals and attending conferences. She reflects that "new data about struggling readers has added a whole new layer to the selection process that I did not intentionally use before."

Helen's personal life also appears to have influenced the way she selects leveled readers. Much of her childhood was spent in Mexico where her father was attending medical school. Helen fondly remembers the sleepy, rural atmosphere that surrounded their home. Books that evoke those memories are special favorites. This was apparent in her comments on Who Is Sleeping? "The ending really drew me to this book. City kids might need an explanation, but I can remember waking up and listening to the roosters crow and wake each other up like dogs barking around a neighborhood."

Helen has a clever, sharp wit, and this also seemed to influence the selection process. Many of her favorites featured some quirky or humorous aspect in the storyline or the illustrations. Super-Duper Sandwich is a good example. And as we discussed this book, Helen immediately thought of a follow-up activity where students would "create their own recipes, then decide what the reaction would be if they ate their own concoctions!" 
Like the other participants, Helen's personal preferences appear to have influenced the way she selects leveled readers. One of her strongest preferences was for books with language that is alive. "I want the child to form a connection with the author. If a book is flat, lacks voice, it is never going to be selected by me." This was apparent in Helen's comments about The Wedding Feast. "My choice of this book as my least favorite was somewhat ironic because it was the last book that I eliminated from my favorites list. The reason it was there was because of the illustrations. They're amazing! But as good as Steven's illustrations are, it was Josh's coloring that added magic to this book. Wow!"

However, the language choice in this book was accurate and clear, but not inspiring at all! When my students read, I want them to savor the language and to be exposed to wonderful word choices. For instance, the text reads 'At midnight there was a loud cry!" Where is the strong word choice that puts you there? Just adding an exclamation point isn't enough. Here's another example: 'Give us some of your oil,' they said. SAID? Put that word to bed! Why not they begged, or cried, or demanded, or even bleated? Please not just said!"

Helen also prefers access to a wide genre of styles rather than "dozens of books that are very similar." Even within the limited constraints of this study, she specifically chose books that were "sweet" and books that were "gritty." This was apparent in the contrast she made between David and Goliath and Baby Moses. "David and Goliath offers an exciting hero and a larger-than-life villain. Its appealing straight-forward approach to the text would delight many first-grade boys." But commenting on Baby Moses she said, "This book is a sharp contrast 
to David and Goliath. It definitely falls in the sweet category. It even has a princess that would delight many Disney fans." Helen emphasized her point by concluding that "too often lower grade books only offer sweet stories that have little appeal for the more gritty-minded inhabitants of our classrooms."

Helen also prefers books with bright colors and clever illustrations. Like Gloria, she had a difficult time evaluating the Set 2 books. "It was hard to choose a least favorite from this series since I found all of these books much less satisfactory due to their small size, poor illustrations, and lack of color."

Helen also expressed her personal preferences through negative concerns. In reference to I'm a Little Tadpole, chosen as a least favorite book, she said, "Not only do I object to the poor illustrations and lack of color, but the author's method of adding new text to a familiar tune just didn't work. The word choice seemed forced and didn't fit the natural flow of language."

Like other participants who were classroom teachers or university literacy professors, Helen's post of employment appears to have influenced the way she selects leveled readers. This was specifically reflected in her focus on the instructional needs of children.

Commenting on Who Is Sleeping? she pointed out that "this book offers a comparison between 'sleep' and 'sleeping." This can be used to expand the child's understanding of language with innovations such as 'the pig is eating ... he eats corn." She also liked the rhythm of What Do You Know? "This pattern offers many opportunities for innovation. 'Sammy girl, Sammy girl, what do you know? I know I love reading, that's what I know' and so on." Super-Duper 
Sandwich made her favorites list, not only because of the quirky nature of the storyline, but also because "the use of 'come' and 'comes' gives teachers an opportunity to see if the reader is decoding these words correctly, then discuss why each is appropriate." Helen also liked this book because it offered opportunities for encouraging students to create books of their own. And the book Peek-a-Boo was chosen primarily because "the variation in punctuation allows teachers opportunities for instruction in same."

Since Helen's job as a consultant requires access to a broad variety of leveled readers, she is deeply interested in the supply process. "Leveled readers in general are a growing trend, and new products built around leveled readers are being introduced all the time." But even though Helen felt that Set 1 was "for the most part excellent books," she was somewhat pessimistic about their future since "few outside the advisory team seem to know about these books" and "there doesn't seem to be a reasonable marketing plan in place."

Regarding selection strategies, Helen did not refer to a list of formal criteria when evaluating and selecting leveled readers in this study. However, her responses do reflect five of Fountas and Pinnell's (1996) nine criteria: enjoyment, meaning, and interest to children; breadth of type or genre; quality of illustrations and their relationship to text; content; and format.

\section{Irene's Story}

Irene is a 71 -year-old female with a PhD in Reading and Language Arts. She was born in New Zealand and spent much of her early life there. 
Irene's educational career began with 12 years of classroom teaching at the elementary level. She went on to spend nearly 30 years in college and university work. At the time of the pilot study, Irene was a Professor of Education at a private Christian college (enrollment 1,800 ) in the Northwest. Although she is now "retired," Irene still teaches literacy courses at a large state university.

Irene's professional life appears to have influenced the way she selects leveled readers. Her own dissertation traced the literacy development of six children from birth to the end of first grade. She believes that "the theory and observational research done for that enterprise has had a large influence over my thinking." Irene also spent many years observing children as they learned to read, giving her "an understanding of the kinds of materials that stimulate interest and teach strategies."

Even though Irene is technically retired, she still has an active professional life. "I am still working in classrooms observing children as I supervise student teachers." In addition, Irene teaches graduate courses in reading during the summers, so "I constantly get a refresher course in the theory and practice of reading." She also pointed out that, "at the moment, I am preparing to teach a graduate class on Beginning Literacy, so I am sure that has had an influence on my thinking as well."

Irene's personal life also appears to have influenced the way she selects leveled readers. She lives alone in "a peaceful valley," and describes herself as "a lover of art, nature, and creativity." Because of this, Irene "is drawn to books about nature that provide content for children so that they can be observers of the 
world around them." This was evident in her comments about Autumn Leaves Are Falling Down. "The last picture is a celebratory one. It is important to teach children to observe the seasons and to celebrate life!" It was also reflected in her remarks about In The Dark of the Night. "This book would be a great introduction to a study of the night, where children explore the sky and animal life after the sun sets. Children can discover that different night sounds are not scary, but filled with interest."

Irene's description of how she reviewed the books provides additional insights into her world. "When the books first arrived, I sat down on the couch in the family room and read them through, then put them in three piles-great, good, and so-so." The rest of her description was almost lyrical. "I left them for a day or two and came back on a sunny afternoon to reread and resort them. My house was quiet and peaceful and I tried to read them with the eyes of a child. . . All contributed to my sense of well-being on that day."

Irene is a deeply spiritual person. She made a direct connection to this while explaining why she chose The Empty Tomb as one of her favorites. "This story will always be my favorite. ... In many ways it is my story of finding the risen Lord and knowing that I am loved and saved." Her beliefs were also apparent in her comments on Jonah and the Whale. "I also like the fact that this story looks at our motives and self-protectiveness and strips us of pretense. It helps me see that God really knows my heart and wants me to listen and respond to his calling."

Like Debra and Francis, Irene appears to have been influenced by 
experiences related to her grandchildren. Since the study in 2003 , she has "watched my grandchildren go from beginning readers to voracious readers who do not want to turn the lights off at night because they want to read just one more page!" She points out that since there are hundreds of children like this around the country, "there will always be a need for more good books" to fill the gap.

Irene expressed a number of personal preferences as well. Because of her poetic nature, she "loved the books that were set to the tune of a song. This incorporates another skill and helps the child gain fluency." Commenting about Autumn Leaves Are Falling Down she said, "children love to sing and to act. This story could be enjoyed by small groups or the whole class. It is predictable, joyful, and filled with movement." She also pointed out that "this book could be a springboard for composing a song about the other seasons."

Irene prefers powerful illustrations that support the text. "The text and pictures need to match, and I believe that for a book to be successful, they must also captivate the interest of the child." Several of Irene's comments concerned this preference. "The illustration of a joyful Mary is unforgettable" (The Empty Tomb); "The pictures are fabulous and match the feelings of the story-despair, fear, man's attempts to save himself, etc." (Jonah and the Whale); "It is well told and the illustrations match the text" (The Prodigal Son); "I am awed by the cover illustration. Here is this elegant lady open to receive directions from God" (Deborah).

Irene also has a personal preference for books with religious themes. Regarding The Empty Tomb she said, "I love this book because it is about sorrow 
being replaced by hope, and a woman who loved her Lord finding him again." She was attracted to The Prodigal Son because it was "the story of a relentless lover who pursues the lost with compassion and forgiveness." Deborah was also one of Irene's special favorites. "Young ladies need to know that God calls women to leadership today just as He did in Bible times.... It reminds me that no matter what the circumstances, God ultimately makes good triumph." She added, "Ultimately, his story is about listening to God, waiting on God, and obeying the leadings of the Lord."

Irene also prefers books with a sense of fun and "interesting action." Her choice of Super-Duper Sandwich as a favorite was a good example of this. "This book really appeals to children's sense of fun and imagination ... it encourages independence and fun." Like Debra and Helen, Irene came up with several extension ideas related to the book. "This book would be wonderful for predicting. Children could list or draw what they like on a sandwich and then open the book and see how many they can find in the book." "Children could create their own imaginary sandwich after they have read the book and write the words out." "The teacher could give children the introductory part (then comes the ...) and they could complete each sentence with their own choice of ingredients." This preference was also evident in her comments on In the Dark of the Night. "I like this book because it rhymes and is filled with interesting action."

Irene's preferences were also expressed as negative concerns. Commenting on Same and Different she wrote, "The concept is good, but the book is not predictable. It does not rhyme, there are no repetitions, and it uses vague, 
uncertain phrases like 'pretty big' and 'in some ways."' When we discussed this in the follow-up interview, she explained, "I prefer books that build, have movement, create a sense of community, and are fun to read. This one does none of those things." She expressed similar concerns about Let's Clean Up! "It lacked excitement. It was my mother telling me to clean up my room-with no storyline! I'm concerned that this generation is not being taught how to clean and care for their space but there must be a more exciting way to do it."

But while Irene expressed strong preferences, she did not always insist that every book meet her own personal standards. For instance, the books in Set 2 "did not always match my personal values in living or eating." However, she cautioned that teachers should not exclude books for that reason alone. "I think that children are very quick to understand that there are differences in people and their values. It's helpful for them to learn acceptance of others at this early stage of life."

Irene's post of employment appears to have influenced how she selects leveled readers. As mentioned earlier, Irene is retired now. But like Francis, Irene reflected that her years of training and experience still influence her selections. This instructional bent was apparent in comments like this: "Research indicates that for fluency and ease of reading, children need to be able to predict and use all three cueing systems-semantic, syntactic, and phonemic. I will always be looking for books that honor these three principles," and "no matter what modern materials we have, we will always need appropriate books to teach beginning reading. Such books can give children a foundation for reading as well as the 
inspiration to live good lives."

Regarding selection strategies, Irene did not refer to a list of formal criteria when evaluating and selecting leveled readers in this study. However, her responses do reflect four of Fountas and Pinnell's (1996) nine criteria: enjoyment, meaning, and interest to children; breadth of type or genre; quality of illustrations and their relationship to text; and content.

\section{Summary of Participant Narratives}

Despite the somewhat homegeneous nature of the sample population, the participant narratives demonstrated the vast variety that exists between individual educators. For example, there were significant differences between how superintendents were influenced in the selection process compared to what influenced classroom teachers and university literacy professors. Yet even within the subgroup of superintendents, there were substantive differences. The beliefs and practices expressed by Cheryl, for instance, were often in marked constrast to those expressed by Gloria.

Other elements, such as the influence of one's professional life, personal life, and personal preferences on the selection process, also showed substantive differences. Often the challenge was not in finding diversities in the participants' responses, but in determining the commonalities which led to the emerging themes. In short, the richness and depth of the participant narratives far exceeded my initial expectations. 


\section{CHAPTER FIVE}

\section{ANALYSIS OF NARRATIVE THEMES}

\section{Introduction}

In this chapter, comparisons are made between the literature and the four specific themes that emerged during data analysis. This chapter also describes an analysis of those narrative themes. In chapter 6, comparisons are made between the literature and additional findings, and between the literature and the underlying construct. Each of these analyses yielded unique insights.

To determine the narrative themes, responses to specific questions, as well as reflections about the decision-making process, were interpreted using a constant comparison method of data analysis (Merriam, 2001, p. 159). In addition, incidents of interest were isolated and compared to the 3D Inquiry Model resulting in specific findings that were categorized into four specific narrative themes.

According to Patton (1990), "It is common in qualitative studies for mounds of field notes and months of work to reduce to a small number of core themes" (p. 7). In this study, four primary themes emerged:

1. Experiences related to an educator's professional life can influence the selection of leveled readers for early literacy instruction. Literacy training, attending reading conferences, reading professional journals, 
and similar activities can influence the selection process.

2. Experiences related to an educator's personal life can influence the selection of leveled readers for early literacy instruction. Childhood experiences, religious beliefs, family concerns, and similar matters can influence the selection process.

3. An educator's personal preferences can influence the selection of leveled readers for early literacy instruction. These preferences can include both negative and positive concerns.

4. An educator's post of employment can influence the selection of leveled readers for early literacy instruction. In this study, superintendents appeared to be more influenced by anticipated reactions of adult constituents. Classroom teachers appeared to be more influenced by the perceived needs of children.

Each of these specific themes was subsequently examined in further detail to explore connections to the relevant literature.

\section{Influence of Professional Life}

The first emerging theme was that experiences related to an educator's professional life can influence the selection of leveled readers for early literacy instruction. Responses from participants suggested that activities such as receiving literacy training, achieving certification, attending reading conferences, or even just reading professional journals can influence selection.For example, Amy pointed to her recent National Board Certification. Betty talked about her 
professional reading and attending literacy conferences. Debra referred to her certification as a Reading Specialist and Learning Disability Specialist. Francis cited her training in Reading Recovery, Action Phonics, and Orton Gillingham. Helen also mentioned professional reading and attending literacy conferences. And Irene joked about her "constant refresher course in the theory and practice of reading" as a result of her preparation for teaching graduate-level literacy courses. In each of these instances, the participant demonstrated that the experience had influenced her in the selection process.

Research supports the concept that experiences related to an educator's professional life can impact specific instructional practices. A study by Sierra and Combs (1990) found that as the teachers became more familiar with an instructional approach, their instructional practices gradually changed. "As we begin to tune into ourselves and our children, new directions slowly become clearer" (p. 125). A similar study by Scharer (1992) found that as teachers were provided assistance through in-service training, conferences, and similar informative help, they began to change both their practices and beliefs about reading instruction. And Meral's (2002) exploration of expert reading teachers discovered that teachers' instructional practices were "remarkably consistent" (p. 350) with the beliefs that the teachers had developed over their years as professional educators.

The findings of this study support the view that experiences related to an educator's professional life can influence specific instructional behaviors. More specifically, experiences related to an educator's professional life can influence the selection of leveled readers for early literacy instruction. 


\section{Influence of Personal Life}

Another emerging theme was that experiences related to an educator's personal life can influence the selection of leveled readers for early literacy instruction. Responses from participants who shared personal experiences (not directly related to their jobs) suggest there is a direct relationship between an educator's personal life and his/her instructional practices.

For instance, Amy made a clear connection between her personal life and the selection of leveled readers. Since her participation in the pilot study 6 years ago, Amy's husband was diagnosed with cancer and her mother passed away. In Amy's words, "I have learned that life is short. If we need to make every minute count, then that goes double for the books we choose for our beginning readers."

Like Amy, Debra saw a direct connection between her personal life and the selection process. "I suspect my personality type and religious beliefs affected the evaluation of these books." As an example, she noted her strong attraction to the Set 1 books. "These books provide opportunities for discussion regarding quality personality traits and the incomparable love of our Father-all good foundational beliefs. . . . These books are wonderful because I can use them not only to share the love of our Father, but also good character traits." For Debra, the selection process is not only influenced by potential student need, but also by a desire to share a love of reading with her six grandsons, resulting in "a strong desire to apply all my skills in choosing only the best."

Francis was also influenced by family concerns. "I'm keenly aware that my 10-year-old grandson, who is progressing very slowly in reading, is really 
hooked by books with some personal interest and humor." Francis feels this personal perspective definitely has an influence on how she selects books. In addition, she pointed out another potential personal influence: "Personality wise I am a melancholy type. I'm not sure how that affects book selection, but I know it likely has a part to play. I'm also introverted, and I think for that reason I find it easier to spend more time with books than some people do. Perhaps that makes it easier for me to like some books that others wouldn't have time for."

Gloria gave a specific example of how an educator's personal life might directly influence the selection of a leveled reader. Since Gloria grew up in a family that loved to camp, she is drawn to books with an outdoor theme. In her comments about The Surprise Breakfast, Gloria laughingly admitted that "I love surprises and I love breakfast! This book reminds me of my family camping out and cooking over an open fire. Good memories!"

Like Gloria, Helen's childhood also played a role in her selection of leveled readers. Helen spent much of her childhood in Mexico, and books that evoke those memories are special favorites. Commenting on Who Is Sleeping?, she said, "The ending really drew me to this book. City kids might need an explanation, but I can remember waking up and listening to the roosters crow and wake each other up like dogs barking around a neighborhood." Helen is also known for her sharp, clever wit, and many of her selections featured some quirky or humorous aspect in the storyline or the illustrations.

Irene describes herself as "a lover of art, nature, and creativity," so she is "drawn to books about nature that provide content for children so that they can be 
observers of the world around them." And like Debra and Francis, Irene pointed out the influence of various experiences related to her grandchildren.

Responses like these seem to indicate a clear link between an educator's personal life and his/her specific instructional practices. While there is currently no literature that clearly supports this finding, this study strongly suggests that experiences related to an educator's personal life can directly influence the selection of leveled readers for early literacy instruction. This is an area worthy of further study.

\section{Influence of Personal Preferences}

Another emerging theme was that an educator's personal preferences can influence the selection of leveled readers for early literacy instruction. Every participant in this study made numerous comments that reflected personal preferences, both of a positive and a negative nature.

For example, Amy expressed a strong personal preference for "bright, colorful illustrations that connect well to the text." But she also had a strong aversion to "preachy" books. This was especially apparent in her comments about the book Let's Clean Up! She also prefers books that are not "rhymy" or full of "overly sappy patriotism."

Betty's personal preference is for "texts that have a positive, uplifting theme" and "good illustrations" that "provide cues for reading development" and are "age appropriate." She also pointed out that "the text needs to complement my religious beliefs if I am to use it for instructional purposes." 
Cheryl's personal preferences were most apparent in the negative comments she made about illustrations. She clearly does not care for "cartoonish artwork" which she feels "is not well accepted by teachers or parents."

Debra seemed well aware of the influence of personal preferences, especially in the areas she called "aesthetic appeal and unity." The first (aesthetic appeal) was expressed in her lengthy comments, both positive and negative, about specific illustrations. The second (utility) revolved around ways she felt the books might or might not be used.

Elaine was influenced by her personal preference for "more realistic illustrations," and for storylines that were "not too over-the-top." Like Cheryl, she expressed negative concerns about many illustrations with such comments as, "That is what turned me away from this book."

While Francis's personal taste leans toward "a more traditional and realistic style of art," she still found herself drawn to the books "where the humor is prominent in the artwork." Francis's growing preference for upbeat stories and humor was apparent in many of her comments. Perhaps due to the influence of her grandson, she observed that "the power of the humorous illustrations pulls kids in... The real magic is in these illustrations."

A sense of fun and humor is important to Gloria, too. This was evident not only in her stated preference for "fun, upbeat books," but also in the little side comments she added just for the researcher. "Colorful, creative illustrations" are also a preference. She emphasized this point by pointing out that "the illustrations are just as important to the overall book rating as the actual words on the page." 
One of Helen's strongest personal preferences was for books with "language that is alive." She commented that "if a book is flat, lacks voice, it is never going to be picked by me." She also has a preference for a wide genre of styles rather than "dozens of books that are very similar."

Irene expressed a strong preference for "books that build, have momentum, create a sense of community, and are fun to read." However, Irene drew a distinction between personal preferences and personal standards. For example, Super-Duper Sandwich was one of her favorites, even though the storyline revolves around a ham sandwich and Irene does not eat pork products. She felt that books could match her personal preferences for children's literature even if they "did not always match my personal values in living or eating."

Research supports this concept that an educator's personal preferences can influence specific instructional practices. A study by Hart and Rowley (1996) found that book selection decisions were more influenced by an individual's personal preferences than by formal criteria. They discovered that personal concerns such as "the extent to which the teacher personally connects to the literature" (p. 4) played a major role in making book selections. Donovan and Smolkin (2002) also found that teacher book selections were based on subjective factors such as "visual features" and "potential uses for the books" (p. 412) rather than specific formal criteria.

Research also supports the concept that personal preferences of a negative nature can influence book selection. One study (Wollman-Bonilla, 1998) found that teachers rejected certain children's literature when they believed that the 
books might frighten or corrupt children; fail to represent dominant social values or myths; or fail to identify racism or sexism as a social problem.

As shown in the excerpts above, the findings of this study support the view that an educator's personal preferences can influence specific instructional behaviors. More specifically, it found that experiences related to an educator's personal preferences can influence the selection of leveled readers for early literacy instruction.

\section{Influence of Post of Employment}

The final emerging theme was that an educator's post of employment can influence the selection of leveled readers for early literacy instruction. An analysis of demographic data suggests that superintendents appear to be more influenced by the anticipated reactions of adult constituents, whereas classroom teachers appear to be more influenced by the perceived needs of children.

For example, Amy followed several child-focused comments with the observation that "we must learn to choose quality materials that engage kids and help them connect to their learning at all ages and in all grades." Debra's primary focus was on ways to use the books with children: "One thing that drew me to this book was the potential to use it as a writing prompt, which could then become another opportunity for reading." Responses from Francis, Helen, and Irene also contained many suggestions focused on children's instructional needs such as "There is an opportunity to work with an in/on confusion if it comes up on pages 6 and 7," "the variation in punctuation allows teachers opportunities for 
instruction in same," and "children need to be able to predict and use all three cueing systems - semantic, syntactic, and phonemic. I will always be looking for books that hone these three principles."

By contrast, the responses and reflections of regional superintendents related primarily to adult constituents. Cheryl pointed out that "unlike teachers who only have to worry about how the parents in one school will accept the materials, I have to work with parents, school boards, pastors, and educators from eight states." Elaine felt that her choices "were greatly affected by thinking about a typical-to-conservative Adventist school. I looked at each piece of literature through the eyes of whether or not it would be appropriate for use in any Adventist school, and what the reactions of the parents and teachers might be."

The newest superintendent, Gloria, even expressed concerns about this shift in priorities due to her post of employment. "In my current job, I must see curriculum materials through the eyes of my parents and school boards. I have to consider what their possible reactions to a book might be." She contrasts this to her years as a classroom teacher when her primary focus was the needs of children in her classroom. "It wasn't that long ago I was a classroom teacher, but in some ways it seems like forever. I pray that I will always have the heart of a teacher. If I lose that, then I feel I will no longer be an effective administrator."

Responses like these seem to indicate a clear link between an educator's post of employment and his/her educational practices. While there is currently no literature that clearly supports this finding, this study strongly suggests that an educator's post of employment can directly influence the selection of leveled 
readers for early literacy instruction. This is an area worthy of further study.

\section{Summary}

In this chapter, comparisons were made between the literature and the four narrative themes. Two of these themes were clearly supported by the literature. The concept that experiences related to an educator's professional life can influence book selection was supported by studies such as Sierra and Combs (1990), Scharer (1992), and Meral (2002). The concept that an educator's personal preferences can influence book selection was supported by studies such as Hart and Rowley (1996), Wollman-Bonilla (1998), and Donovan and Smolkin (2002).

Regarding the other two themes, responses strongly indicated that both an educator's personal life and her post of employment can influence the selection of leveled readers for early literacy instruction. Outside of this study, however, there is currently no literature that clearly supports these findings. Thus, both of these areas are worthy of further study. 


\section{CHAPTER SIX}

\section{CONCLUSIONS AND RECOMMENDATIONS}

\section{Introduction}

The problem addressed in this qualitative study reflects educators' concerns about the quality of childrens' books in general and leveled readers in particular. As stated in chapter 1, even though the marketplace is filled with thousands of leveled reader titles, educators appear to be searching for "something better" (Buxton \& Austin, 2003; Darigan et al., 2002; Donovan \& Smolkin, 2002; Duke, 2000; Kruse, 2001; Lempke, 1999; Lowery, 2000; Manjari, 1998; Short \& Fox, 2003; Wolfson, 2007; Worthy et al., 1999; Yenika-Agbaw, 2003). But before educators, authors, and publishers can respond to this perceived need for better beginners' books, they must have a clearer understanding of influences affecting the selection of leveled readers.

Thus, the purpose of this qualitative study was to explore "influences affecting the selection of leveled readers for early literacy instruction." To do this, it examined how three groups of educators (classroom teachers, district superintendents, and university literacy professors) made decisions when selecting specific titles from two sets of leveled readers. Because the use of leveled readers can affect reading achievement, the overall goal of this study was not only to 
raise awareness of how educators select leveled readers, but also to identify areas needing further study.

The central research question was, "What influences affect the selection of leveled readers by professional educators for early literacy instruction?" Specific interview questions also helped explore influences related to temporal dimensions, social/personal contexts, and the notion of place.

\section{Research Design}

This qualitative study was based on a narrative inquiry approach. It grew out of a pilot study (Morelan, 2003) on this topic. The current study used the same participants and built on their responses from the earlier study.

A major focus of this study was the relationship of the data to what Clandinin and Connelly (2000) have called the "three-dimensional inquiry space" (p. 50). This includes the concepts of interaction (personal and social dimensions), continuity (past, present, future), and situation (the notion of place), and how they may have influenced the selection process. This underlying construct informed every aspect of both data collection and analysis throughout the study.

Research was conducted through three closely related phases and a followup interview. Phase I questions collected background data on each participant. Phase II questions focused on the evaluation of two sets of leveled readers that participants were asked to review. Part one of Phase II helped isolate incidents of interest related to the continuity (temporal dimensions) portion of the underlying construct. Part two of Phase II helped isolate incidents of interest related to the 
interaction (personal/social) portion of the underlying construct. Phase III questions were reflective in nature, and were designed to help participants identify and reflect on specific influences that may have impacted the selection process.

Finally, in order to seek deeper insights into the selection process and the influences that impacted participants' decisions, a follow-up interview was conducted with each participant after Phase III was complete.

\section{Purposeful Sampling}

Participants in this study were purposefully chosen to represent three distinct groups who have the potential to significantly impact the selection of leveled readers for early literacy instruction. These three groups were university literacy professors, regional superintendents, and classroom teachers.

University literacy professors often help mold perspective teachers' views of leveled readers even before those teachers have classrooms of their own.

Regional superintendents can formulate policies that impact the selection of such books, often determining which books are placed in classrooms. Individual classroom teachers usually make the final decision regarding which leveled readers they will use on a regular basis.

The population for the pilot study (Morelan, 2003) included three classroom teachers, three regional superintendents, and three university literacy professors. For reasons outlined earlier, these same participants also composed the population for the current study.

As would be expected, changes in the composition of these groups took 
place over time, especially in the categories of post of employment and geographic location. However, such changes simply added to the richness of the narrative, providing those participants with even broader perspectives into the selection process.

\section{Conceptual Framework}

The conceptual framework of this study flowed from constructivism (Bruner, 1966; Dewey, 1938; Piaget, 1950; Vygotsky, 1962), to teacher beliefs (Clark \& Peterson, 1986; Fang, 1996; Hargreaves, 1994; Pajares, 1992; Parker \& Neuharth-Pritchett, 2006; Richardson, 2003; Thompson, 1992; Vartuli, 2005), to beliefs about early literacy instruction (Fountas \& Pinnell, 1996; Hart \& Rowley, 1996; Meral, 2002; Scharer, 1992; Wollman-Bonilla, 1998; Zarillo, 1989), to an ultimate focus on influences affecting the selection of leveled readers for early literacy instruction. By forming the environment in which the study took place, this framework helped provide perspective and focus to the findings.

\section{Findings}

This research query began with one central question: "What influences affect the selection of leveled readers by professional educators for early literacy instruction?" Upon analysis of the data, four specific themes emerged:

1. Experiences related to an educator's professional life can influence the selection of leveled readers for early literacy instruction. Literacy training, attending reading conferences, reading professional journals, and similar activities can influence the selection process. 
2. Experiences related to an educator's personal life can influence the selection of leveled readers for early literacy instruction. Childhood experiences, religious beliefs, family concerns, and similar matters can influence the selection process.

3. An educator's personal preferences can influence the selection of leveled readers for early literacy instruction. These preferences can include both negative and positive concerns.

4. An educator's post of employment can influence the selection of leveled readers for early literacy instruction. Superintendents appeared to be more influenced by anticipated reactions of adult constituents. Classroom teachers appeared to be more influenced by the perceived needs of children.

Two of these themes are clearly supported by the literature. The concept that experiences related to an educator's professional life can influence book selection was supported by studies such as Sierra and Combs (1990), Scharer (1992), and Meral (2002). The concept that an educator's personal preferences can influence book selection was supported by studies such as Hart and Rowley (1996), Wollman-Bonilla (1998), and Donovan and Smolkin (2002).

Regarding the other two themes, responses strongly indicated that both an educator's personal life and her post of employment can influence the selection of leveled readers for early literacy instruction. Outside of the current study, however, there is no literature that clearly supports these findings. 


\section{Additional Findings}

In addition to the four primary themes, this study supports three related findings from the literature. First, educators' beliefs directly influence literacy instruction in the classroom. Second, educators do not rely on lists of formal selection criteria when selecting reading materials for the classroom. Third, educators are more influenced by personal preferences than by formal criteria when making such selections.

Studies of teacher beliefs about early literacy education (Allen et al., 1990; Allen et al., 1995; Altieri, 1998; Buike \& Duffy, 1979; Campbell et al., 2004; Mills \& Clyde, 1991; Richardson et al., 1991; Scharer, 1992; Sierra \& Combs, 1990; Thompson, 1992; Zarillo, 1989) suggest that teacher beliefs directly impact the way that teachers implement literacy instruction in their classrooms. In this study, many responses from participants reflected personal beliefs. This was true for every participant. Participant narratives show a direct relationship between these beliefs and the leveled readers that individual participants chose. Therefore, this study supports the concept that educators' beliefs directly influence literacy instruction.

Studies on the selection of general reading materials show a growing body of literature outlining strategies for choosing books for beginning readers (Atkinson et al., 2009; Brooks, 1996; Crawley, 1977; Fountas \& Pinnell, 1996; Kragler, 2000; Lukens, 1999; Pascual, 1972; Richardson \& Miller, 2000; Rog \& Burton, 2002; Smith \& Sensenbaugh, 1992; Williams, 2000). Such studies suggest several types of formal selection criteria. However, none of the participants in this 
study referenced a specific list of formal criteria as part of the selection process, and only one participant (Betty) referenced any kind of list at all. Therefore, this study supports the concept that educators do not rely on lists of formal selection criteria when selecting reading materials for the classroom.

However, many of the participants did informally refer to isolated criteria (usually two or three) that can be found in formal lists. This seems to indicate that even though educators do not rely on lists of formal criteria when selecting reading materials, those criteria still play some role in the selection process. Further study is needed to clarify this issue.

Studies that focus on the selection of general reading books for young readers (Hart \& Rowley, 1996; Miller, 1979; Sword, 1982; Wollman-Bonilla, 1998) suggest that the selection process is more influenced by an educator's personal preferences, including negative factors, than by formal criteria. In this study, responses and reflections from participants were filled with references that indicated personal preferences. There were also a number of comments that indicated the rejection of a book was due to something that the participant viewed as a negative influence. Participant narratives showed a direct relationship between personal preferences, both positive and negative, and the specific books that were chosen or rejected by individual participants. Therefore, this study strongly supports the concept that educators are more influenced by personal preferences than by formal criteria. 


\section{Discussion of the Underlying Construct}

As mentioned earlier, the underlying construct of a "three-dimensional inquiry space" informed every aspect of both data collection and analysis throughout this study. Clandinin and Connelly (2000) expanded Dewey's work into three dimensions: interaction (personal, social), continuity (past, present, future) and situation (the notion of place).

Using this set of terms, any particular inquiry is defined by this three-dimensional space: studies have temporal dimensions and address temporal matters; they focus on the personal and social in a balance appropriate to the inquiry; and they occur in specific places or sequences of events. (p. 50)

The four primary themes that emerged in this study strongly support this underlying construct. Responses demonstrated that the selection of leveled readers for early literacy instruction can be influenced by the passage of time (continuity), by personal and social contexts (interaction), and, in a more limited fashion, specific places or sequences of events (situation).

\section{Continuity}

As illustrated in the model, continuity refers primarily to temporal issues-the relationship of any experience to the past, the present, and the future. Clandinin and Connelly (2000) point out that the researcher "addresses temporal issues by looking not only to the event but to its past and to its future" (p. 50). Phase II of this study began by asking participants to make selections from a group of 15 leveled readers that were relatively recent additions to the $A$ Reason For ${ }^{\circledR}$ Reading series. Since these books were very similar to the books used in the 
pilot study, both in format and content, there were many opportunities for incidents of interest related to the passage of time (temporal dimensions). Responses clearly demonstrated the influence of continuity on the selection process.

For example, 6 years ago, Amy was a classroom teacher. Her comments at that time were primarily about illustrations. "The illustrations with the similar faces are delightful" (Angels Care for Me); "The illustrations of Naaman dipping in the river are delightful" (Naaman); "The illustrations are what make this book terrific" (I Can Draw). Since then, however, Amy has left the classroom and now works as an Intervention Specialist. After changes in employment and the passage of time, her comments cover a much broader range. "The vocabulary in this book is far more interesting than some" (The Empty Tomb); "This story moves right along ... keeps the reader interested" (The Surprise Breakfast); "Parts that might not be appropriate for small children have been left out" (Ruth).

Six year ago, Gloria was also a full-time teacher. Her comments reflected her experience at that time. "This typifies what we hear as teachers every single day. 'Johnny won't play with me,' 'Susie said she wasn't my friend anymore,' 'They don't want me on their team.' We hear these refrains a thousand times a day, but the words in this book make a child stop and consider who their best friend should be—a friend that will never stop being a friend!" (My Forever Friend); "My students can identify with this naughty puppy ... that he is still loved no matter what. It helps them see Jesus in the same way" (Jesus Loves Me Anyway); and responding to a follow-up question, "Most of my teaching experience has been in the lower grades, so I am looking at these books through the 
eyes of a teacher in the grades these books serve." Today, however, Gloria serves as a regional superintendent. Like Amy, there are obvious changes in the tone of her responses due to the passage of time. "This wonderful book about second chances would be welcome in any of my schools" (The Prodigal Son); "The message about something bad turning into something good is important for all age groups" (The Surprise Breakfast); "As I get older, I seem to appreciate stories about family even more. My whole family is in this book!" (What Do You Know?). Responses like these serve to illustrate the role that continuity plays in the selection of leveled readers for early literacy instruction.

\section{Interaction}

Interaction has to do with the ongoing relationship between the personal and social aspects of any experience. According to Clandinin and Connelly (2000), this can also be thought of in terms of inward and outward. "By inward, we mean toward the internal conditions such as feelings, hopes, aesthetic reactions, and moral dispositions. By outward, we mean toward the existential conditions ..." including, of course, social influences (p. 50). The second part of Phase II asked participants to make selections from a second group of 15 leveled readers. The books reviewed for Set 2 were taken from Scholastic's Little Leveled Readers (Set C). Although these books were evaluated separately, during the follow-up interviews I gave participants the chance to compare them to the first set of books. Since these two sets of books were very different, both in format and content, there were many opportunities for incidents of interest related to 
interaction (personal/social dimensions).

Responses clearly demonstrated the influence of interaction on the selection process. Almost every follow-up interview included overtones of both personal and social dimensions. For example, Gloria reflected that, "as a child, I always had a backpack filled with books from the library. That stash was replenished regularly. I love books and I love reading." But referring to the second set of books, her response moved away from personal feelings to a specific social application. "I did not like these books. The storylines were weak and the illustrations were unrealistic and unattractive. I can't imagine recommending any of these for use in my classrooms."

Debra had similar feelings. "I suspect that my personality type as well as my professional experiences affected the evaluation of these books. The Set 2 books simply do not reflect qualities of good children's literature. The illustrations were not well done and did not match up with the rest of the text."

There were other incidents of interest that reflect personal/social dimensions. For example, comments from both Cheryl and Elaine demonstrated that they have been strongly influenced by their involvement in the development of a national denominational literacy program (social dimension). Amy's experience with her husband's cancer resulted in a commitment to "make every minute count. . . . That goes double for the books we choose for our beginning readers"; and Debra's passion to share her love of reading with her grandsons resulted in a strong desire to apply all her skills in choosing "only the best" leveled readers for their use (personal dimensions). Responses like these serve to illustrate the role 
interaction plays in the selection of leveled readers for early literacy instruction.

\section{Situation}

As illustrated in the model, situation refers to the notion of place-"the specific concrete physical and topological boundaries of inquiry landscapes" (Clandinin \& Connelly, 2000, p. 51). In this study, the most notable incidents of interest related to "situation" revolved around professional changes in the participants' lives that resulted in new settings and different audiences.

For example, Amy has moved out of the classroom and is now working as an Intervention Specialist. "As a classroom teacher, I think that I looked at [books] with a narrower viewpoint. ... what stories do I know, what are my favorites ... just what appeals to me. But I think that now I have this perspective to say, 'Oh, that would be good for second grade social studies, or that's a first grade reader'... . I fit books into the curriculum and integrate curriculum a lot better than I would have before."

In her follow-up interview, Gloria said, "When I was teaching in the classroom, most of that experience was in the lower grades. . . Working with small children for so many years allowed me the privilege of seeing things through their eyes. But now I have a different audience. As an administrator, I also see curriculum materials through the eyes of parents and school boards. I have to consider what their possible reactions may be."

Irene retired from a relatively small Christian college, but now teaches some classes for a large state university - a significantly different setting. She 
pointed out, "At the moment I am preparing to teach a graduate class on beginning literacy. I am sure that has an impact on my thinking." Responses like these serve to illustrate the role that situation plays in the selection of leveled readers for early literacy instruction.

\section{A Core Assumption}

In addition to the three dimensions of continuity, interaction, and situation, the underlying construct is based on a core assumption that "reality is holistic, multidimensional, and ever-changing; it is not a single, fixed, objective phenomenon waiting to be discovered" (Merriam, 2001, p. 202). Two of the participants made comments that addressed this assumption directly, without any prompting or any exposure to the concept or the model.

As part of her reflections during the follow-up interview, Irene said, "It was very difficult to be consistent, you know. If I looked at [the books] one day, I would come up with one conclusion. If I looked at them another day, it would be another conclusion. . . I I think I gave you a somewhat sure response, but it could have been slightly different at different times."

Francis made a similar comment. "When I'm asked about a favorite of anything, it seems to vary from one time to another. So whatever I choose is simply representative of what I like, not the one favorite. . . Perhaps on another day or week, I'd have made a different choice." Francis was so aware of this issue that she pointed it out again in the follow-up interview. "Probably on a given day I might have picked different books as a favorite or whatever, because it's such 
a complex process in terms of the whole reading process, and the variations that are out there, and the different purposes that one might be using them for."

As in the pilot study, I found the underlying construct (as expressed through all three dimensions of the model) to be a very useful tool. Continually referencing the three-dimensional inquiry space helped enhance the richness and depth of both the data collection and its analysis.

\section{General Recommendations}

As discussed in chapter 1 , this study has the potential to improve the practices of classroom teachers, university literacy professors, regional superintendents, as well as the practices of the authors and publishers who create and distribute early literacy materials, by providing insights into how leveled readers are selected and how the selection process is impacted by the three-dimensional inquiry space.

Regarding the four primary themes, educators must understand that their decisions are influenced by experiences related to their professional lives, experiences related to their personal lives, their personal preferences, and their posts of employment. Becoming consciously aware of the role these influences play in individual decisions should help improve the overall quality of the selection process.

This study also found that superintendents appear to be more influenced by the anticipated reactions of adult constituents, whereas classroom teachers and university literacy professors appear to be more influenced by the perceived 
needs of children. Both groups could benefit from awareness of this phenomonen. A clear understanding of these influences should lead to a better balance between the desire to meet the needs of children and concerns about angering or offending adult constituents.

In addition, the study supported the concept that educators are more influenced by personal preferences than by lists of formal criteria when selecting materials for the classroom. Therefore, authors and publishers would benefit from a deeper understanding of how personal preferences affect the selection of leveled readers for early literacy instruction. For instance, almost every participant expressed a strong preference for "bright, colorful illustrations that connect well to the text." But the current trend of using stock photographs (often only vaguely connected to text) is in direct opposition to this finding. Publishers should also note that illustrations based on black-and-white line art were considered less desirable by the educators in this study. Identifying commonalities of personal preference in a large population of educators would be an excellent area for further research.

Finally, all but one of the participants expressed a preference for readers that contain what Fountas and Pinnell (1996) call "accuracy and diversity in multicultural representation" (p. 107). Authors and publishers of early literacy materials would benefit by becoming familiar with the literature related to various facets of this topic (see "Historical Concerns," chapter 2), and taking active steps to incorporate these basic principles into their products. This would result in more leveled readers that equally represent racial groups, are gender-balanced, 
and avoid cultural stereotypes-thus providing greater choice and improving the quality of early literacy materials available to educators.

\section{Recommendations for Further Study}

One of the findings of this study was that an educator's personal life can influence the selection of leveled readers for early literacy instruction. Further study is needed on how (and to what degree) personal experiences affect instructional practices.

Another finding of this study was that an educator's post of employment can influence the selection of leveled readers. Further study is needed on how (and to what degree) one's post of employment affects instructional practices.

Although this study did find that educators do not refer to lists of formal criteria when selecting leveled readers for early literacy instruction, the data suggested that formal criteria may still have some kind of influence on the selection process. Therefore, further study is needed on how (and to what degree) formal selection criteria influence the selection of leveled readers.

The study also found that educators are strongly influenced by personal preferences when selecting leveled readers for early literacy instruction. Thus, identifying commonalities of personal preference in a large population of educators would be an excellent area for further research.

In addition, since all participants in this study were female, further study is needed to explore the influence of gender on the selection of leveled readers. This would be a logical extension to the studies conducted by Bender and Alyce 
(1990), Campbell (1993), Witt (1997), Manjari, (1998), and Yeoman (1999).

Finally, all participants in this study were reading professionals with years of experience. Thus, the youngest participant was in her late 40s and the oldest in her early 70s. Although this wealth of experience added significant depth to the current study, it provided no data on how younger and less experienced educators would have responded. Therefore, further study is needed to discover what influences affect this younger group when they are selecting leveled readers for early literacy instruction.

Adlai Stevenson (1952) once said, "If we value the pursuit of knowledge, we must be free to follow wherever that search may lead us." It is hoped that the findings of this study will be helpful in leading educators, authors, and publishers to practices that will enhance the reading experience of the children they serve. 


\title{
APPENDIX A
}

\section{Andrews University}

Department of Leadership

\section{INFORMED CONSENT FORM}

\author{
Dissertation Title: \\ An Exploration of Influences Affecting the Selection of Leveled Readers \\ for Early Literacy Instruction
}

Purpose of Study: I have been informed that the purpose of this study is to research influences affecting the selection of leveled readers for early literacy instruction by professional educators. All activities related to my participation in this study are designed to take place in my normal working environment (home, office, school, etc.).

Benefits \& Risks: I have been informed that this study may yield a better understanding of why educators select specific books, leading to improved professional practice and better classroom instruction. I will be allowed to keep all leveled readers supplied for this study. My involvement as a participant in this study presents no significant physical or emotional risks.

Confidentiality: I understand that each participant in this study will be assigned a pseudonym. In order to maintain full confidentiality, participant profiles, responses, and reflections will never be referenced in any fashion except by this assigned pseudonym.

Voluntary Participation: I understand that my participation in this study is voluntary, and that I may discontinue participation at any time without penalty or loss of any benefit to which I would be otherwise entitled if I had completed participation.

Contact Information: I have been informed that any questions I have about the research, my rights related to this study, or other related matters, should be directed either to the researcher (William K. Morelan, P.O. Box 1515, Siloam Springs, AR; email: ozarkauthor@gmail.com; phone: 479-685-8282), or to his Dissertation chair (Dr. Shirley Freed, Andrews University, Berrien Springs, MI 49104; email: freed@andrews.edu; phone: 269-471-6163).

I have been given a copy of this form for my personal records.

Signature of Principal Investigator Date:

Signature of Subject: Date: Date: 


\section{APPENDIX B \\ Specific Questions Used In This Study}

\section{Phase I Questions}

Phase I questions were designed to gather specific background data. They were identical to the questions used in the pilot study (Morelan, 2003).

Question 1: What is your age?

Question 2: What is your gender (male/female)?

Question 3: What is your education (degree, field of study)?

Question 4: What is your current job title? (If you have changed jobs within the last 12 months, please include previous job title as well.)

Question 5: What is your current state of residence?

Question 6: What is your "geographic heritage"? (Example: "I'm a 'big city' kid from Boston and later Chicago," "I'm a Midwestern Farm girl," "I'm a New Englander from a small fishing village," etc.)

Question 7: Briefly describe your educational career. (Example: Ten years as a classroom teacher, five years as a superintendent, etc.)

\section{Phase II Questions}

Phase II questions involved the evaluation of two sets of books that participants were asked to review. Except for the books referenced, these questions were identical to the instructions/questions used in the pilot study (Morelan, 2003).

Here are the instructions/questions for Set 1:

"Review the 15 Leveled Readers from the 2005 edition of A Reason For $囚$ Reading. From this group, you will be choosing four books for early literacy instruction. First, choose three books as your favorites. Describe what caused you to select each of these books as a favorite. Next, choose one book you would consider your least favorite. Describe what caused you to select this book as your least favorite."

Here are the instructions/questions for Set 2:

"Review the 15 Leveled Readers from Scholastic's Little Leveled Readers, Set C. From this group, you will be choosing four books. 
First, choose three books as your favorites. Give a brief description of why you like each of these books. Next, choose one book you would consider your least favorite. Give a brief description of why you do not like this book."

\section{Phase III Questions}

Phase III questions were reflective in nature. Except for question 6, they were identical to questions used in the pilot study (Morelan, 2003). They were designed to help participants identify and reflect on influences impacting the selection process. In the final stage of this phase, participants had access not only to their recent answers and responses, but also their answers and responses from the pilot study.

Question 1: What past experience(s) have you had that might have influenced your selections?

Question 2: What future uses do you see for these books, and how might that have influenced your selections?

Question 3: What personal attributes (personality type, religious beliefs, esthetic preferences, etc.) may have influenced your selections? How?

Question 4: What work-related factors (constraints, expectations, regultions, etc.) may have influenced your selections? How?

Question 5: Think about your physical environment at the time you made your selections (home, hotel room, office, commercial airliner, etc.) What environment factors (comfort, noise, security, etc.) may have influenced your selections and how?

Question 6: "What personal or professional changes have you experienced over the past six years. How do you think these changes may have impacted the way you select leveled readers for early literacy instruction ?"

\section{Follow-up Interviews}

After all participants had responded to the Phase I and Phase II questions, followup interviews were conducted by phone. There was no time limit set on these interviews, and after the opening question, the conversations were designed to be open-ended.

Question 1: "What are some ways your life has changed, either personally or professionally, over the past six years? How you think these changes may have impacted the way you select leveled readers?"

Additional Questions: After Question 1, all additional questions and re- 
sponses were open-ended, depending on where the conversation led.

Closing Question: "What additional comments do you have about the selection process, the study itself, or anything else that might be relevant to this study?" 


\title{
APPENDIX C
}

\author{
Overview of the Pilot Study
}

\section{Overview}

Approximately six years ago, I conducted an pilot study of this topic (Morelan, 2003). Since the results from that study formed a starting point for the current study, the following description is provided to supply additional information that may prove helpful in understanding how this pre-existing data was compiled.

\section{Documentation}

As part of the pilot study, I not only preserved all artifacts related to the study, but I also took great care to document any related data that might serve as a reference point for future study. For example, the dates that specific questions were sent to participants and the dates of each individual response were logged in case there was a need to later explore this aspect of the study in relation to temporal dimensions. This documentation allowed me to easily access and reference pre-existing data as needed in the current study.

\section{Inquiry Model}

As part of the pilot study, I also developed a "3D Inquiry Model" (see Chapter 3) to illustrate the concept of the three-dimensional inquiry space. It was designed to show how responses are affected by multiple dimensions, and to provide a graphic representation of the idea that every response is influenced by various interactions and is only exact at a particular moment. This model proved quite helpful in applying the concept of the three-dimensional inquiry space to the research I was conducting at that time - not only in terms of the interview process itself, but also in the analysis of participant responses. The passage of time, as well as changes in the personal and professional lives of participants, make this model even more relevant in framing the current study.

The 3D Inquiry Model serves as a kind of "behind the scenes" filter through which a qualitative researcher can view all aspects of data collection and analysis. While it operates subtly in the background, its influence is woven into the very fabric of the work itself. And like the thread in a garment, it may not be readily apparent - but is an integral part of the whole.

\section{Data Collection}

Data collection in the pilot study was purposely designed to be experimental in nature. At the time, I was senior editor for a publisher developing a new series of leveled readers for private schools. Participants in the study were all members of the project's advisory team, and I had been working closely with all of them for over a year. In addition, I had recently taken my first online WebCT course, and was amazed at how much more freely information was exchanged in this format as opposed to a more traditional face-to-face setting. 
Therefore, since I knew each of the participants personally and also wished to experiment with this emerging media, I conducted all data collection for the pilot study in electronic form rather than in face-to-face interviews. This proved to be a very useful technique.

In order to more fully isolate individual components, the data collection process was broken into three steps. Step 1 involved responding to a series of general background questions. These became the profiles for each participant. Step 2 required reviewing forty-six leveled readers used as a reference in the study, ranking the top four favorites and one least favorite, then giving specific reasons for these decisions. Step 3 was a follow-up activity requiring reflective responses to five questions based on the "three-dimensional inquiry space" concept.

Originally Step 3 was planned as a series of oral interviews. Further reflection, however, led to a change of approach — primarily based on two factors:

First, I realized it was vital to give participants sufficient time to reflect on the follow-up questions. While face-to-face interviews have many advantages, spurof-the-moment answers are often less informative than reflective responses developed over time. By requesting unhurried written responses, I hoped to get these "better" answers right from the start.

Second, I believed that using a format identical to the previous steps would minimize any variations that could be attributable to a change in format rather than other significant influences. This was an effort to increase the validity to the results.

Step 3 questions were not submitted to participants until all responses from Step 2 were received. Since this resulted in a delay of about six weeks, all participants were given access to their Step 2 responses for reference as they began Step 3 .

Even though the pilot study was limited, the results far exceeded my expectations, both in the quantity of material and the quality of the responses. Based on the success of the data collection process in that setting, the current study used a similar data collection process, except for the follow-up interviews in Phase III.

\section{Results of the Pilot Study}

Since results from the pilot study were used as type of reference point in this study, it is important to provide a summary of my conclusions from the pilot study. Findings fell into two broad categories: the relationship of participant responses to formal criteria, and additional influences that appeared to affect the selection process.

\section{Relationship to Formal Criteria}

Participants in the pilot study were not provided with any formal list of criteria, 
nor were they encouraged in any way to refer to such a list. This was a purposeful attempt to avoid planting the idea of referencing formal criteria in participant's minds.

The composition of the responses appeared to support Sword's contention (Sword, 1982) that educators seldom refer to such lists when selecting books, but instead tend to rely on their personal experience and background. This was apparent in the fact that some types of formal criteria were mentioned repeatedly in the responses, while others received little or no attention at all.

Comparing responses to a common list of selection criteria (Fountas \& Pinnell, 1996) not only supports this finding, but also emphasizes how participant responses reflect the various dimensions of the three-dimensional inquiry space. For example, Item 1 (enjoyment, meaning, and interest to children) was addressed in some fashion by almost every participant. Representative responses included the following: Participant 1 - "This book has tremendous kid appeal." Participant 4 - "This book is inviting to children, both in message and illustration." Participant 5- "... has appeal for kids and it's fun to watch their feelings of both success and interest as they read the book." Participant 6 - "It attracts a child's attention even before the first word is read."

However, Fountas and Pinnell's Item 2 (accuracy and diversity in multicultural representation) was only directly addressed by one participant (Participant 7 ). Although this omission appeared to be significant, the lack of emphasis may have been related to the fact that there were no minority participants in the pilot study.

Fountas and Pinnell's Items 3, 4, and 5 had more to do with selecting a reading series rather than a particular book. Therefore these Items had little relevance to the pilot study and no significant results emerged.

Fountas and Pinnell's Item 6 (quality of illustrations and their relationship to text) was addressed by every participant in the pilot study, often in considerable detail. References to illustrations abounded throughout the responses. Since this was a significant "incident of interest" in the pilot study, I paid special attention to this item in the present study, watching closely for any changes in the way participants viewed issues related to the quality of illustrations and their relationship to text.

Fountas and Pinnell's Item 7 (content) was often referred to as "the message" by many of the participants in the pilot study. As with Item 6, it was addressed in some fashion by every participant - though sometimes in a positive fashion and sometimes in a negative way. Positive remarks included: Participant 1 - "The gentle spirit of this story draws me in." Participant 3 - "It sends a good positive message ... the storyline is predictable." Participant 7 - “. . direct quotes/ use of quotation marks; three forms of ending punctuation as well as commas; 
vocabulary that provides a challenge." Negative references included: Participant 5 - "Though the concept is important, I think the book is mundane in content." Participant 7 - "There is no story. There is no message. And there isn't much to offer for instruction."

Fountas and Pinnell's Items 8 and 9 (length and format) received only minimal attention from participants. This may be due to the fact that length and format of books used in the pilot study was similar and presumably acceptable. In the current study, the purposeful inclusion of variations offered by a different series (second half of Phase II) was designed to encourage more comments on this issue, and resulted in some additional insights.

\section{Additional Influences Affecting Selection}

Many of the participant responses in the pilot study seemed to support Hart and Rowley's suggestion (Hart \& Rowley, 1996) that an educator's personal experience plays the major role in the selection process.

Regarding her selection of Michael Never Gives Up, Participant 1 said, "After living with my father in a wheelchair for 24 years, stories of people with disabilities are close to my heart." Participant 3 selected two books on disabilities and commented "As a parent of both children and grandchildren who have special needs, I have a great passion for special education and for special needs individuals." Participant 7 was the only one to address multicultural issues directly, and her profile shows she's lived in three different countries. Participant responses to follow-up questions 3 and 4 were replete with examples supporting Hart and Rowley's views.

Regarding the concept that educators reject certain literature they believe might "corrupt children" (Wollman-Bonilla, 1998), about a third of the participant responses appeared to support this idea to some degree. For instance, Participant 2 felt "Queen Esther is overly made-up \& heavy with jewelry ... I think the point could have been made that she stood out . . . for her inner beauty rather than all the adornments." Participant 4 shared this concern. "I was not particularly drawn to illustrations that glamorized women or had a strong emphasis on jewelry." Participant 6 was concerned that "the illustrator has made this Naaman appear to be a 'superman.' That is what I as a teacher am trying to get my kids away from. NO man should be seen as super human." This was one of the areas I watched closely in the present study to see if these strong personal preferences changed over time or with a change in a participant's post of employment.

Perhaps the most significant finding to come out of the pilot study was the powerful impact that illustrations can play in the selection process. The overall tone of participant responses suggested that the most significant selection factor was personal preference regarding illustrations. Phrases such as "I liked . .." "I didn't like ..." and similar personal evaluative terms were used extensively in reference 
to this most-commonly discussed feature of the books.

Since this appeared to be the most significant "incident of interest" in the pilot study, I paid close attention to the way participants related to this issue in the present study, and how (or if) it was impacted by the three-dimensional inquiry space.

\section{Summary}

Interaction with participants in the pilot study provided a fascinating source of qualitative data. Many responses strongly reflected personal/social dimensions of the model, and the passage of time has only increased the significance of its temporal aspects. Thus the richness and depth of the participants' original comments in the pilot served as an excellent starting point for the current study. 


\section{APPENDIX D}

Representative Sample of Books

\section{Overview}

As a part of providing a "rich, thick description" (Merriam 2001, p. 211), representative samples of the books reviewed in this study have been supplied in this section of the Appendix.

Books in this section were the ones most referenced in the responses, and were often the "favorite" for some participants, but the "least favorite" for other participants. The complete text for each book has been provided.

Books from Set 1 include The Empty Tomb, The King on Trial, and What Do You Know? Books in Set 2 include George Washington Loved His Country, Squanto the Pilgrims' Friend, and Super-Duper Sandwich.

The samples begin on the following page. Books are presented in alpha-betical order by set. A sample illustration from each book has also been included. 
Complete Text and Sample Illustration

Level I

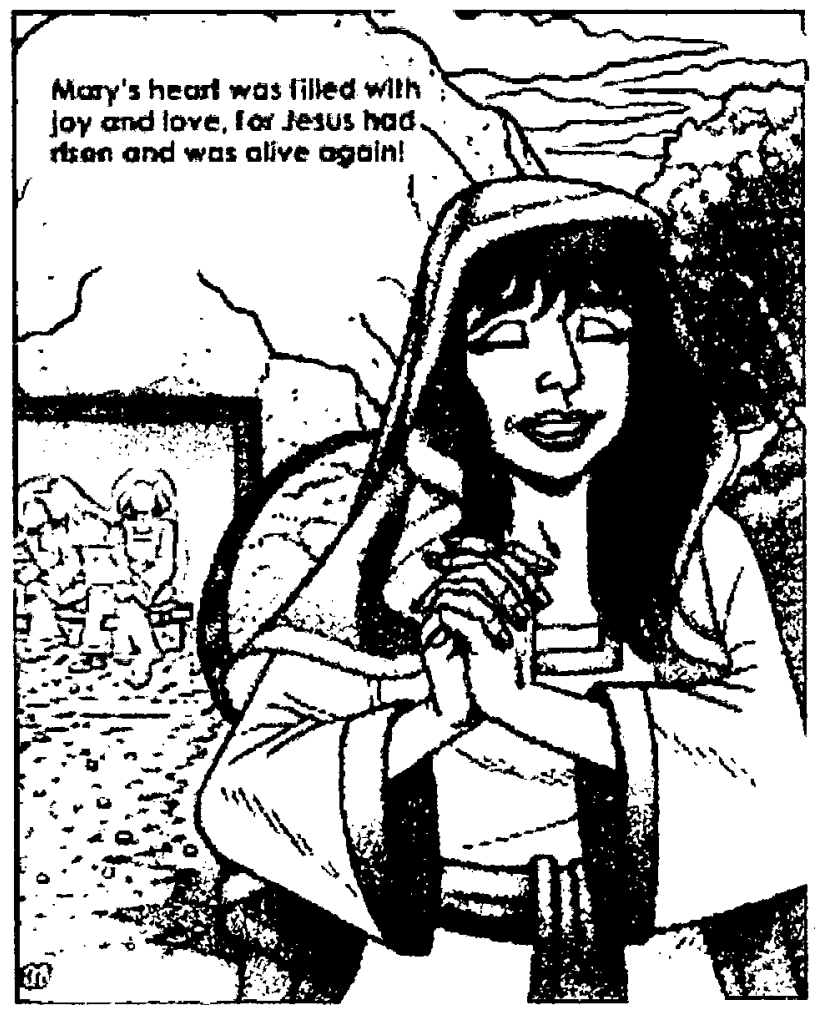

It was early Sunday morning. The sky was still dark. The birds were sleeping and silent. But Mary was wide awake. She couldn't sleep because her heart was broken. Her best friend Jesus was dead. They had buried him on Friday. Mary didn't know what to do. She decided to go to Jesus' tomb to be near him. She found her way down the dark streets and through the fields to the hillside cave where Jesus had been buried.

But when Mary reached the tomb, she couldn't believe her eyes. The huge stone sealing the door had been rolled away! "I must find Jesus' disciples and tell them," she thought. Without even looking inside, she ran to find Peter and John. "Someone has taken Jesus from the tomb," she cried, "and I don't know where they have put him!" Peter and John couldn't believe it. They began to run toward the tomb. Mary followed, but soon lagged far behind.

John arrived at the tomb first. He looked inside and saw the strips of linen that had been wrapped around Jesus' body. But he didn't see Jesus. Peter came next. Peter went into the tomb and saw the linen burial cloth folded neatly. But he didn't see Jesus either. Now Peter and John knew that Mary was telling the truth. 
But this was a mystery they couldn't understand. Thoughtfully, they left the empty tomb and slowly walked home.

Mary arrived a few minutes later. She stood outside the tomb and cried and cried. Then she bent over to look inside the tomb. Suddenly she jumped with surprise. Two angels dressed in shining white robes were sitting right where Jesus' body had been!

The angels spoke tenderly to Mary. "Woman, why are you weeping?" "Because they have taken Jesus," Mary cried, "and I can't find him." Then she turned sadly away.

Suddenly Mary heard another voice. "Woman, why are you crying? Who are you looking for?" Mary thought it must be the gardener. "Sir, if you have carried Jesus away, tell me where you have put him and I will get him." Then Jesus quietly whispered her name. "Mary." Immediately Mary recognized his voice. "Jesus!" she cried.

Jesus spoke gently to Mary. "Go tell my disciples that I am alive." Mary was so happy that she began to cry, but this time her tears were tears of joy! Mary ran swiftly to do as Jesus said. She felt the warm sunshine on her face. She heard the birds singing. It seemed as though all of creation was celebrating with her.

Mary's heart was filled with joy and love, for Jesus had risen and was alive again! 


\section{THE KING ON TRIAL}

Complete Text and Sample Illustration

Level $\mathrm{M}$

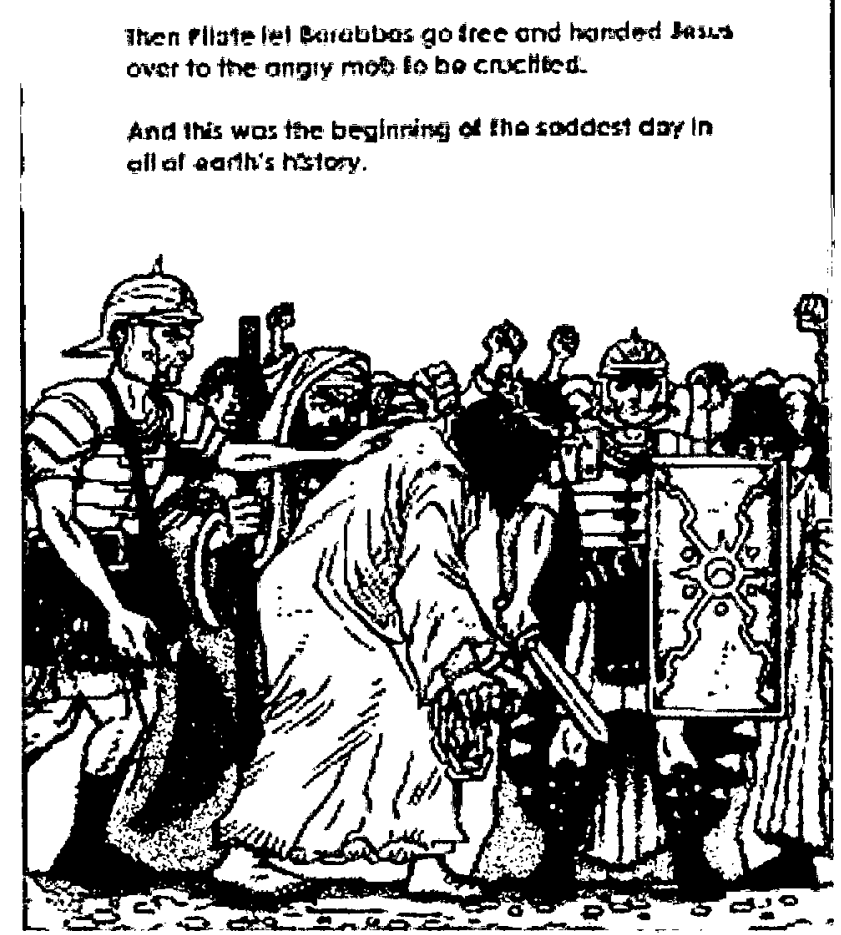

Pilate, the Roman governor, was sleeping peacefully. Suddenly there was a knock at his door. His servant entered and told Pilate a prisoner had been sentenced to death. As governor, Pilate had to sign the papers.

As he walked into the judgment hall, Pilate was tired and grumpy. But when he looked into the face of the prisoner, he was suprised. This man did not look like a criminal. Pilate could see goodness, kindness, and love in his face. Pilate's servant told him the man was Jesus.

Pilate had heard about Jesus. He had heard about the miracles of healing. He wanted to find out more. Pilate did not want to condemn an innocent man. He waiting to hear the charges the Jews brought against Jesus.

The priests had hired a man to tell lies. This man said, "Jesus is a very bad man. He does not pay taxes to Caesar. He even declares himself to be king." But Pilate did not believe the man. Pilate did not believe that Jesus was bad.

So Pilate turned to Jesus. "Are you the King of the Jews?" he asked. Jesus qui- 
etly replied. "It is as you say." As Jesus spoke, his face glowed. The whole room seemed full of light.

Pilate heard the noisy crowds shouting outside. He went to them and called out, "I find no fault in him." But the people were angry at Pilate's judgement., and Pilate wanted the people to like him. When he heard that Jesus was from Galilee he thought to himself, "I will get rid of this problem. I will send the man to Herod."

Many priests and elders followed Jesus and the soldiers to Herod's judgement hall. Herod had heard stories about Jesus. "I want to ask this man some questions," he said. But mostly Herod wanted to see Jesus perform some kind of miracle.

Herod asked many questions, but Jesus didn't speak. Finally Herod told Jesus that if he would perform just one simple miracle he could go free. The crowd became very angry. They thought Jesus might be released. They began to shout angry words. But Jesus still did nothing.

Herod and his soldiers began to make fun of Jesus. They placed a royal robe around his shoulders. They bowed down mocking him. But Jesus did not respond to their insults. Then Herod became afraid. He wanted nothing more to do with Jesus. So Herod sent Jesus back to Pilate.

Pilate was not happy when he saw Jesus again. "I have already judged this man and found him innocent," he told the people. "I will beat him and let him go." Pilate thought that would satisfy the crowd.

Just then a servant arrived with a message from Pilate's wife. She'd had a frightening dream about Jesus. "Have nothing to do with this man," she wrote. Pilate was very concerned. He trusted his wife, but he knew he must act at once. He was very troubled.

So Pilate called out to the crowd, "Shall I set this man free?" But the crowd shouted back, "Crucify him!" "Why, what evil has he done?" Pilate asked. "I will beat him and let him go." But the crowd shouted out again and again, "Crucify him! Crucify him!"

Suddenly Pilate remembered a custom that might save Jesus. It was a tradition to free one prisoner chosen by the people. Pilate thought of Barabbas, a very evil man who had committed many crimes. So Pilate sent for Barabbas and stood him beside Jesus. "Who shall I release?" asked Pilate. "Barabbas or Jesus?"

To Pilate's amazement, the people shouted "Barabbas!" "Then what shall I do with Jesus?" he asked. "Crucify him!" the angry crowd shouted. "Shall I crucify 
your king?" asked Pilate in surprise. "We have no king but Caesar!" the people shouted.

Pilate saw he could not change the minds of the people. He called for a basin of water and washed his hands in front of them. "I am innocent of this man's blood!" he shouted. "The responsibility is yours!" Then the high priest answered, "His blood be on us and our children!" And the crowd agreed, chanting the priest's angry words.

Then Pilate let Barabbas go free and handed Jesus over to the angry mob to be crucified. And this was the beginning of the saddest day in all of earth's history. 


\section{WHAT DO YOU KNOW}

Complete Text and Sample Illustration

Level C

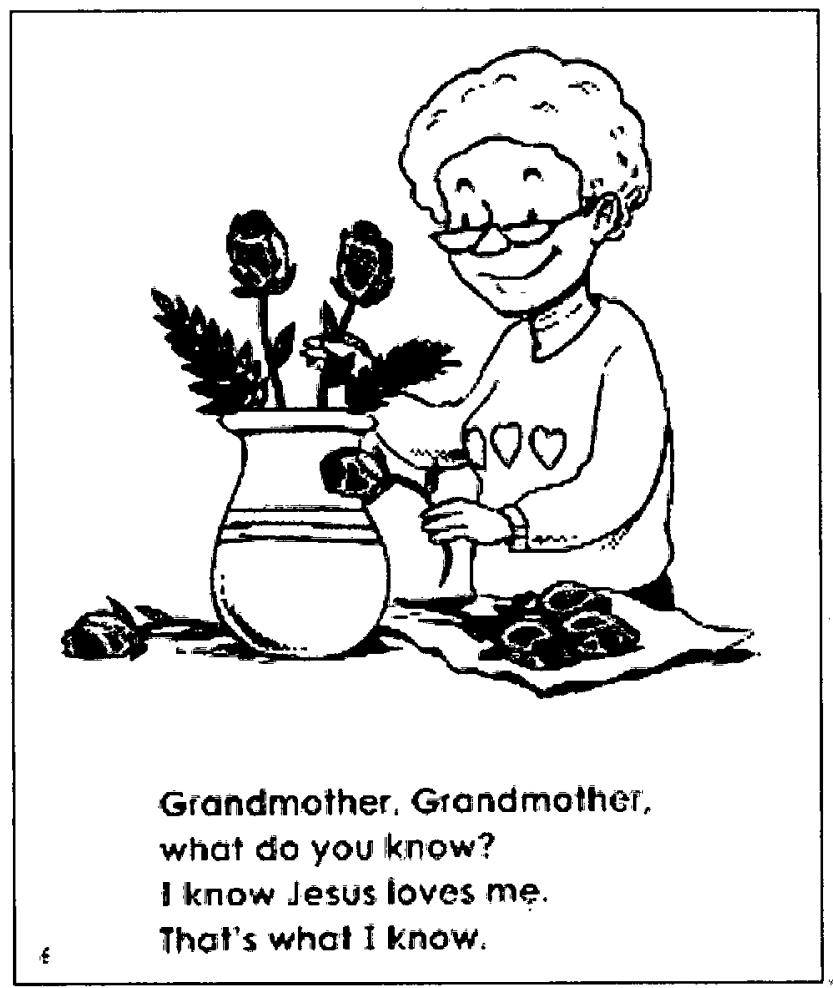

Little girl, little girl, what do you know? I know Jesus loves me. That's what I know.

Little boy, little boy, what do you know? I know Jesus loves me. That's what I know.

Mother dear, Mother dear, what do you know? I know Jesus loves me. That's what I know.

Father dear, Father dear, what do you know? I know Jesus loves me. That's what I know.

Grandmother, Grandmother, what do you know?

I know Jesus loves me. That's what I know.

Grandfather, Grandfather, what do you know?

I know Jesus loves me. That's what I know.

Father God, Father God, what do you know? I know I love everyone. That's what I know. 


\section{GEORGE WASHINGTON LOVED HIS COUNTRY}

Complete Text and Sample Illustration

Level D

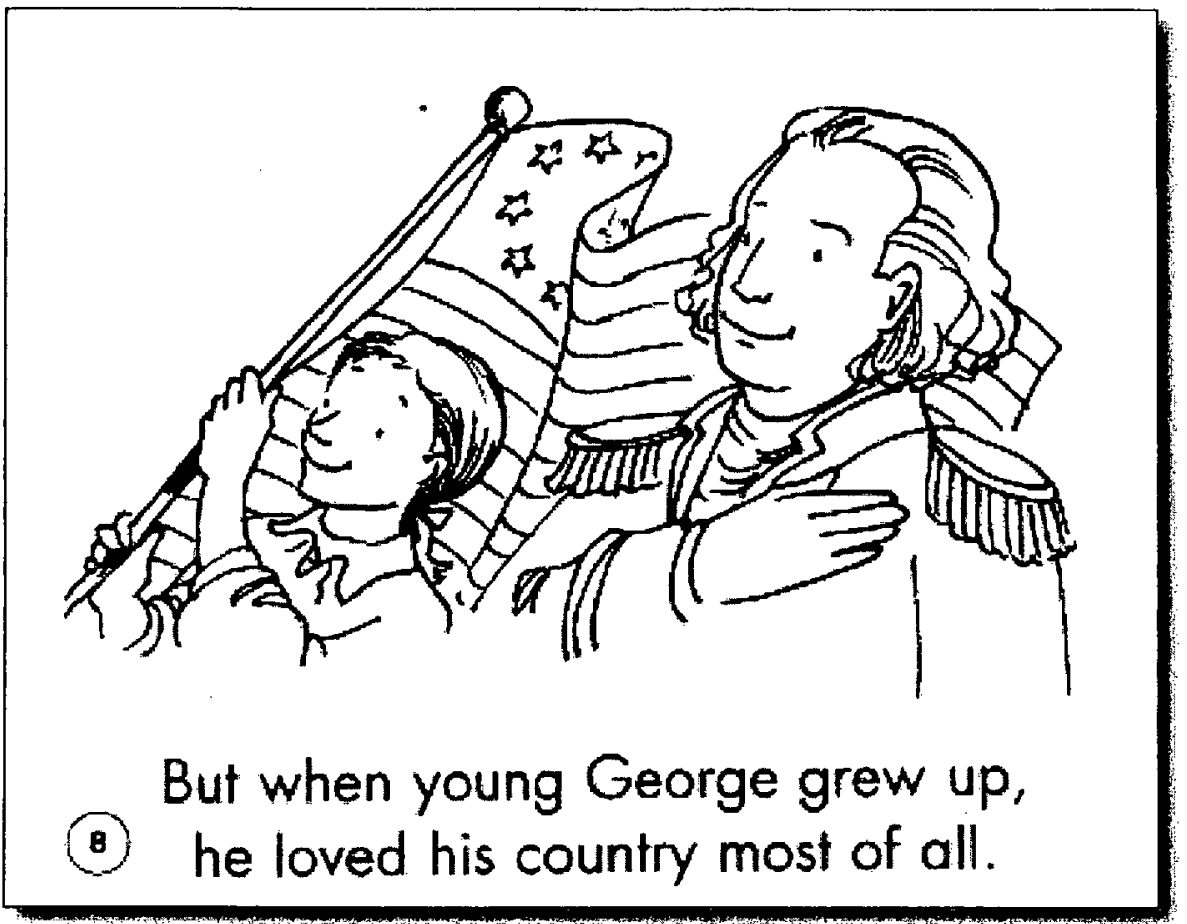

Young George loved to fish in the river.

Young George loved to climb the trees.

Young George loved to hunt in the woods.

Young George loved to sail the seas.

Young George loved to ride the horses.

Young George loved to dance at a ball.

But when young George grew up, he loved his country most of all. 


\section{SQUANTO THE PILGRIMS' FRIEND}

Complete Text and Sample Illustration

Level D

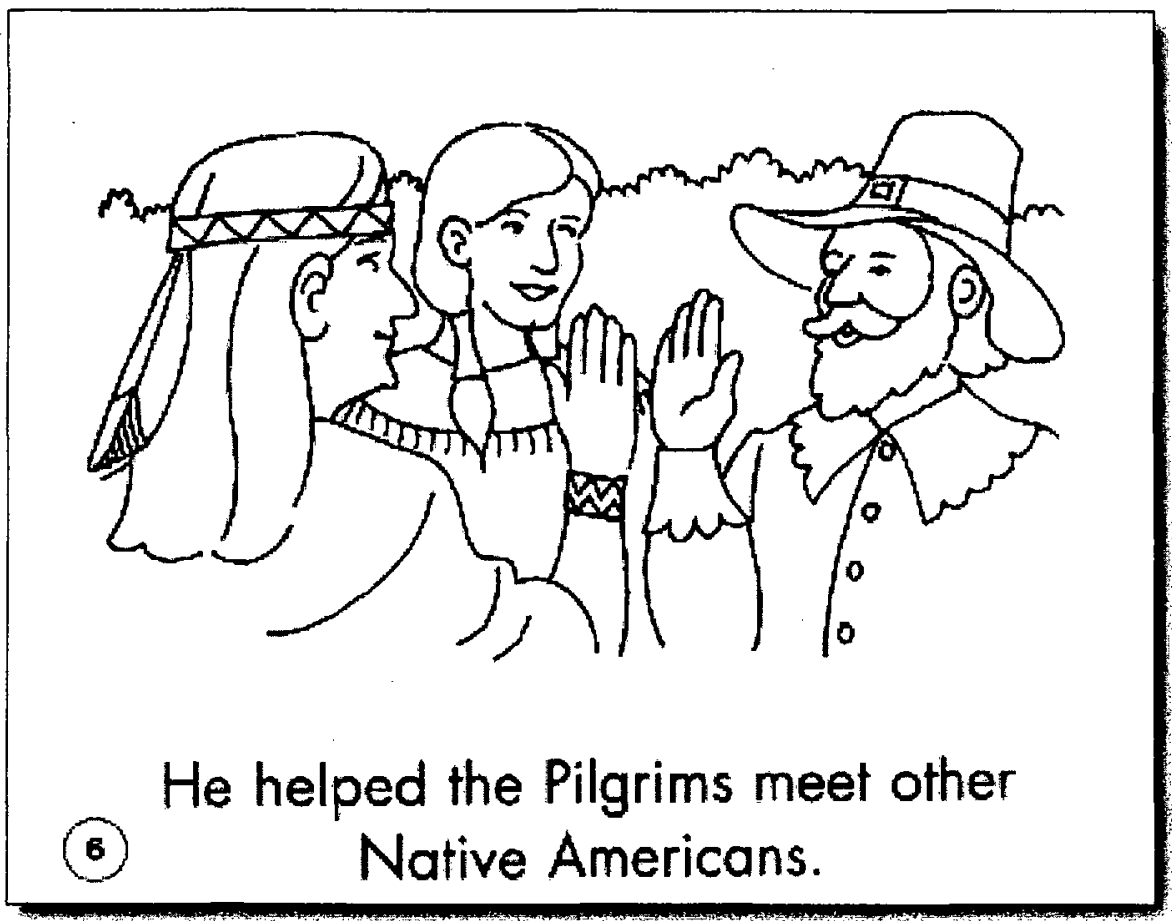

Squanto was a Native American. He became the Pilgrims' good friend.

Squanto helped the Pilgrims grow corn.

He helped the Pilgrims find places to fish.

He helped the Pilgrims find herbs and berries.

He helped the Pilgrims meet other Native Americans.

He helped the Pilgrims celebrate the first Thanksgiving.

The Pilgrims were thankful that Squanto was their friend. 


\section{SUPER-DUPER SANDWICH}

Complete Text and Sample Illustration

Level D

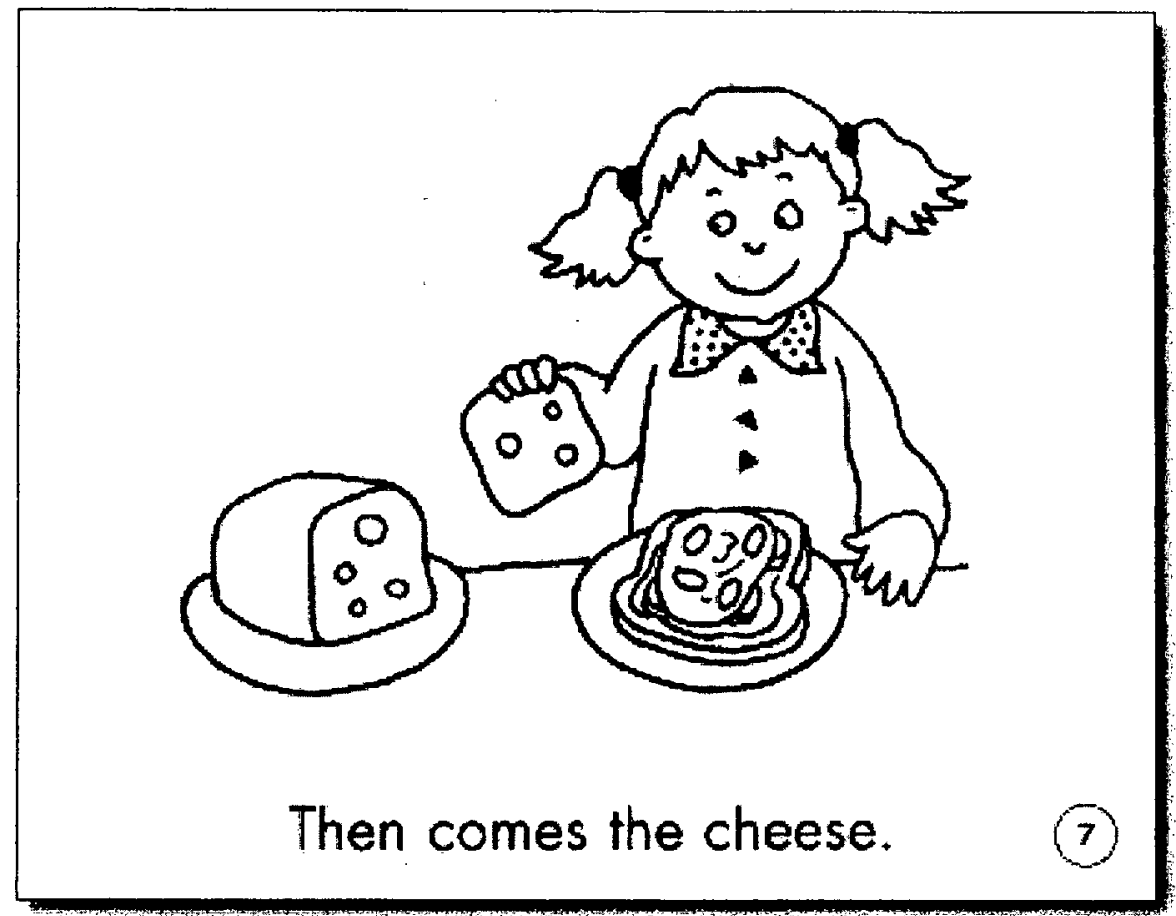

First comes the peanut butter.

Then comes the jam.

Then come the pickles.

Then comes the ham.

Then come the jelly beans.

Then comes the cheese.

Then comes the stomachache. No more for me, please! 


\section{REFERENCE LIST}

Allen, V., Freeman, E., \& Lehman, B. (1990). Teacher perceptions and practices for using chilren's literature in elementary reading instruction. Paper presented at the meeting of the National Reading Conference, Miami, FL. (ERIC Document Reproduction Service, No. ED329937)

Allen, V., Freeman, E., Lehman, B., \& Scharer, P. (1995). Amos and Boris: A window on teachers' thinking about the use of literature in their classrooms. Reading Teacher, 48(5), 384-390.

Allington, R. (2006). What really matters for struggling readers: Designing research-rased programs. New York: Pearson.

Altieri, J. (1998). One first-grade reacher's experience with a literature-based reading series: A look at her first year. Reading Horizon, 39(1), 21-31.

American heritage dictionary of the English language (4th ed.). Retrieved January 07, 2008, from Dictionary.com website: http://dictionary .reference.com/browse/influences

Atkinson, T., Matusevich, M., \& Huber, L. (2009). Making science tradebook choices for elementary classrooms. The Reading Teacher, 62(6), 484-497.

Bandre', P. (2005). The status of the selection and use of children's literature in K-6 rural Ohio public school classrooms. Unpublished dissertation, Ohio State University, Columbus, $\mathrm{OH}$.

Baumann, J., Hoffman, J., Moon, J., \& Duffy-Hester, A. (1998). Where are teachers' voices in the phonics/whole language debate? Results from a survey of U.S. elementary classroom teachers. The Reading Teacher, 51(8), 636-650.

Bawden, R., Buike, S., \& Duffy, G. (1979). Teacher conceptions of reading and their influence on instruction. Research Series No. 47. Institute for Research on Teaching, Michigan State University, East Lansing, MI.

Bear, D., Caserta-Henry, C., \& Venner, D. (2004). Personal readers for emergent and beginning readers. San Diego, CA: Teaching Resource Center. 
Bender, S., \& Alyce, M. (1990). Gender stereotypes in children's books: their prevalence and influence on cognitive and affective development. Gender and Education 11(1), 185-193.

Bloomberg, L., \& Volpe, M. (2008). Completing your qualitative dissertation: A roadmap from beginning to end. Thousand Oaks CA: Sage.

Brabham, E., \& Villaume, S. (2002). Leveled text: The good news and the bad news. Reading Teacher, 55(2), 438-441.

Brickhouse, N. (1990). Teachers' beliefs about the nature of science and their relationship to classroom practice. Journal of Teacher Education, 41(3), 53-62.

Brooks, E. (1996). Just-right books for beginning readers: Leveled booklists \& strategies. Jefferson City, MO: Scholastic.

Bruner, J. (1966). Toward a theory of instruction. Cambridge, MA: Harvard University Press.

Buxton, C., \& Austin, P. (2003). Better books, better teaching. Science and Children, 41(2), 28-32.

Campbell, J., Kyriakides, L., Muijs, D., \& Robinson, W. (2004). Assessing teacher effectiveness: Developing a differentiated model. New York: Routledge.

Campbell, P. (1993). Sexism and the world of children's books. The Horn Book Magazine, 69(1), 577-581.

Clandinin, D., \& Connelly, F. (1990). Stories of experience and narrative inquiry. Educational Researcher, 19(5), 2-14.

Clandinin, D., \& Connelly, F. (2000). Narrative inquiry: Experience and story in qualitative research. San Fransisco: Jossey-Bass.

Clark, C., \& Peterson, P. (1986). Teachers' thought process. In M. Wittrock (ed.), Handbook of research on teaching (3rd ed.). New York: Macmillan.

Clay, M. (1993). Becoming literate: The construction of inner control. Ackland, New Zealand: Heinemann.

Coffey, A., \& Atkinson, P. (1996). Making sense of qualitative data. Thousand Oaks, CA: Sage. 
Crawley, S. (1977). SOB: Selection of basals. New England Reading Assocition Journal, 12(1), 2-3. (ERIC Document Reproduction Service, No. ED155588)

Darigan, D., Tunnell, M., \& Jacobs, J. (2002). Children's literature: Engaging teachers and children in good books. Upper Saddle River, NJ: Merrill Prentice Hall.

Dean, J. (2001). Organising learning in the primary school classroom. New York: Routledge.

Dewey, J. (1938). Experience and education. New York, NY: Collier Books, MacMillan.

Dickinson, D., \& Neuman, S. (2006). Handbook of early literacy research (Vol. 2). New York: Guilford Press.

Dillion, J., \& Maguire, M. (2007). Becoming a teacher: Issues in secondary teaching. New York: McGraw-Hill.

Donovan, C., \& Smolkin, L. (2002). Considering genre, content, and visual features in the selection of trade books for science instruction. The Reading Teacher, 55(6), 502-520.

Duke, N. (2000). Print environments and experiences offered to first-grade students in very low-and very high-SES school districts. Reading Research Quarterly, 35(1), 456-457.

Eisner, E. (1998). The enlightened eye: qualitative inquiry and the enhancement of educational practice. Upper Saddle River, NJ: Prentice Hall.

Fang, Z. (1996). A review of reseach on teacher beliefs and practices. Educational Research, 38(1), 47-65.

Flood, J., Lapp, D., Squire, J, \& Jensen, J. (2003). Handbook of research on teaching the English language arts. New York: Erlbaum Associates.

Fountas, I., \& Pinnell, G. (1996). Guided reading: Good first teaching for all children. Portsmouth, NH: Heinemann.

Fountas, I., \& Pinnell, G. (1999). Matching books to readers: Using leveled text in guided reading, $K-3$. Portsmouth, $\mathrm{NH}$ : Heinemann.

Goodman, K., Shannon, P., Freeman, Y., \& Murphy, S. (1988). Report card on basal readers. Katonah, NY: Richard C. Owen. 
Hargreaves, A. (1994). Changing teachers, changing times: Teachers'work and culture in the postmodern age. London: Cassell.

Hart, P., \& Rowley, J. (1996). Different, but alike: An exploration of preservice teacher decision making with regard to the selection of children's literature for classroom use. Reading Research and Instruction, 35, 3-4. (ERIC Document Reproduction Service, No. EJ530600)

Harvey, S., \& Goudvis, A. (2007). Strategies that work: Teaching comprehension for understanding and engagement ( 2 nd ed.). Portland, ME: Stenhouse.

Hedrick, W., Harmon, J., \& Linerode, P. (2004). Teachers' beliefs and practices of vocabulary instruction with social studies textbooks in grades 4-8. Reading Horizons, 45(2), 103-125.

Hodkinson, P., \& Issitt, M. (1994). The challenge of competence: Professionalism through vocational education and training. London: Continuum International.

Huberman, M., \& Miles, M. (2002). The qualitative researcher's companion. London: Sage.

Igoa, C. (1995). The inner world of immigrant children. New York: Erlbaum.

Kragler, S. (2000). Choosing books for reading: An analysis of three types of readers. Journal of Research in Childhood Education, 14(2), 133-141. (ERIC Document Reproduction Service, No. EJ611826)

Kramer, L., \& Radey, C. (1997). Improving sibling relationships among young children: A social skills training model. Family Relations, 46(1), 237-246.

Kruse, M. (2001). Aprons, overalls, and so much more: Images of farm workers in children's picture books. Journal of Children's Literature, 27(1), 22-28.

LeCompte, M., \& Preissle, J. (1992). Toward an ethnology of student life in schools and classrooms: Synthesizing the qualitative research tradition. In M. LeCompte, W. Millroy, \& J. Preissle (Eds.), The handbook of qualitative research in education. Orlando, FL: Academic Press.

Lempke, S. (1999). The faces in the picture books. The Horn Book Magazine 75(2), 141-142.

Lowery, R. (2000). Immigrant literature from a critical perspective. The Florida Reading Quarterly, 35(1), 26-31. 
Lukens, R. (1999). A critical Handbook of children's literature (6th ed.). Reading, MA: Addison Wesley Longman.

Manjari, S. (1998). Gender issues in children's literature. ERIC Digest \#135. Retrieved November 3, 2007, from http://www.indiana.edu/ reading/ieo/ digests/d135.html

Martinez, M., \& McGee, L. (2000). Children's literature and reading instruction: Past, present, and future. Reading Research Quarterly, 35(1), 154-169.

McCardle, P., \& Chabra, V. (2004). The voice of evidence in reading research. Baltimore, MD: Paul H. Brookes.

Meral, K. (2002). An exploration of expert reading teachers'beliefs and instructional practices related to children's literature. Unpublished doctoral dissertation, Ohio State University, Columbus, $\mathrm{OH}$.

Merriam, S. (2001). Qualitative research and case study applications in education. San Fransisco: Jossey-Bass.

Miller, J. (1979). Teachers' abilities to judge the difficulty of reading materials. Reading Horizons, 19(2), 151-158.

Mills, H., \& Clyde, J. (1991). Children's success as readers and writers: It is the teacher's beliefs that make the difference? Young Children, 46(2), 54-59.

Morelan, W. (2003). A study of factors affecting the selection of leveled readers. Unpublished manuscript, Andrews University, Berrien Springs, MI.

Myers, D. (2006). Quotations about reality. Retrieved May 17, 2007, from www. quotegarden.com/reality.html

Nevelson, L. (1978). Quotations about reality. Retrieved November 25, 2007 , from www.quotegarden.com/reality.html

Nolan, J., \& Meister, D. (2000). Teachers and educational change: The lived experience of secondary school restructuring. Albany, NY: SUNY Press.

O'Conner, R., Bell, K., Harty, L., Sackor, S., \& Zigmond, N. (2002). Teaching reading to poor readers in the intermediate grades: A comparison of text difficulty. Journal of Educational Psychology, 94(1), 474-485.

Pajares, M. (1992). Teachers' beliefs and educational research: Cleaning up a messy construct. Review of Educational Research, 62(3), 307-332. 
Parker, A., \& Neuharth-Pritchett, S. (2006). Developmentally appropriate practice in kindergarten: Factors shaping teacher beliefs and practice. Journal of Research in Childhood Education, 21(1), 65-78.

Pascual, H. (1972). Reading strategies for New Mexico (Resource Guide Number 2). New Mexico Dept. of Education. (ERIC Document Reproduction Service, No. ED061022)

Patton, M. (1990). Qualitative evaluation and research methods (2nd ed.). Newbury Park, CA: Sage.

Perry, T., \& Fraser, J. (1993). Freedom's plow: Teaching in the multicultural classroom. New York: Routledge.

Piaget, J. (1950). The psychology of intelligence. New York: Routledge.

Ravitz, J., \& Snow, J. (1998). Constructivist-compatible teacher beliefs. Paper presented at the Teaching, Learning, and Computing Conference, University of California, Irvine, CA.

Rasinski, T. (2003). The fuent reader: Oral reading strategies for building word recognition, fluency, and comprehension. New York: Scholastic.

Richardson, M., \& Miller, M. (2000). Picture book selection for small rural schools. Rural Educator, 21(3), 28-34. (ERIC Document Reproduction Service, No. EJ607035)

Richardson, V., Andres, P., Tidwell, D., \& Lloyd, C. (1991). The relationship between teachers' beliefs and practices in reading comprehension instruction. American Educational Research Journal, 28(3), 559-586.

Richardson, V. (1996). The role of attitudes and beliefs in learning to teach. In Handbook of research on teacher education. New York: Macmillan.

Richardson, V. (2003). Constructivist pedagogy. Teachers College Record, 105(9), 1623-1640.

Rodman, N. (1994). Family diversity and family housing between 1943 and 1993: Content analysis of children's picture storybooks. Unpublished doctoral dissertation, Texas Women's University, Austin.

Rog, L., \& Burton, W. (2002). Matching texts and readers: Leveling early reading materials for assessment and instruction. Reading Teacher, 55(4), 348-356. (ERIC Document Reproduction Service, No. EJ638858) 
Rudestam, K., \& Newton, R. (2001). Surviving your dissertation: A comprehensive guide to content and process. Thousand Oaks, CA: Sage.

Scharer, P. L. (1992). Teachers in transition: An exploration of changes in teachers and classrooms during implementation of literature-based reading instruction. Research in the Teaching of English, 26(4), 408-443.

Shannon, P. (1982). A retrospective look at teachers' reliance on commercial reading materials. Language Arts, 59(1), 844-853.

Short, K., \& Fox, D. (2003). The complexity of cultural authenticity in children's literature: Why the debates really matter. In D. Fox \& K. Short (Eds.), Stories matter: The complexity of cultural authenticity in children's literature. Urbana, IL: National Council of Teachers of English.

Sierra, M., \& Combs, M. (1990). Transitions in reading instruction: Handling contradictions in beliefs and practice. Reading Horizons, 31(2), 113-126.

Smith, C., \& Sensenbaugh, R. (1992). Helping children overcome reading difficulties. ERIC Digest. ERIC Clearinghouse on Reading and Communication Skills. Bloomington, IN. (ERIC Document Reproduction Service, No. ED344190)

Stevenson, A. (1952, October 8). Speech at University of Wisconsin, Madison. Retrieved September 20, 2009, from http://www.quotationspage.com/ subjects/knowledge

Sugrue, C. (1997). Complexities of teaching: Child-centred perspectives. New York: Routledge.

Sword, J. (1982) The what and how of book selection: Research findings. Paper presented at the Annual Meeting of the National Council of Teachers of English, Minneapolis, MN. (ERIC Document Reproduction Service, No. ED235506)

Szymusiak, K., Sibberson, F., \& Koch, L. (2008). Beyond leveled readers: Supporting early and transitional readers in $K-5$ (2nd ed.). Portland, ME: Stenhouse.

Thompson, A. (1992). Teachers' beliefs and conceptions: A synthesis of the research. In D. Grouws (Ed.), Handbook of research on mathematics teaching and learning (pp. 127-146). New York: Macmillian.

Vartuli, S. (2005). Beliefs: The heart of teaching. Young Children, 60(5), 76-86. 
Vygotsky, L. (1962). Thought and language. Cambridge, MA: MIT Press.

Wilcox-Herzog, A. (2002). Is there a link between teachers' beliefs and behaviors? Early Education and Development, 13(1), 81-106.

Williams, N. (2000). Children's literature selections and strategies for students with reading difficulties: A resource for teachers. Norwood, MA: Christopher-Gordon.

Witt, S. (1997). Boys will be boys, and girls will be hard to find: Gender representations in third grade basal readers. Education and Society, 15(1), 1-11.

Wolfson, D. (2007). Let sleeping beauties lie: A review of the Norton Anthology of Children's Literature. Retrieved November 3, 2007, from http://www. claremont.org/publications/crb/id.1122/article_detail.asp

Wollman-Bonilla, J. (1998). Outrageous viewpoints: Teachers' criteria for rejecting works of children's literature. Language Arts, 75(4), 287-295. (ERIC Document Reproduction Service, No. EJ568480)

Worthy, J., Moorman, M., \& Turner, M. (1999). What Johnny likes to read is hard to find in schools. Reading Research Quarterly, 34(10), 12-27.

Worthy, J., \& Sailors, M. (2001). That book isn't on my level: Moving beyond text difficulty in personalizing reading choice. New Advocate, 14, 229-239.

Yenika-Agbaw, V. (2003). Images of West Africa in children's books: Replacing old stereotypes with new ones? In D. Fox \& K. Short (Eds.), Stories matter: The cultural complexity of cultural authenticity in children's literature. Urbana, IL: National Council of Teachers of English.

Yeoman, E. (1999). How does it get into my imagination? Elementary school children's intertextual knowledge and gendered storyline. Gender \& Education, 11(1), 1-12.

Zarillo, J. (1989). Teachers' interpretations of literature-based reading. The Reading Teacher, 43(1), 22-28.

Zeichner, K., \& Gore, J. (1990). Teacher socialization. In Handbook of research on teacher education. New York: Macmillan. 


\section{VITA}

\section{William K. Morelan}

\section{Education}

Andrews University

Andrews University

1999-present PhD studies in Educational Leadership

1979 MAT: Communication

Southwestern Adventist University 1977 BS: Communication (English, Speech)

\section{Experience}

Corporate VP in charge of curriculum development for an educational publisher Senior editor of numerous educational curricula for elementary school classrooms

Designer of textbook formats that reflect accepted learning theories

Educational administrator with experience in a variety of settings

Classroom teacher with a learner-based instructional philosophy

Author of a leveled reading series based on national science standards

Author of a best-selling non-fiction book on relationships

Popular workshop presenter at national educational conventions

Sponsor of three award-winning high-school yearbooks

\section{Employment}

WillowRock Press, LLC

The Concerned Group, Inc.

Gravette High School

The Concerned Group, Inc.

Weimar Academy

Ozark Elementary

Tri-City Junior Academy

Lake Michigan College

$\begin{array}{ll}\text { President } & \text { 2009-Present } \\ \text { VP, Product Development } & 1994-2009 \\ \text { Chair, English Department } & 1991-1994 \\ \text { Curriculum Developer } & 1988-1991 \\ \text { Principal } & 1986-1988 \\ \text { Principal } & 1983-1986 \\ \text { Vice-Principal, Teacher } & 1979-1982 \\ \text { Adjunct Professor, Communication } & 1978-1979\end{array}$

President

VP, Product Development

1994-2009

1991-1994

1988-1991

1986-1988

1979-1982

Adjunct Professor, Communication 1978-1979

\section{Publications}

Author of Married For Life, stories about couples married 50 years or more (best-seller translated into Spanish, Danish, German, and Chinese)

Author of WillowRock Science Readers, 18 leveled readers and 36 teacher guides based on the National Science Education Standards

Senior editor for 95 leveled readers, a guided reading curriculum, a spelling curriculum, a handwriting curriculum, and an elementary science curriculum

\section{Certifications}

Valid Arkansas Teaching Certificate (English, Journalism, Oral Communication)

Eligible for ALCP (Arkansas Administrator Licensure Completion Program)

Member Phi Delta Kappa International 